\title{
The Impact of Sea Level Rise on Developing Countries: A Comparative Analysis
}

\author{
By \\ Susmita Dasgupta* \\ Benoit Laplante \\ Craig Meisner ${ }^{\star}$ \\ David Wheeler ${ }^{\star \star \star}$ \\ and \\ Jianping Yan $^{\text {** }}$
}

\begin{abstract}
World Bank Policy Research Working Paper 4136, February 2007
The Policy Research Working Paper Series disseminates the findings of work in progress to encourage the exchange of ideas about development issues. An objective of the series is to get the findings out quickly, even if the presentations are less than fully polished. The papers carry the names of the authors and should be cited accordingly. The findings, interpretations, and conclusions expressed in this paper are entirely those of the authors. They do not necessarily represent the view of the World Bank, its Executive Directors, or the countries they represent. Policy Research Working Papers are available online at http://econ.worldbank.org.
\end{abstract}

*Development Research Group, World Bank.

** Independent consultants, Canada.

*** Senior Fellow, Center for Global Development

Correspondence should be addressed to: Dr. Susmita Dasgupta, World Bank, 1818 H Street, NW, Washington, DC 20433, sdasgupta@worldbank.org.

Acknowledgements: Funding for this project was provided by the Canadian Trust Fund (TF030569) sponsored by the Canadian International Development Agency (CIDA). We would also like to extend our special thanks to Piet Buys, Uwe Deichmann and Jillian Kingston for their guidance and valuable help. 


\begin{abstract}
Sea level rise (SLR) due to climate change is a serious global threat: The scientific evidence is now overwhelming. Continued growth of greenhouse gas emissions and associated global warming could well promote SLR of $1 \mathrm{~m}-3 \mathrm{~m}$ in this century, and unexpectedly rapid breakup of the Greenland and West Antarctic ice sheets might produce a $5 \mathrm{~m}$ SLR. In this paper, we have assessed the consequences of continued SLR for 84 developing countries. Geographic Information System (GIS) software has been used to overlay the best available, spatially-disaggregated global data on critical impact elements (land, population, agriculture, urban extent, wetlands, and GDP) with the inundation zones projected for $1-5 \mathrm{~m}$ SLR. Our results reveal that hundreds of millions of people in the developing world are likely to be displaced by SLR within this century; and accompanying economic and ecological damage will be severe for many. At the country level, results are extremely skewed, with severe impacts limited to a relatively small number of countries. For these countries (e.g., Vietnam, A.R. of Egypt, and The Bahamas), however, the consequences of SLR are potentially catastrophic. For many others, including some of the largest (e.g., China), the absolute magnitudes of potential impacts are very large. At the other extreme, many developing countries experience limited impacts. Among regions, East Asia and Middle East/North Africa exhibit the greatest relative impacts. To date, there is little evidence that the international community has seriously considered the implications of SLR for population location and infrastructure planning in developing countries. We hope that the information provided in this paper will encourage immediate planning for adaptation.
\end{abstract}




\section{Introduction}

As noted by the International Panel on Climate Change (IPCC, 2001b), climate change will have many negative effects, including greater frequency of heat waves; increased intensity of storms, floods and droughts; rising sea levels; a more rapid spread of disease; and loss of biodiversity. Sea level rise (SLR) poses a particular threat to countries with heavy concentrations of population and economic activity in coastal regions.

Until recently, studies of SLR typically predicted a 0-1 meter rise during the $21^{\text {st }}$ century (Church et al. 2001, IPCC Third Assessment, 2001). The three primary contributing factors have been cited as: (i) ocean thermal expansion; (ii) glacial melt from Greenland and Antarctica (plus a smaller contribution from other ice sheets); and (iii) change in terrestrial storage. Among these, ocean thermal expansion was expected to be the dominating factor behind the rise in sea level. However, new data on rates of deglaciation in Greenland and Antarctica suggest greater significance for glacial melt, and a possible revision of the upper-bound estimate for SLR in this century. Since the Greenland and Antarctic ice sheets contain enough water to raise the sea level by almost $70 \mathrm{~m}$ (Table 1), small changes in their volume would have a significant effect. ${ }^{1}$

Table 1: Physical characteristics of ice on Earth.

\begin{tabular}{|c|c|c|c|c|c|}
\hline & Glaciers & Ice caps & $\begin{array}{l}\text { Glaciers and } \\
\text { ice caps * }\end{array}$ & $\begin{array}{l}\text { Greenland } \\
\text { ice sheet }\end{array}$ & $\begin{array}{l}\text { Antarctic ice } \\
\text { sheet }\end{array}$ \\
\hline Number & $>160,000$ & 70 & & & \\
\hline Area $\left(10^{6} \mathrm{~km}^{2}\right)$ & 0.43 & 0.24 & 0.68 & 1.71 & 12.37 \\
\hline Volume $\left(10^{6} \mathrm{~km}^{3}\right)$ & 0.08 & 0.10 & $0.18 \pm 0.04$ & 2.85 & 25.71 \\
\hline Sea-level rise equivalent (m) & 0.24 & 0.27 & $0.50 \pm 0.10$ & 7.2 & 61.1 \\
\hline $\begin{array}{l}\text { Accumulation } \\
\text { (sea-level equivalent, } \mathrm{mm} / \mathrm{yr} \text { ) }\end{array}$ & & & $1.9 \pm 0.3$ & $1.4 \pm 0.1$ & $5.1 \pm 0.2$ \\
\hline
\end{tabular}

Since the IPCC Third Assessment Report in 2001, there has been an increased effort to improve measures of mass loss for the Greenland ice sheet and its contribution to SLR. Using satellite interferometry observations, Ringot and Kanagaratnam (2006) detected widespread glacier flow acceleration in the lower latitudes between 1996 and 2000, and rapid extension to higher latitudes by 2005 . When combined with surface loss estimates

\footnotetext{
${ }^{1}$ If the Greenland ice sheet were to melt completely, it would raise average sea level by approximately 7 meters (Church et al. 2001).
} 
by Hanna et al. (2005), they calculated a total loss double that in the previous decade. Comparing this rate of contribution of Greenland's ice sheet to SLR with the IPCC estimate for the $20^{\text {th }}$ century, the new measures are roughly two to five times greater. In another study of mass loss for Greenland using repeat altimetry, Krabill et al. (2004) found that between 1993-1994 and 1998-1999, the ice sheet was losing $54 \pm 14$ gigatons of ice per year (Gt/yr). In contrast, net mass loss over the 1997-2003 interval averaged $74 \pm 11 \mathrm{Gt} / \mathrm{yr}$. At these rates of net mass loss, the contribution of the Greenland ice sheet to SLR is roughly double the rate assumed in the IPCC Third Assessment (2001) report ${ }^{2}$.

In Antarctica, using the Gravity Recovery and Climate Experiment (GRACE) satellites, Velicogna and Wahr (2006) have determined mass variations of the entire Antarctic ice sheet during 2002-2005. ${ }^{3}$ Their results indicate that the mass of the ice sheet decreased significantly, at a rate of $152 \pm 80$ cubic kilometers of ice per year; most of this loss came from the West Antarctic ice sheet (WAIS). This rate is several times greater than that assumed in the IPCC Third Assessment, and the IPCC admitted that its final estimate did not take into account the dynamic changes in the WAIS. Increasing concern also attaches to the stability of the WAIS, which currently rests on bedrock below sea level. Mercer (1978) speculated that human-induced global warming could cause the WAIS to be released into the ocean by a sliding mechanism (also referred to as WAIS collapse). This would cause a rapid rise in sea level, since it would be triggered solely through a displacement of the WAIS without its having to melt. Were the WAIS to collapse, it would raise average sea level by approximately 5 to 6 meters (Tol et al., 2006).

While there remains considerable uncertainty about the above scenarios, and the time horizon over which they may unfold, recent research and expert opinion indicate that significant SLR may occur earlier than previously thought. ${ }^{4}$ This has prompted a number of researchers to model the estimated impact of significant increases in SLR (these are sometimes termed 'extreme climate scenarios'). A number of studies have provided estimates of the potential impacts for specific developed countries (e.g. France, the

\footnotetext{
${ }^{2} 360$ gigatons of ice correspond approximately to $1 \mathrm{~mm}$ of sea level.

${ }^{3}$ The GRACE result for total Antarctic ice mass change includes complete contributions from such regions as the EAIS coastline and the circular cap south of $82^{\circ} \mathrm{S}$, which has not been completely surveyed with other techniques.

${ }^{4}$ See Vaughan and Spouge, 2002.
} 
Netherlands, Poland, Singapore and the United States) ${ }^{5}$; developing countries (e.g. Bangladesh, Benin, China, Nigeria, and Senegal) ${ }^{6}$; or specific areas of individual countries (e.g. deltas of the Nile and Bengal; Rhine Delta, Thames Estuary and Rhone Delta) ${ }^{7}$. Only a limited number of studies have assessed the impacts of SLR on a broader regional or world scale. Such studies include: Darwin and Tol (1999), Hoozemans et al. (1993), Nicholls and Mimura (1998), Nicholls et al. (2004), Nicholls and Lowe (2006), and Nicholls and Tol (2006). Some of these studies examine the impact of 'extreme climate scenarios' such as a 5 meter SLR (e.g. Nicholls et al., 2004). However, while indicators of impacts generally include land loss, population affected, capital loss value and wetlands loss, different studies have used different subsets of indicators or regions, making it difficult to compare the relative magnitude of impacts across countries or regions. ${ }^{8}$

This paper provides a broader comparison, by assessing the impacts of SLR for all developing countries using a homogeneous set of indicators, and for multiple SLR scenarios. To our knowledge, this is the first such exercise. Mendelsohn et al. (2006) provide complementary evidence, by examining the market impacts of climate change on rich and poor countries for a number of different climate scenarios. However, their work does not assess the impact of SLR on multiple physical and economic indicators.

For this study, we group 84 coastal developing countries into 5 regions (corresponding to the 5 regional departments of the World Bank): ${ }^{9}$ Latin America and the Caribbean (25 countries); Middle East and North Africa (13); Sub-Saharan Africa (29); East Asia (13); and South Asia (4). For each country and region, we assess the impact of SLR using the following 6 indicators: land, population, gross domestic product (GDP), urban extent, agricultural extent, and wetlands. Finally, these impacts are calculated for SLR scenarios ranging from 1 to 5 meters.

\footnotetext{
${ }^{5}$ See Baarse et al. (1994), Bijlsma et al. (1996), Mendelsohn and Neumann (1999), Ng and Mendelsohn (2005), Olsthoorn et al. (2002), and Zeidler (1997).

${ }^{6}$ Adam (1995), Dennis et al. (1995), French et al. (1995), Han et al. (1995), and Warrick et al. (1996).

${ }^{7}$ Tol et al. (2005), Yim (1995).

${ }^{8}$ For example, the regional assessments presented in Nicholls and Mimura (1998) cover four regions: Europe; West Africa; South, South-East, and East Asia; and the Pacific Small Islands. It does not include Latin America and the Caribbean or other regions of Africa.

${ }^{9}$ Hoozemans et al. (1993) divided the globe (including developed countries) into 20 regions.
} 
At the outset, we acknowledge that this analysis has limitations. First, we do not assess the likelihood of alternative SLR scenarios. We take each scenario as given, and assess the impacts using our 6 indicators for each of the 84 developing countries and 5 regions. Second, we assess the impacts of SLR using existing populations, socio-economic conditions and patterns of land use, rather than attempting to predict their future states. Since human activity is generally increasing more rapidly in coastal areas, our approach undoubtedly underestimates the future impacts of SLR in most cases. This underestimation will be greatest for SLR impacts on population and GDP in absolute terms (number of people impacted or \$ of GDP impacted), Third, our study is conservative because we do not consider storm surge augmentation. Even a small increase in sea level can significantly magnify the impact of storm surges, which occur regularly and with devastating consequences in some coastal areas.

Despite these limitations, we believe that our comprehensive baseline estimates of SLR impacts can assist policymakers and international development institutions in allocating resources for adaptation to climate change. In particular, we believe that our specific estimates, based on existing coastal conditions, are more likely to interest decisionmakers than estimates based on projections of future coastal population, economic activity, etc.

In the next section, we describe the methodology and data sources used to estimate the impact of SLR in developing countries. We present our results in Section III, at the global, regional and country levels. Section IV provides a summary and conclusions.

\section{Methodology and data sources}

\section{II.1 Data Sources}

We employed geographic information system (GIS) software to overlay the critical impact elements (land, population, agriculture, urban extent, wetlands, and GDP) with the inundation zones projected for 1-5 m. SLR. We used the best available, spatiallydisaggregated data sets from various public sources, including the Center for Environmental Systems Research (CESR), the Center for International Earth Science Information Network (CIESIN), the International Centre for Tropical Agriculture (CIAT), 
the International Food Policy Research Institute (IFPRI), the National Aeronautics and Space Administration (NASA), the National Oceanographic and Atmospheric Administration (NOAA), and the World Bank. Table 2 summarizes the data sources for assessments of inundation zones and impacts.

Table 2

Summary of Data Sources

\begin{tabular}{|l|l|l|l|l|}
\hline \multicolumn{1}{|c|}{ Dimension } & \multicolumn{1}{|c|}{$\begin{array}{c}\text { Dataset } \\
\text { Name }\end{array}$} & \multicolumn{1}{|c|}{ Unit } & Resolution & \multicolumn{1}{c|}{ Source(s) } \\
\hline $\begin{array}{l}\text { Coastline and } \\
\text { country } \\
\text { boundary }\end{array}$ & WVS & $1: 250,000$ & NOAA/NASA \\
\hline Elevation & $\begin{array}{l}\text { SRTM 90m } \\
\text { DEM V2 }\end{array}$ & $\mathrm{km}^{2}$ & $90 \mathrm{~m}$ & CIAT \\
\hline Population & GPW-3 & $\begin{array}{l}\text { Population } \\
\text { counts }\end{array}$ & $1 \mathrm{~km}$ & CIESIN \\
\hline $\begin{array}{l}\text { Economic } \\
\text { activity }\end{array}$ & GDP2000 & $\begin{array}{l}\text { million US } \\
\text { dollars }\end{array}$ & $5 \mathrm{~km}$ & $\begin{array}{l}\text { World Bank, based on } \\
\text { Sachs et al. (2001) }\end{array}$ \\
\hline Urban extent & GRUMP V1 & $\mathrm{km}^{2}$ & $1 \mathrm{~km}$ & CIESIN \\
\hline $\begin{array}{l}\text { Agricultural } \\
\text { extent }\end{array}$ & GAE-2 & $\mathrm{km}^{2}$ & $1 \mathrm{~km}$ & IFPRI \\
\hline Wetlands & GLWD-3 & $\mathrm{km}^{2}$ & $1 \mathrm{~km}$ & $\begin{array}{l}\text { CESR, Lehner, B. and } \\
\text { Döll, P. (2004) }\end{array}$ \\
\hline
\end{tabular}

\section{II.2 Methodology}

The country indicator database was developed by following the six-step procedure described below.

II.2.1 Preparing country boundaries and coastlines

Country coastlines were built by sub-setting polygons from the World Vector Shoreline (polygon), a standard National Geospatial Intelligence Agency (formerly Defense Mapping Agency) product at a nominal scale of $1: 250,000$. It contains worldwide coverage of shorelines and international boundaries. The subset country coastlines were also used as a mask for calculating country totals for the selected exposure indicators. 
II.2.2 Building coastal terrain models (DTM)

Coastal terrain models were derived from the CIAT SRTM 90 meters digital elevation model (DEM) data (Version 2), released in 2005. ${ }^{10}$ Zipped data files were downloaded from the CIAT website, and then converted into raster format, and mosaiced in terms of country boundaries in the ArcGIS environment.

\section{II.2.3 Identifying inundation zones}

Inundation zones were derived from the coastal terrain model (DTM) by setting the value of pixels in the DTM to 1 for the different SLR scenarios examined in this study. Pixels that are apparently not connected to coastlines, such as inland wetlands and lakes, were masked out manually.

\section{II.2.4 Calculating exposure indicators}

Estimates for each indicator were calculated by overlaying the inundation zone with the appropriate exposure surface dataset (land area, GDP, population, urban extent, agriculture extent, and wetland). Exposure surface data were collected from various public sources. Unless otherwise indicated, latitude and longitude are specified in decimal degrees. The horizontal datum used is the World Geodetic System 1984 (WGS 1984). For area calculation, all units are projected to World Equal Area.

For the exposure grid surfaces, two GIS models were built for calculating the exposed value. Because the values of the pixels in GDP and population surfaces are respectively in millions of US dollars and number of people, the exposure is calculated by multiplying the exposure surface with the inundation zone and then summing up by multiplying grid count and value. Exposure indicators, such as land surface, urban extent, agriculture extent and wetland are measured in square kilometers.

\section{II.2.5 Adjusting absolute exposure indicators}

For exposure indicators such as land area, population and GDP, which have measured country totals available, the exposed value is adjusted to reflect its real value by using the following formula:

\footnotetext{
${ }^{10}$ Shuttle Radar Topographic Mission.
} 
$V_{\text {adj }}=\frac{C T_{\text {mea }}}{C T_{\text {cal }}} \cdot V_{c a l}$

where

$V_{a d j}$ - Exposed value adjusted;

$V_{c a l}-$ Exposed value calculated from exposure grid surfaces;

$C T_{\text {mea }}$ - Country total obtained based on statistics;

$C T_{c a l}$ - Country total calculated from exposure grid surface.

II.2.6 Conducting data quality assurance and control

Quality control was conducted to adjust for errors caused by overlaying grid surfaces of different resolutions, such as the 90-meter resolution inundation zone with 1-kilometer or 5-kilometer exposure grid surfaces. The following procedure was employed:

1) Calculate the country total from the grid surface using the country boundary;

2) Calculate the aspect exposure that is under 5 -meter SLR;

3) Calculate the aspect exposure that is over 5-meter SLR;

4) Compare the country total with the sum of both aspect exposures. If the difference is less that $5 \%$, the calculated aspect exposure was considered within the error tolerance. If not, the exposure calculation was reviewed and estimates revised until the $5 \%$ difference threshold was reached.

A more detailed description of each dataset is provided in Appendix 1.

\section{Results}

In the first sub-section below, we present results at the global level for the 84 developing countries included in this analysis. In sub-section III.2, we present the results for each of the 5 regions and, individually, for each of the 84 countries. Our results indicate that for a number of countries, even a 1-meter SLR would have a very significant impact.

\section{III.1 Global results}

Table 3 indicates that approximately $0.3 \%\left(194,000 \mathrm{~km}^{2}\right)$ of the territory of the 84 developing countries would be impacted by a 1-meter SLR. This would increase to $1.2 \%$ 
in a $5 \mathrm{~m}$ SLR scenario. Though this remains relatively small in percentage terms, approximately 56 million people (or $1.28 \%$ of the population) of these countries would be impacted under a $1 \mathrm{~m}$ SLR scenario. This would increase to 89 million people for $2 \mathrm{~m}$ SLR (2.03\%), and 245 million people (5.57\%) for 5m SLR. The impact of SLR on GDP is slightly larger than the impact on population, because GDP per capita is generally above average for coastal populations and cities. Wetlands would experience significant impact even with a $1 \mathrm{~m}$ SLR. Up to $7.3 \%$ of wetlands in the 84 countries would be impacted by a $5 \mathrm{~m}$ SLR.

As shown in the next section, these impacts are not uniformly distributed across the regions and countries of the developing world. The impacts are particularly severe in a limited number of countries.

Table 3

Impacts of sea level rise: Global level

\begin{tabular}{|c|c|c|c|c|c|}
\hline & $1 \mathrm{~m}$ & $2 \mathrm{~m}$ & $3 \mathrm{~m}$ & $4 m$ & $5 m$ \\
\hline \multicolumn{6}{|c|}{ Area (Total = 63,332,530 sq. km.) } \\
\hline Impacted area & 194,309 & 305,036 & 449,428 & 608,239 & 768,804 \\
\hline$\%$ of total area & 0.31 & 0.48 & 0.71 & 0.96 & 1.21 \\
\hline \multicolumn{6}{|c|}{ Population (Total $=4,414,030,000)$} \\
\hline Impacted population & $56,344,110$ & $89,640,441$ & $133,049,836$ & $183,467,312$ & $245,904,401$ \\
\hline$\%$ of total population & 1.28 & 2.03 & 3.01 & 4.16 & 5.57 \\
\hline \multicolumn{6}{|c|}{ GDP (Total = 16,890,948 million USD) } \\
\hline Impacted GDP (USD) & 219,181 & 357,401 & 541,744 & 789,569 & $1,022,349$ \\
\hline$\%$ of total GDP & 1.30 & 2.12 & 3.21 & 4.67 & 6.05 \\
\hline \multicolumn{6}{|c|}{ Urban extent (Total $=1,434,712$ sq. $\mathrm{km})}$. \\
\hline Impacted area & 14,646 & 23,497 & 35,794 & 50,742 & 67,140 \\
\hline$\%$ of total area & 1.02 & 1.64 & 2.49 & 3.54 & 4.68 \\
\hline \multicolumn{6}{|c|}{ Agricultural extent (Total $=17,975,807 \mathrm{sq} . \mathrm{km})}$. \\
\hline Impacted area & 70,671 & 124,247 & 196,834 & 285,172 & 377,930 \\
\hline$\%$ of total area & 0.39 & 0.69 & 1.09 & 1.59 & 2.10 \\
\hline \multicolumn{6}{|c|}{ Wetlands area (Total $=4,744,149$ sq. $\mathrm{km}$.) } \\
\hline Impacted area & 88,224 & 140,355 & 205,697 & 283,009 & 347,400 \\
\hline$\%$ of total area & 1.86 & 2.96 & 4.34 & 5.97 & 7.32 \\
\hline
\end{tabular}




\section{III.2 Regional results}

In this sub-section, we examine results for Latin America and the Caribbean, Middle East and North Africa, Sub-Saharan Africa, East Asia, and South Asia. ${ }^{11}$ To facilitate the reading of these results, we follow a similar structure of presentation for all regions.

(i) Latin America and the Caribbean region

As shown in Table 4, the impact of SLR in Latin America and the Caribbean is relatively similar to the impact noted earlier for all developing countries insofar as land area, agriculture and wetlands are concerned. However, a much smaller percentage of the region's population and GDP would be impacted $(0.57 \%$ and $0.54 \%$ respectively for $1 \mathrm{~m}$ SLR, vs. $1.28 \%$ and $1.30 \%$ respectively worldwide). The same holds for the impact on urban infrastructure.

\section{Table 4}

Impacts of sea level rise:

\section{Latin America \& Caribbean region}

\begin{tabular}{|c|c|c|c|c|c|}
\hline & $1 \mathrm{~m}$ & $2 m$ & $3 \mathrm{~m}$ & $4 m$ & $5 \mathrm{~m}$ \\
\hline \multicolumn{6}{|c|}{ Area (Total = 18,806,598 sq. km.) } \\
\hline Impacted area & 64,632 & 101,736 & 149,183 & 193,786 & 234,117 \\
\hline$\%$ of total area & 0.34 & 0.54 & 0.79 & 1.03 & 1.24 \\
\hline \multicolumn{6}{|c|}{ Population (Total = 501,550,000) } \\
\hline Impacted population & $2,873,505$ & $4,732,734$ & $7,247,905$ & $10,268,489$ & $13,472,827$ \\
\hline$\%$ of total population & 0.57 & 0.94 & 1.45 & 2.05 & 2.69 \\
\hline \multicolumn{6}{|c|}{ GDP (Total $=3,649,731$ million USD) } \\
\hline Impacted GDP (USD) & 19,663 & 36,201 & 49,447 & 67,403 & 86,850 \\
\hline$\%$ of total GDP & 0.54 & 0.99 & 1.35 & 1.85 & 2.38 \\
\hline \multicolumn{6}{|c|}{ Urban extent (Total $=505,477$ sq. $\mathrm{km})}$. \\
\hline Impacted area & 3,080 & 5,212 & 8,090 & 11,614 & 15,294 \\
\hline$\%$ of total area & 0.61 & 1.03 & 1.60 & 2.30 & 3.03 \\
\hline \multicolumn{6}{|c|}{ Agricultural extent (Total $=4,889,156 \mathrm{sq} . \mathrm{km})}$. \\
\hline Impacted area & 16,104 & 29,514 & 47,003 & 66,330 & 85,959 \\
\hline$\%$ of total area & 0.33 & 0.60 & 0.96 & 1.36 & 1.76 \\
\hline \multicolumn{6}{|c|}{ Wetlands area (Total $=1,651,735$ sq. km.) } \\
\hline Impacted area & 22,314 & 38,782 & 60,876 & 85,734 & 108,476 \\
\hline$\%$ of total area & 1.35 & 2.35 & 3.69 & 5.19 & 6.57 \\
\hline
\end{tabular}

\footnotetext{
${ }^{11}$ These differ from the 20 coastal regions used in Nicholls and Nomura (1998). Our selection of these 5 regions is simply explained by the fact that those regions correspond to the 5 regional departments of the World Bank.
} 
When the results are examined at the country level, one notes very significant differences within the region. As is starkly revealed in Figure 1a, The Bahamas would experience the largest percentage of impacted land: Even with a $1 \mathrm{~m}$ SLR, approximately $11 \%$ of the land area of The Bahamas would be impacted. This percentage reaches in excess of $60 \%$ under a $5 \mathrm{~m}$ SLR scenario. Cuba and Belize would also experience significant impacts, albeit at a much reduced scale when compared with The Bahamas.

Figure 1a

Latin America \& Caribbean: Country area impacted ${ }^{12}$

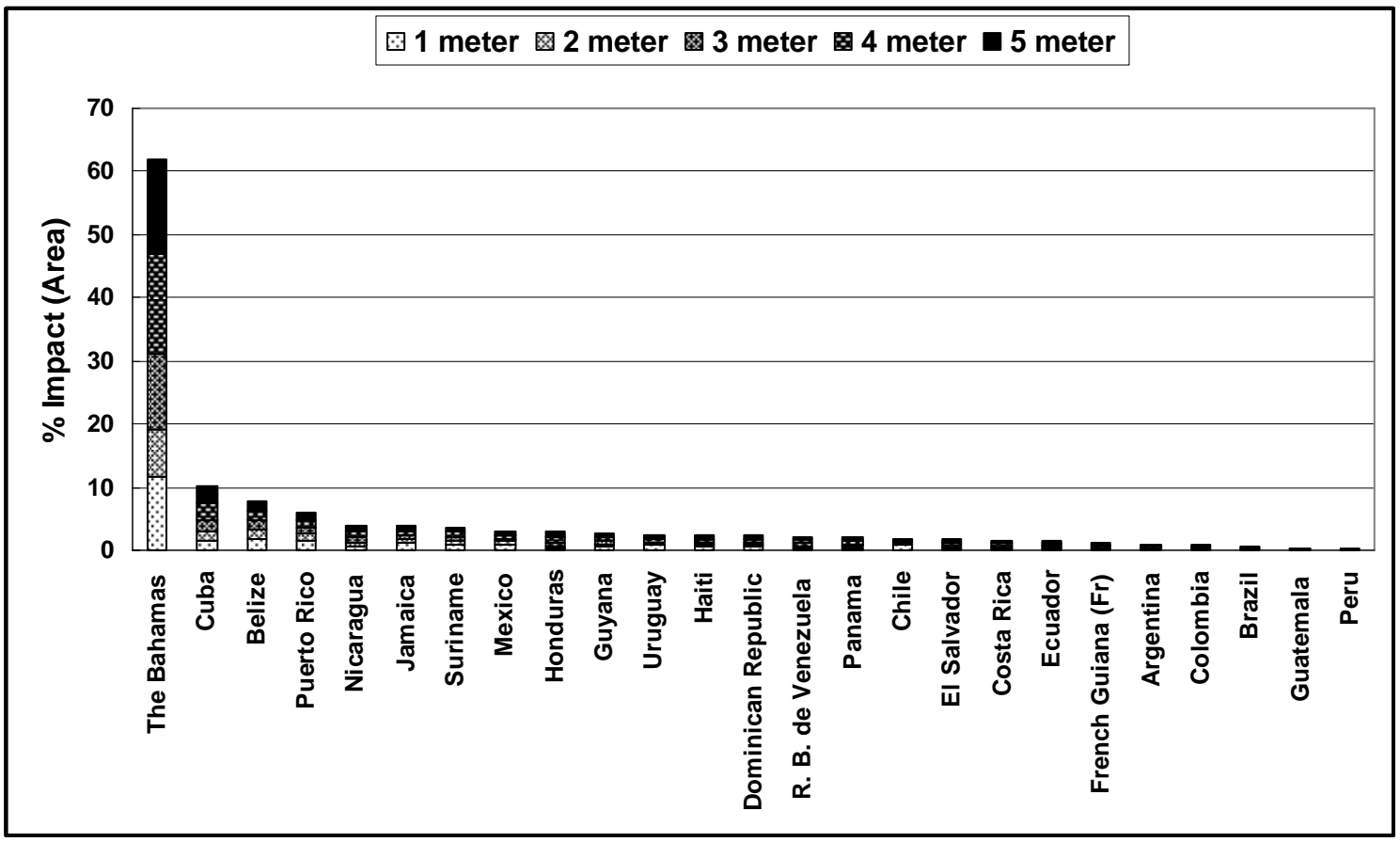

Figures $1 \mathrm{~b}$ and $1 \mathrm{c}$ show the impact of SLR on population. With a $1 \mathrm{~m}$ SLR, the populations of Suriname, Guyana, French Guiana, and The Bahamas would be most severely impacted (as a percentage of national population): $7.0 \%, 6.3 \%, 5.4 \%$ and $4.5 \%$ respectively. These percentages increase rapidly, reaching $30 \%$ in Suriname and $25 \%$ in Guyana for a $3 \mathrm{~m}$ SLR. Approximately half of the population of these countries would be impacted with a $5 \mathrm{~m}$ SLR.

In terms of economic activity (Figure 1d), the impact of a 1m SLR on Suriname, Guyana, and The Bahamas' GDP is expected to reach approximately $5 \%$. With a $3 \mathrm{~m}$ SLR, impacted GDP reaches $20 \%$ in Suriname, and approximately 15\% in both Guyana and

${ }^{12}$ Note that Puerto Rico is officially a Territory, and not a country. 
The Bahamas. Guyana would exhibit the largest percentage of urban extent impacted (Figure 1e). It reaches $10 \%$ with a $1 \mathrm{~m}$ SLR, and increases to $22 \%$ and $38 \%$ with a $2 \mathrm{~m}$ and $3 \mathrm{~m}$ SLR.

Figure 1b

Latin America \& Caribbean region: Exposed population (5m SLR)

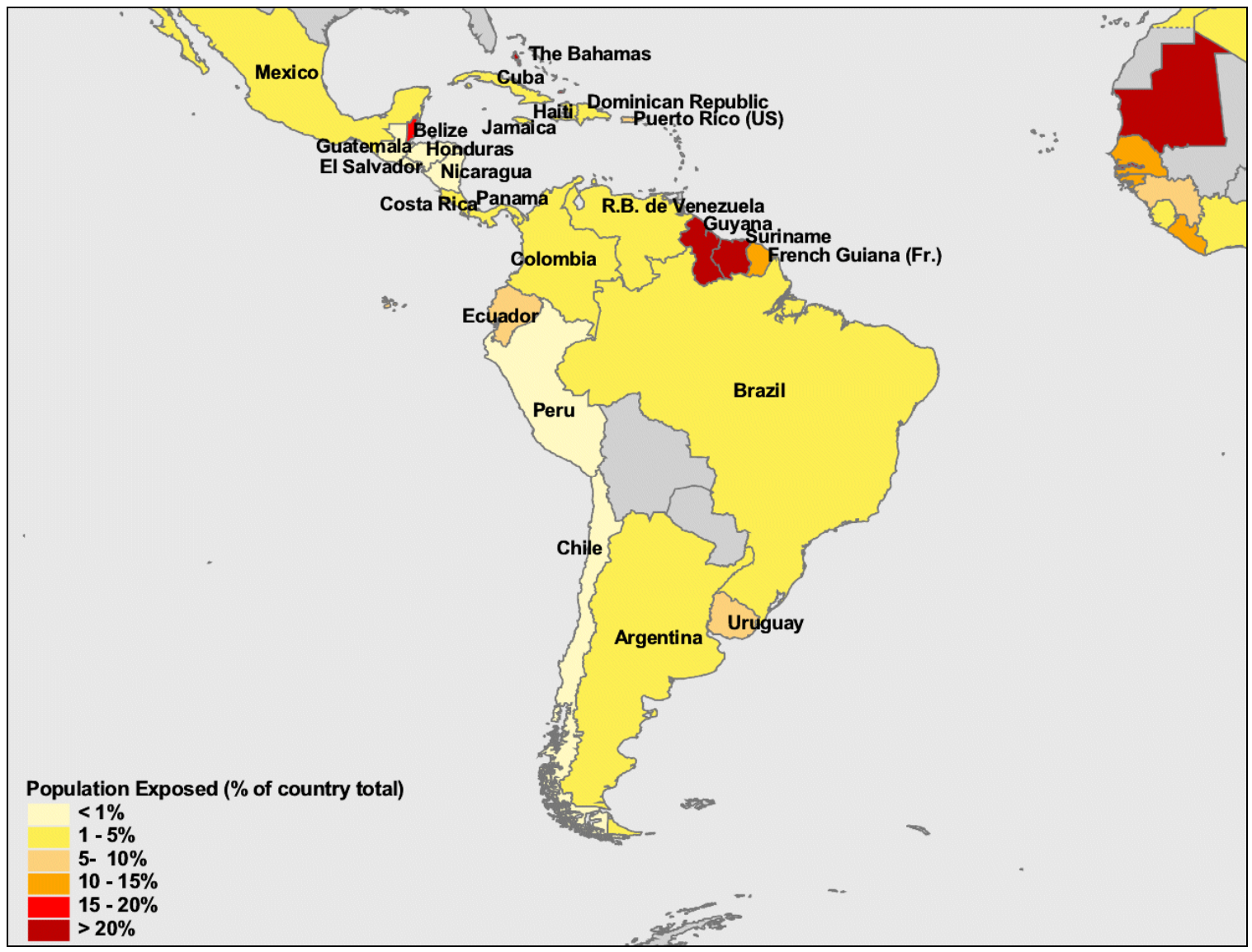


Figure 1c

Latin America \& Caribbean: Population impacted

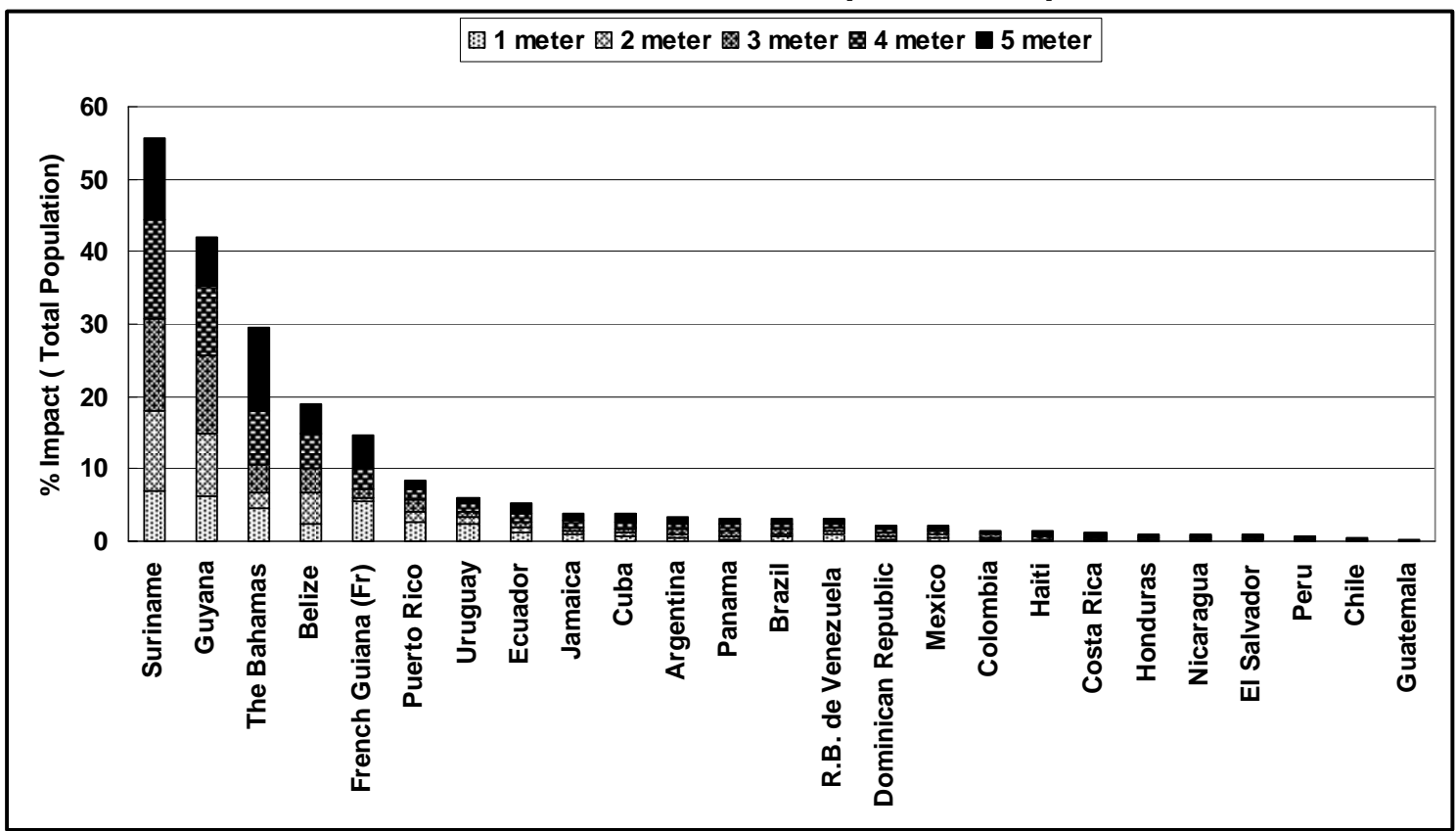

Figure 1d

Latin America \& Caribbean: GDP impacted

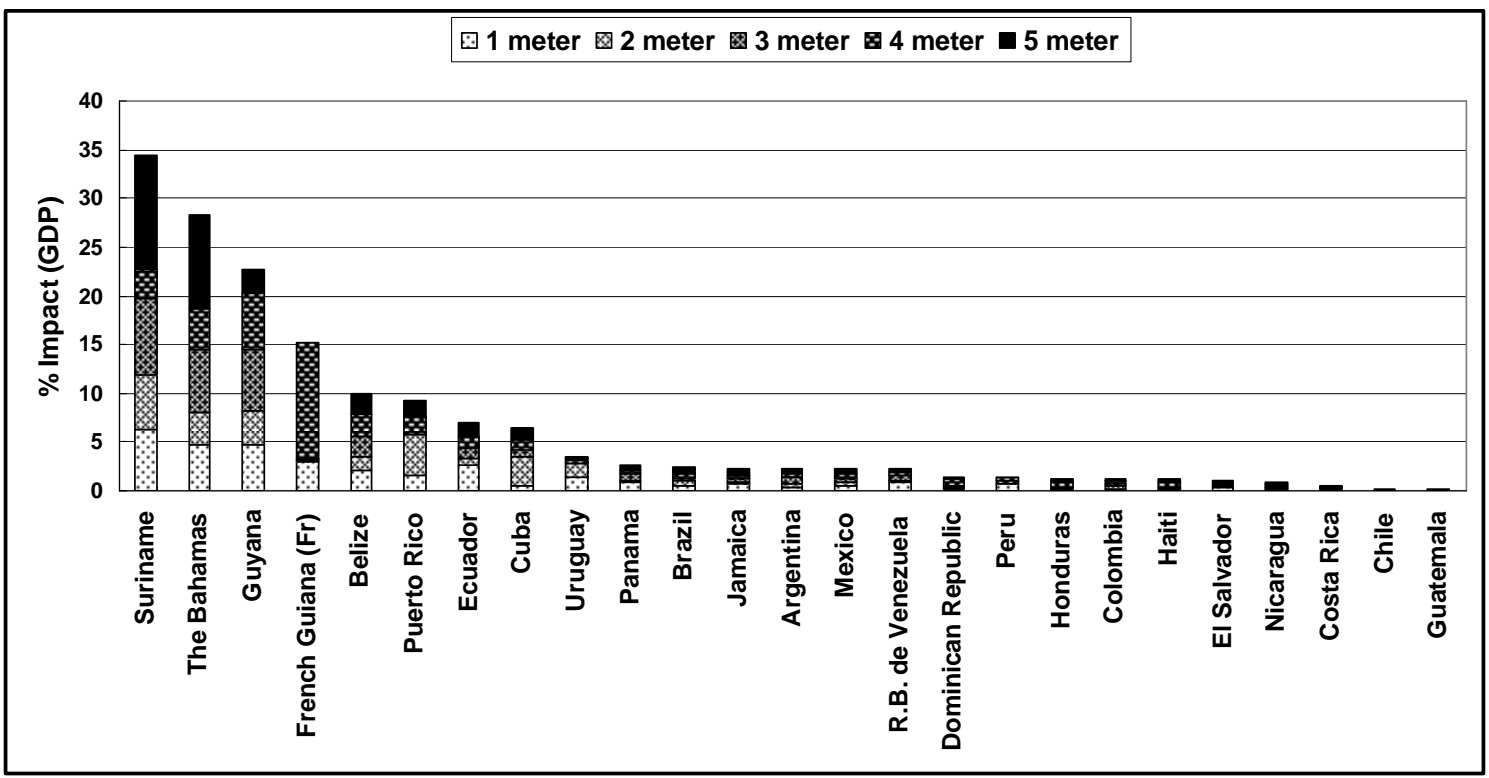


Figure 1e

Latin America \& Caribbean: Urban extent impacted

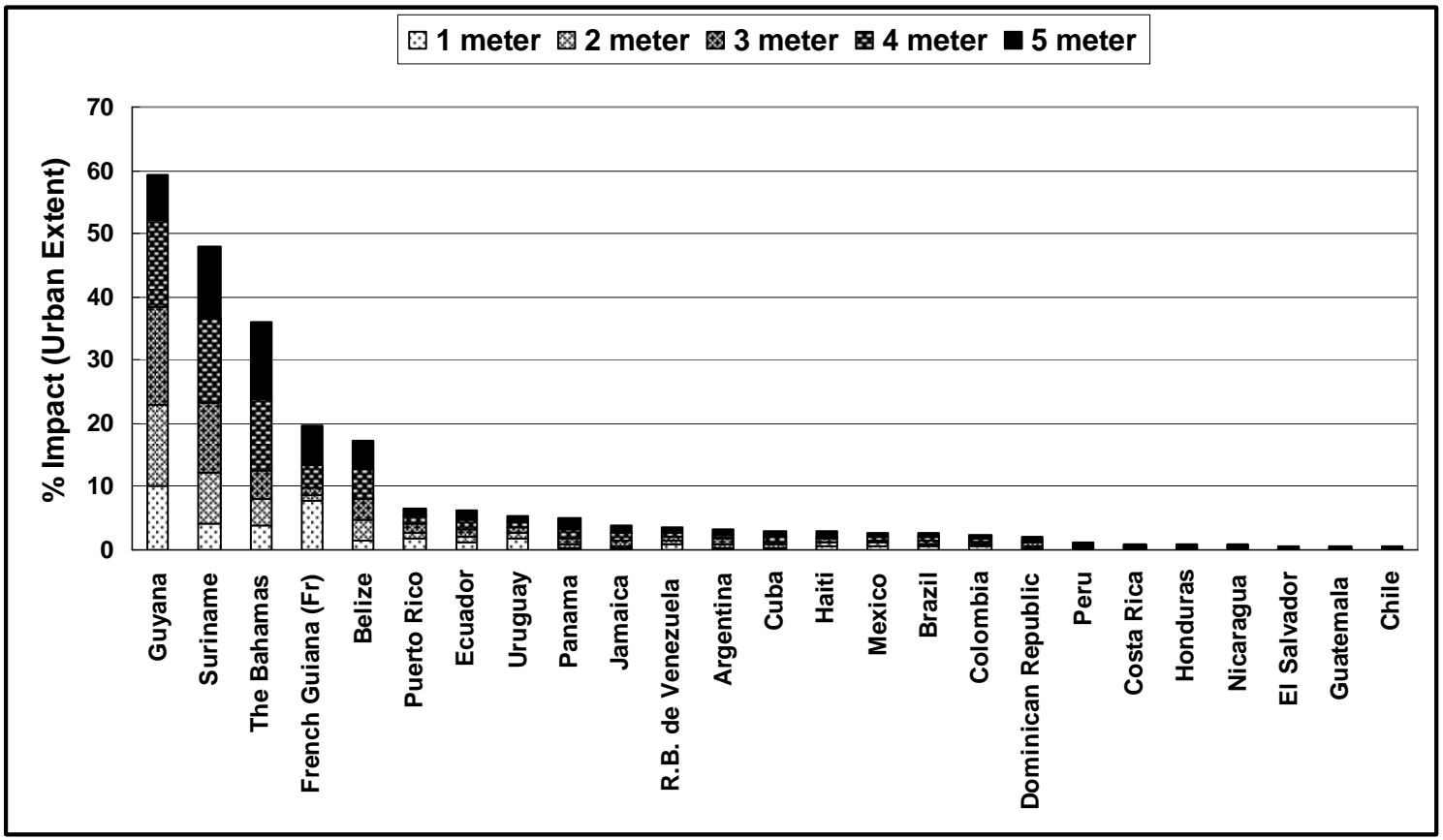

The Bahamas' agricultural extent exhibits the highest impact (Figure 1f). It is of interest to note that while Argentina's area, population and GDP would not be significantly impacted by SLR, its agricultural extent would be significantly impacted.

Finally, this analysis reveals that wetlands of the region would be severely impacted by SLR (Figure $1 \mathrm{~g}$ ). With a $1 \mathrm{~m}$ SLR, approximately $30 \%$ of Jamaica's and Belize's wetlands would be impacted. With a 5m SLR, most of The Bahamas' and Belize's wetlands would be impacted, as well as more than half of Cuba's wetlands. 
Figure 1f

Latin America \& Caribbean: Agricultural extent impacted

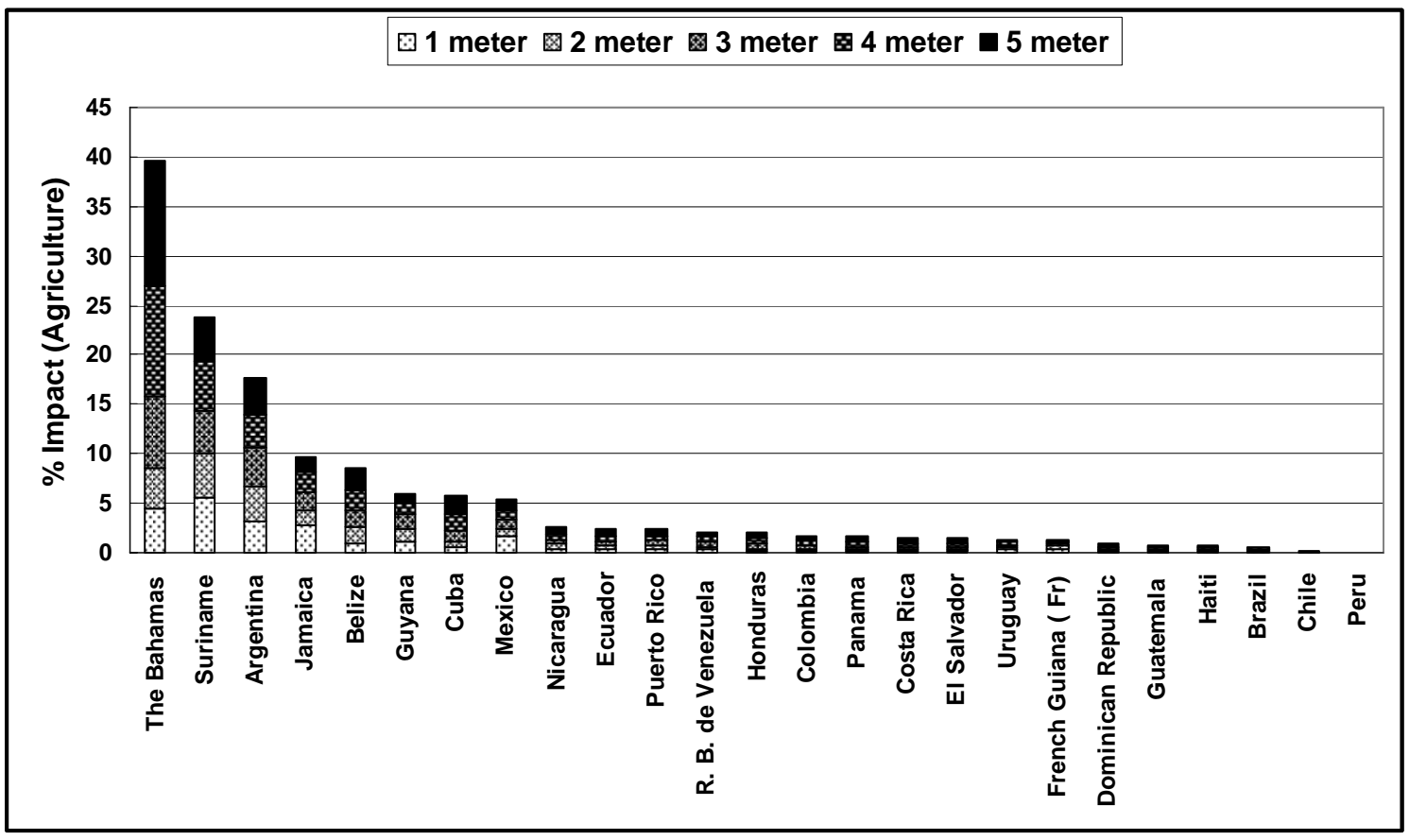

Figure 19

Latin America \& Caribbean: Wetlands impacted

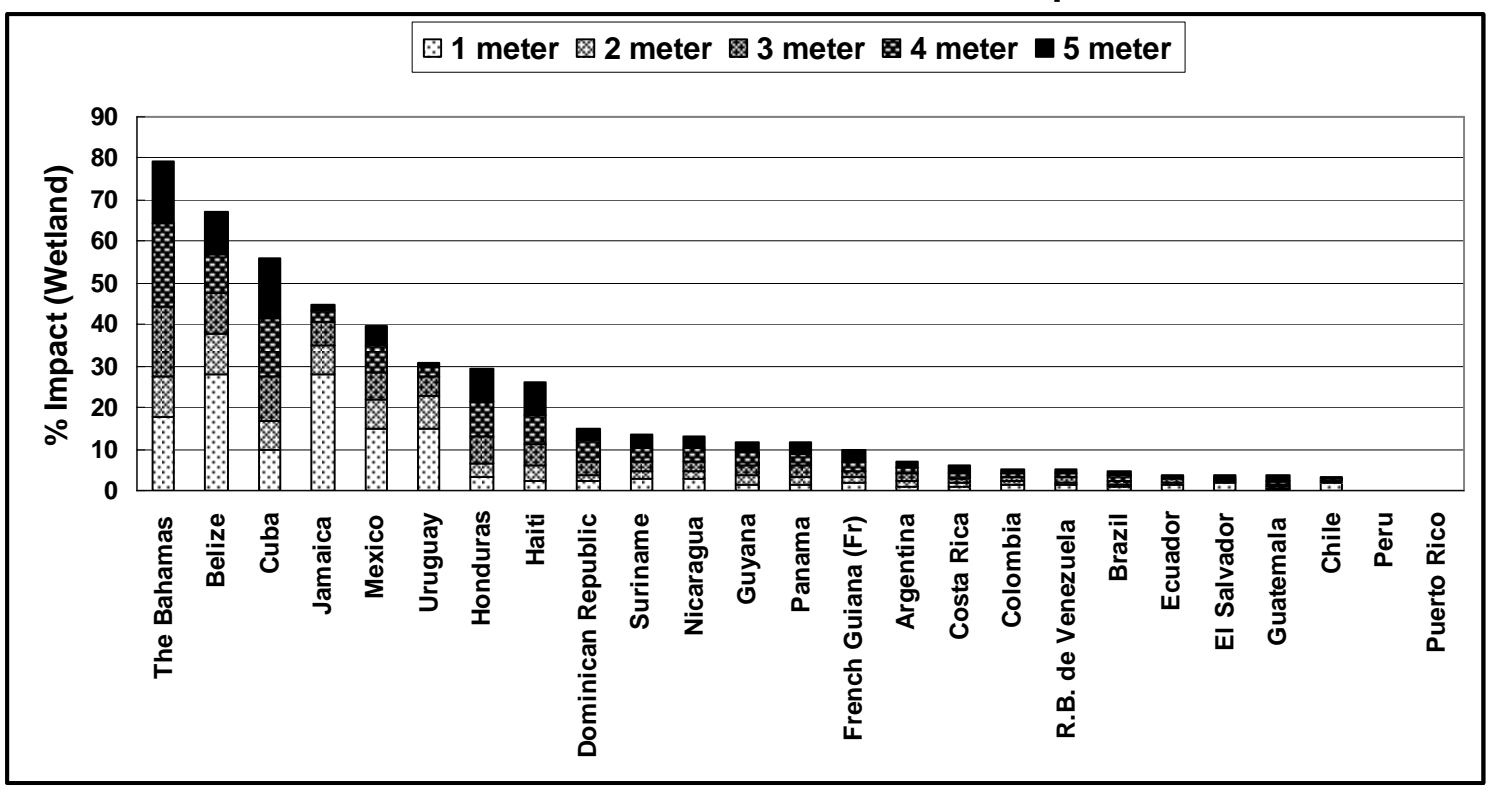




\section{(ii) Middle East and North Africa}

Table 5 reveals that, while the land area of the Middle East and North Africa region would be less impacted by SLR than the developing world generally $(0.25 \%$ vs. $0.31 \%$ with a $1 \mathrm{~m}$ SLR), all other indicators suggest more severe impacts of SLR in this region. In particular, with a $1 \mathrm{~m}$ SLR, $3.2 \%$ of its population would be impacted (vs. 1.28\% worldwide), $1.49 \%$ of its GDP (vs. $1.30 \%$ worldwide), $1.94 \%$ of its urban population (vs. $1.02 \%$ worldwide), and $3.32 \%$ of its wetlands (vs. 1.86\% worldwide). Except for land area, the impacts of SLR are much more severe in this region than in Latin America and the Caribbean.

Table 5

Impacts of sea level rise: Middle East and North Africa region

\begin{tabular}{|c|c|c|c|c|c|}
\hline & $1 \mathrm{~m}$ & $2 m$ & $3 m$ & $4 \mathrm{~m}$ & $5 \mathrm{~m}$ \\
\hline \multicolumn{6}{|c|}{ Area (Total $=10,050,556$ sq. $\mathrm{km})}$. \\
\hline Impacted area & 24,654 & 33,864 & 43,727 & 53,615 & 63,120 \\
\hline$\%$ of total area & 0.25 & 0.34 & 0.44 & 0.53 & 0.63 \\
\hline \multicolumn{6}{|c|}{ Population $($ Total $=259,396,000)$} \\
\hline Impacted population & $8,307,472$ & $10,912,744$ & $13,684,993$ & $16,454,655$ & $19,439,678$ \\
\hline$\%$ of total population & 3.20 & 4.21 & 5.28 & 6.34 & 7.49 \\
\hline \multicolumn{6}{|c|}{ GDP (Total = 1,404,470 million USD) } \\
\hline Impacted GDP (USD) & 20,870 & 30,365 & 39,037 & 46,209 & 54,853 \\
\hline$\%$ of total GDP & 1.49 & 2.16 & 2.78 & 3.29 & 3.91 \\
\hline \multicolumn{6}{|c|}{ Urban extent (Total $=190,030 \mathrm{sq} . \mathrm{km})}$. \\
\hline Impacted area & 3,679 & 5,037 & 6,529 & 7,951 & 9,384 \\
\hline$\%$ of total area & 1.94 & 2.65 & 3.44 & 4.18 & 4.94 \\
\hline \multicolumn{6}{|c|}{ Agricultural extent (Total $=354,294$ sq. $\mathrm{km}$. ) } \\
\hline Impacted area & 4,086 & 6,031 & 8,007 & 9,819 & 11,451 \\
\hline$\%$ of total area & 1.15 & 1.70 & 2.26 & 2.77 & 3.23 \\
\hline \multicolumn{6}{|c|}{ Wetlands area (Total = 342,185 sq. km.) } \\
\hline Impacted area & 11,361 & 14,758 & 18,224 & 21,417 & 24,277 \\
\hline$\%$ of total area & 3.32 & 4.31 & 5.33 & 6.26 & 7.09 \\
\hline
\end{tabular}

When examined at the country level, only Qatar's land area would experience a significant impact (Figure 2a). 
Figure 2a

Middle East and North Africa region: Country area impacted

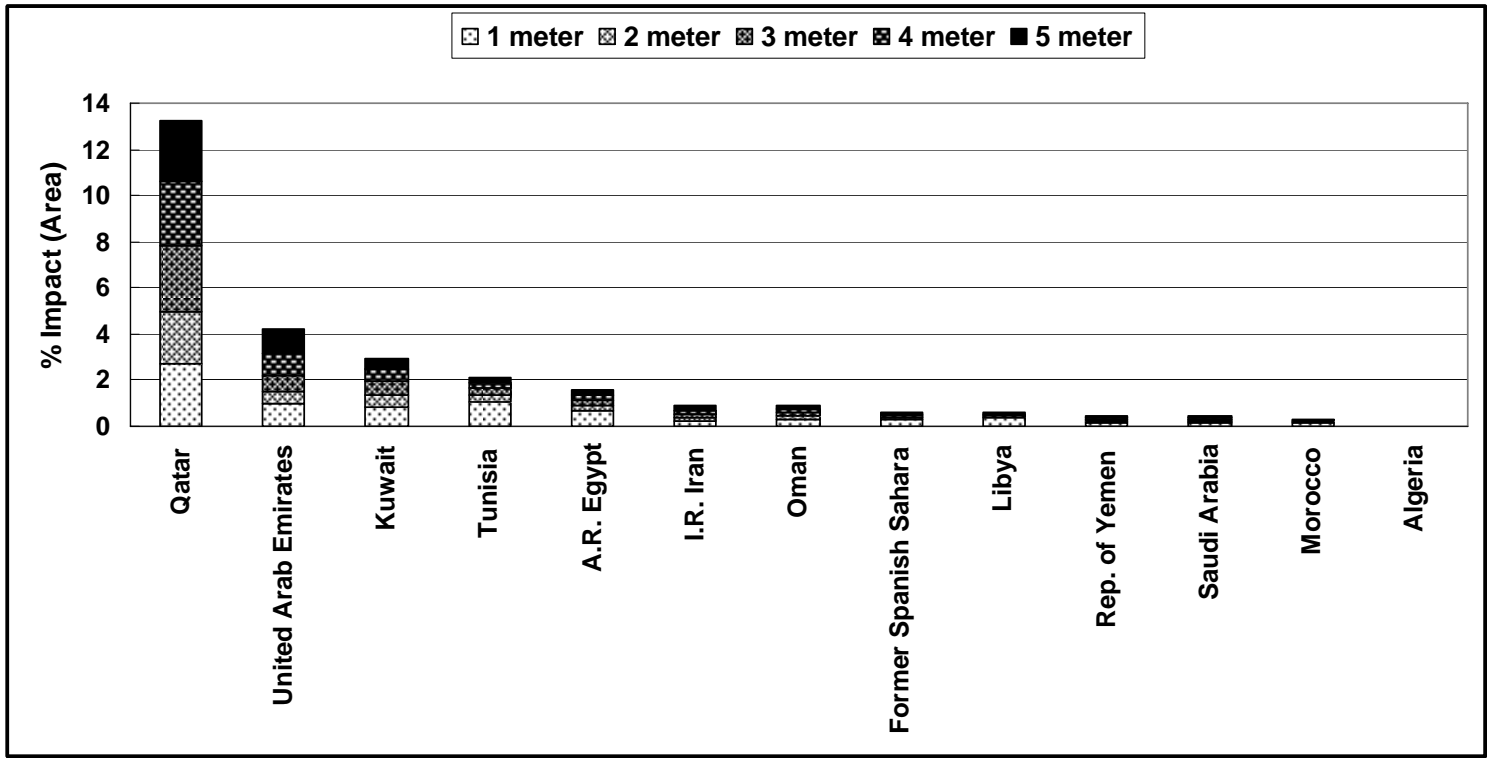

The A.R. of Egypt's population would be most severely impacted by SLR (Figures $2 b$ and $2 \mathrm{c}$ ). With a $1 \mathrm{~m}$ SLR, approximately $10 \%$ of the A.R. of Egypt's population would be impacted. Most of this impact takes place in the Nile Delta; it reaches $20 \%$ with a $5 \mathrm{~m}$ SLR. Approximately 5\% of the population of United Arab Emirates and Tunisia would be impacted by a $1 \mathrm{~m}$ SLR. The A.R. of Egypt's GDP would also be significantly impacted by SLR (Figure 2d). This is partly explained by the impact of SLR on the A.R. of Egypt's agricultural extent. Indeed, most of the impact of SLR on the agricultural sector of the region would take place in the A.R. of Egypt which would experience a severe impact (Figure 2f). Even with a $1 \mathrm{~m}$ SLR, approximately $12.5 \%$ of the A.R. of Egypt's agricultural extent would be impacted; this percentage reaches $35 \%$ with a $5 \mathrm{~m}$ SLR. The A.R. of Egypt's agricultural sector may thus experience severe disruption as a result of SLR. 
Figure 2b

Middle East and North Africa region: Exposed population (5m SLR)

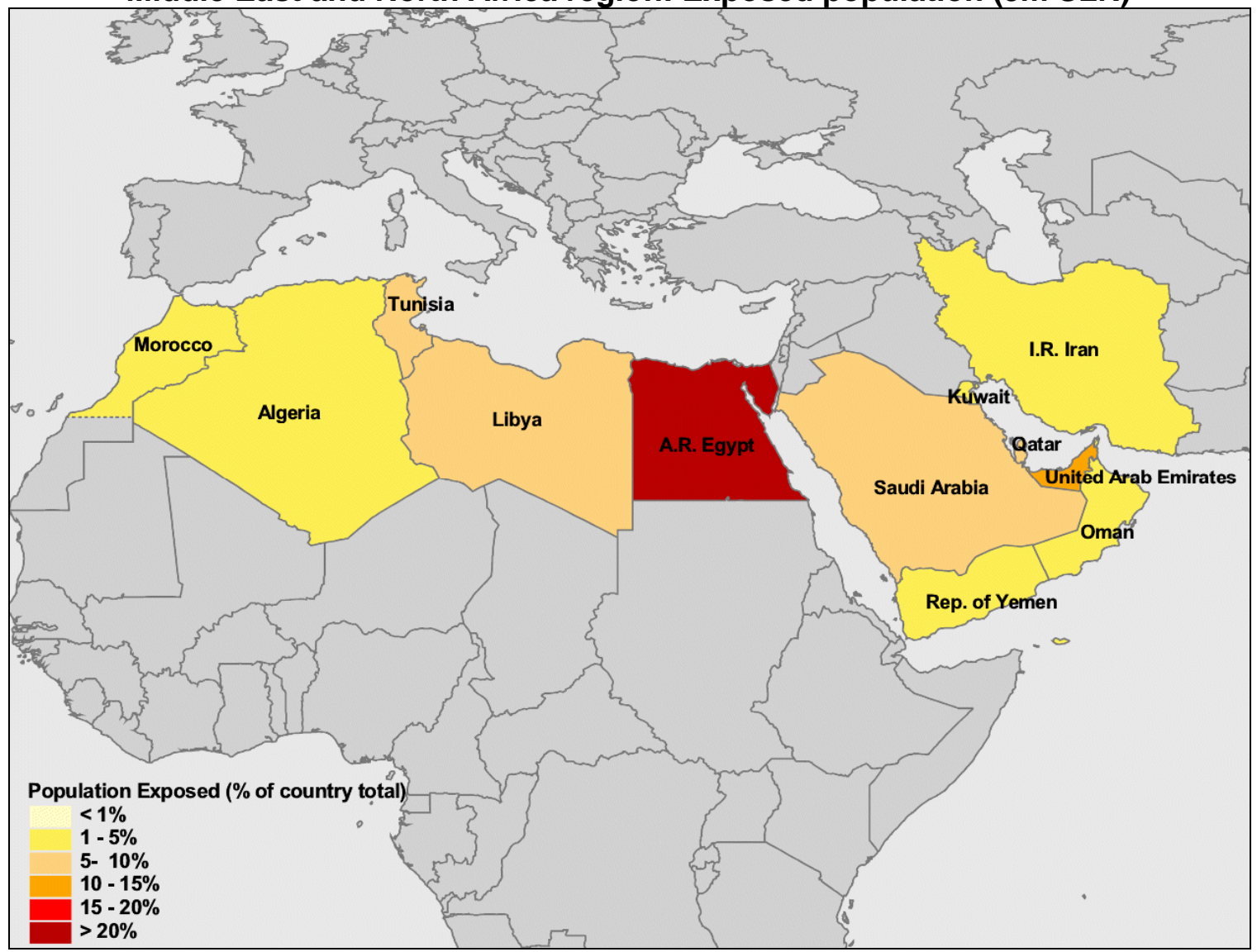


Figure 2c

Middle East and North Africa region: Population impacted

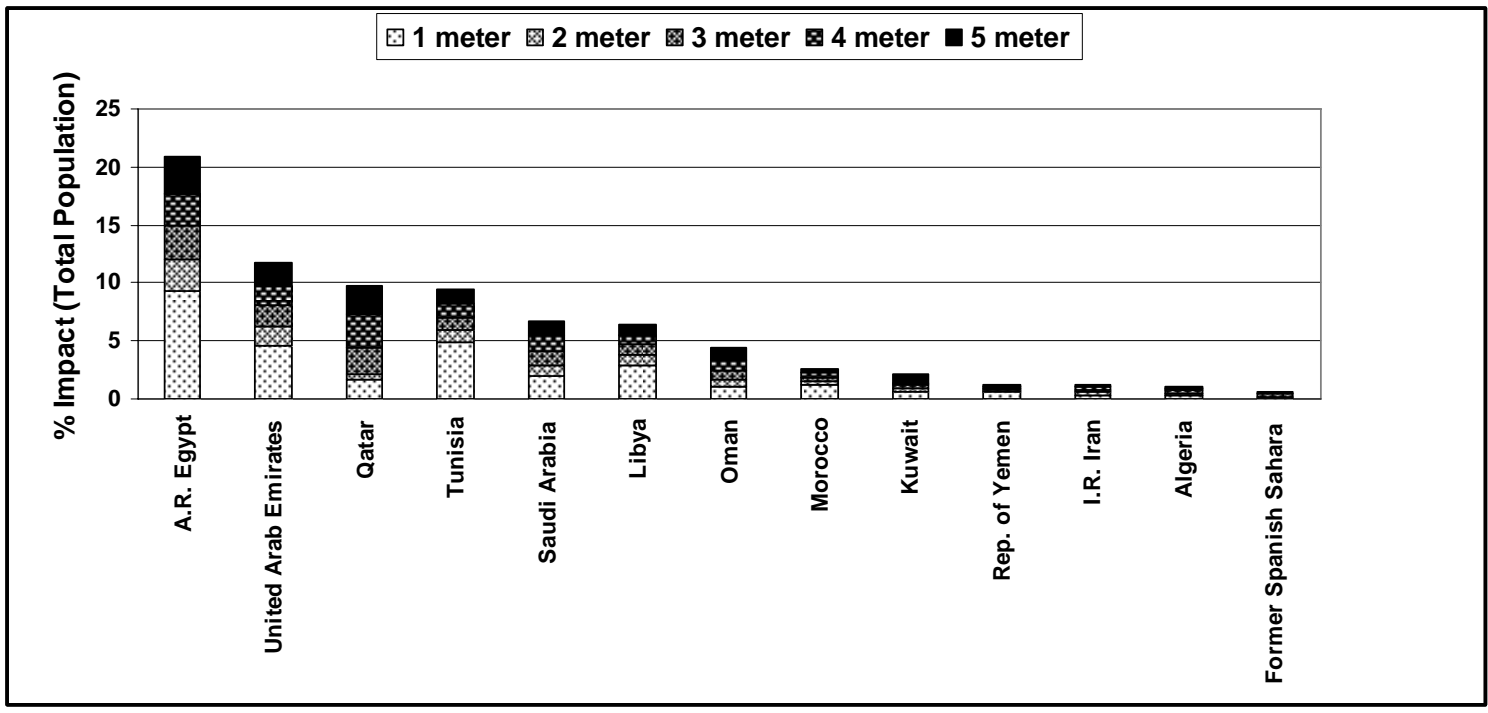

Figure 2d

Middle East and North Africa: GDP impacted

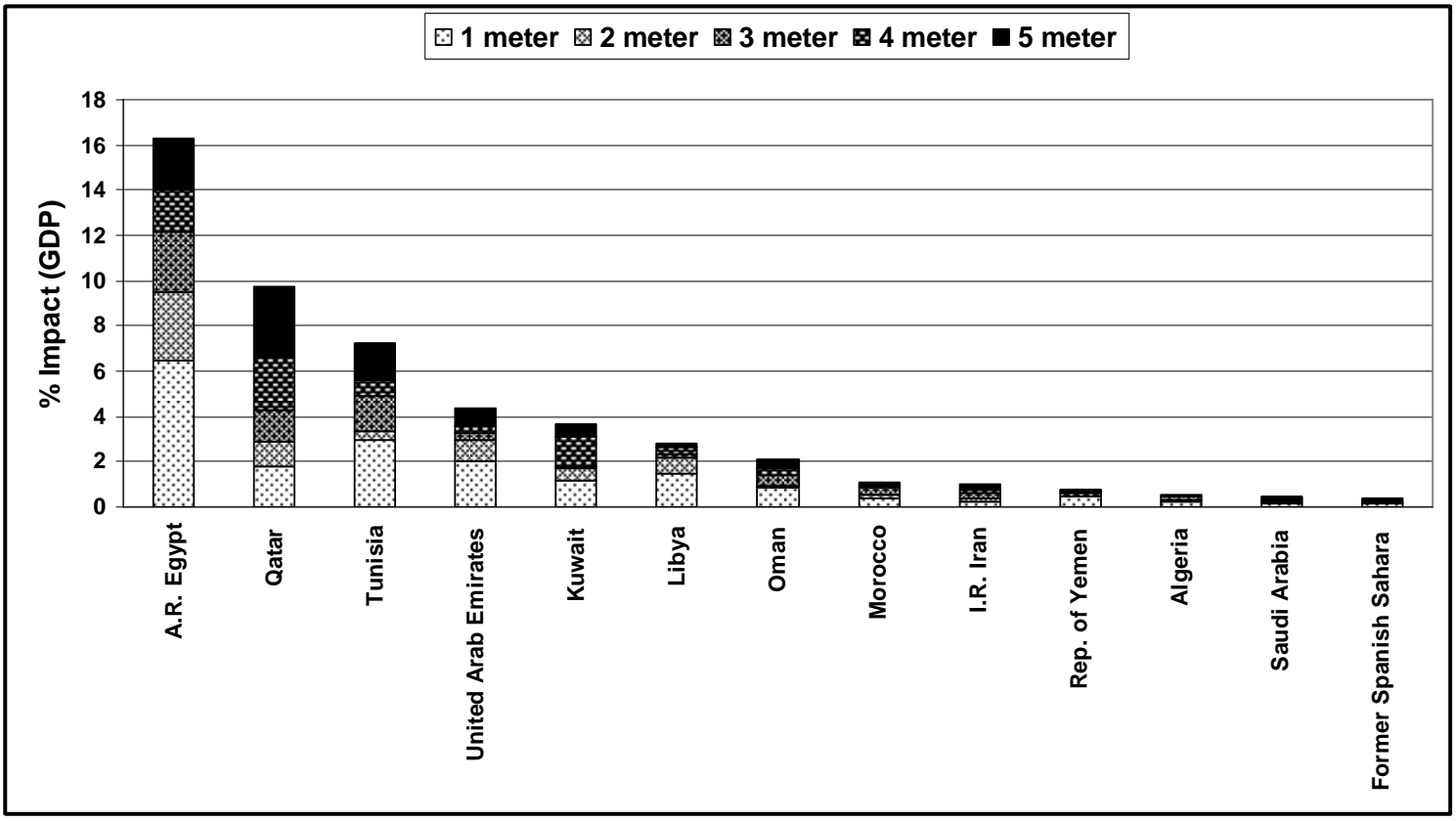

The urban extent of the region would also be significantly impacted (Figure 2e). In the A.R. of Egypt, Libya, United Arab Emirates, and Tunisia, the impact reaches approximately $5 \%$ with a $1 \mathrm{~m}$ SLR, 6 to $7 \%$ with a $2 \mathrm{~m}$ SLR, and approximately $10 \%$ with a 5m SLR. The wetlands of Qatar, and to a lesser extent Kuwait, Libya, and United Arab Emirates would be significantly impacted by SLR (Figure $2 \mathrm{~g}$ ). 
Figure 2e

Middle East and North Africa: Urban extent impacted

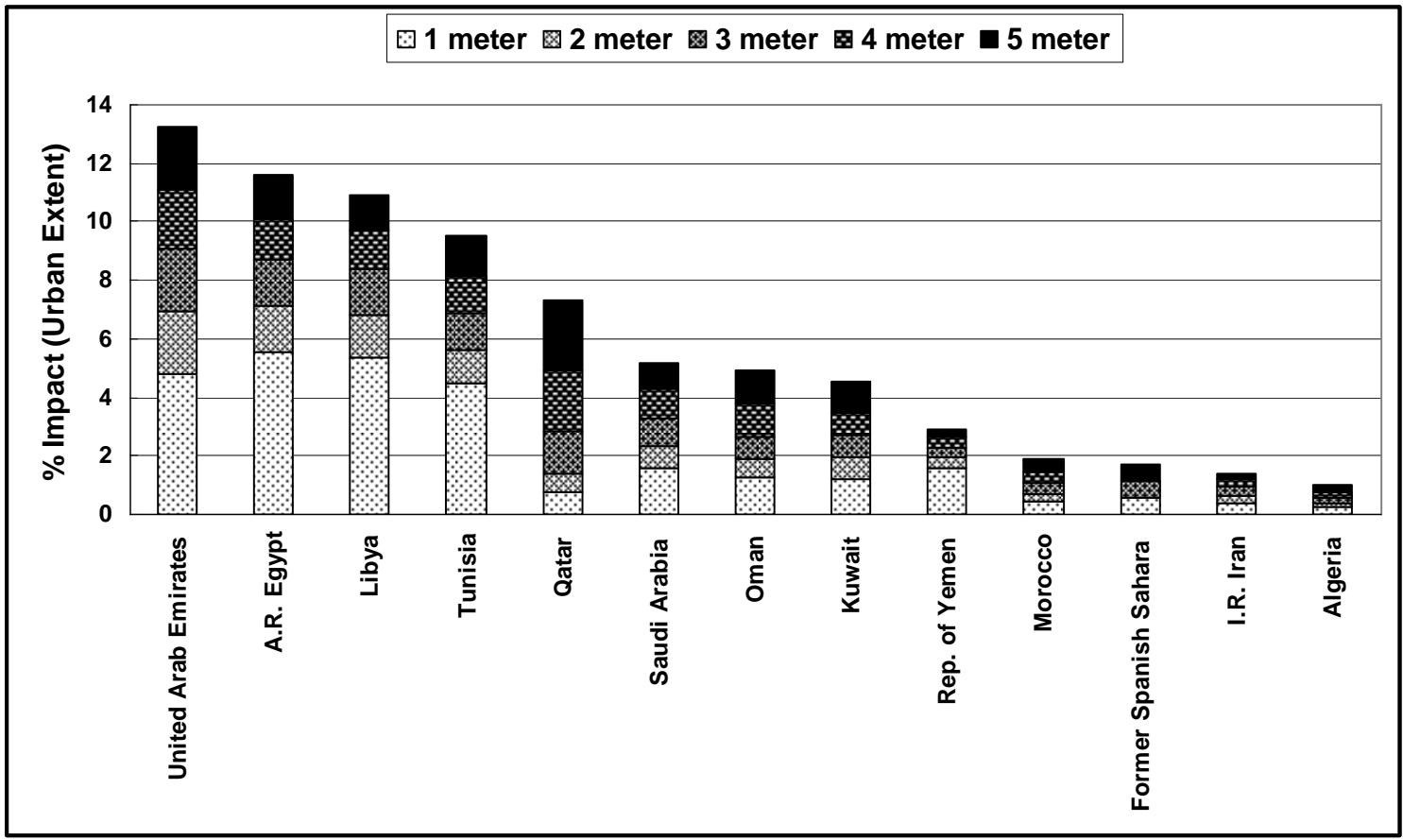

Figure $2 f$

Middle East and North Africa: Agricultural extent impacted

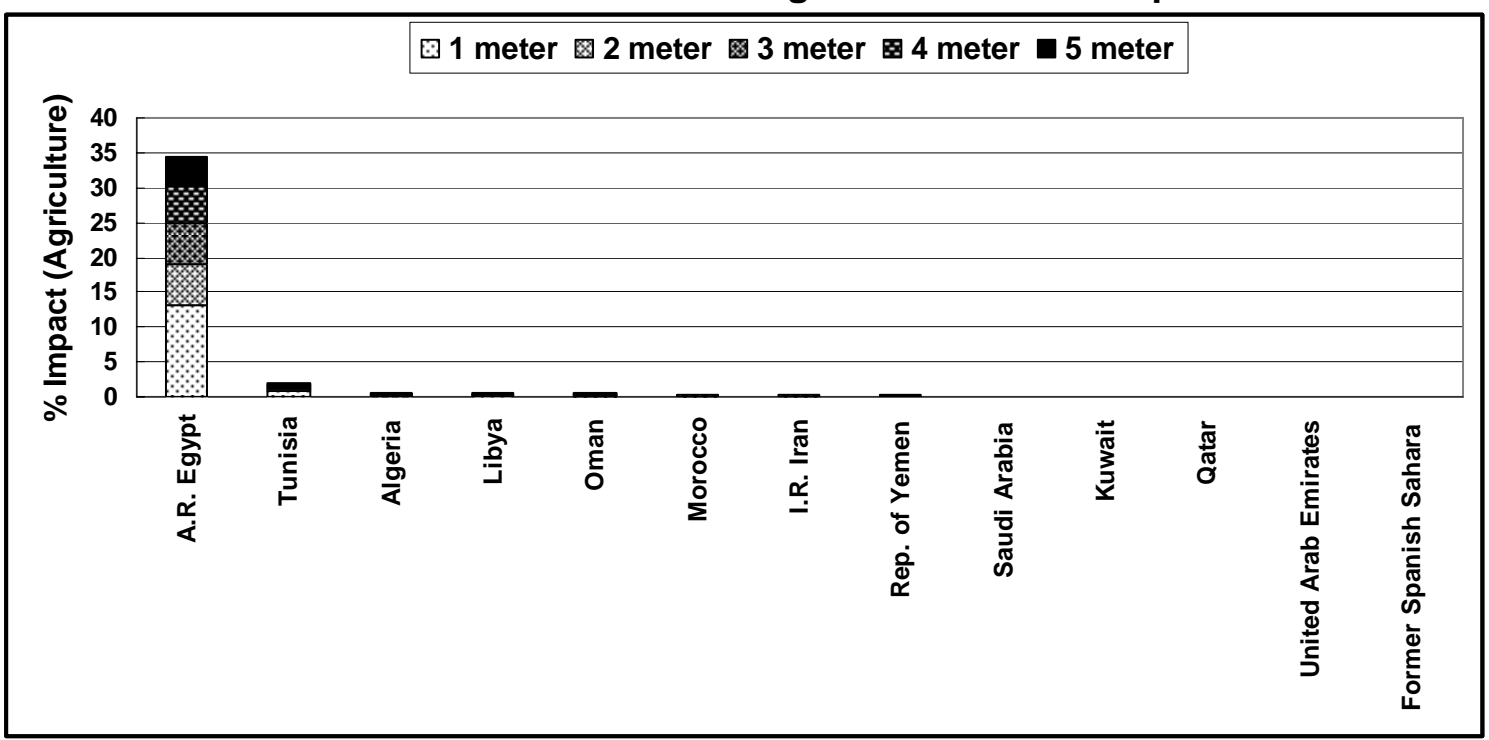


Figure 2g

Middle East and North Africa: Wetlands impacted

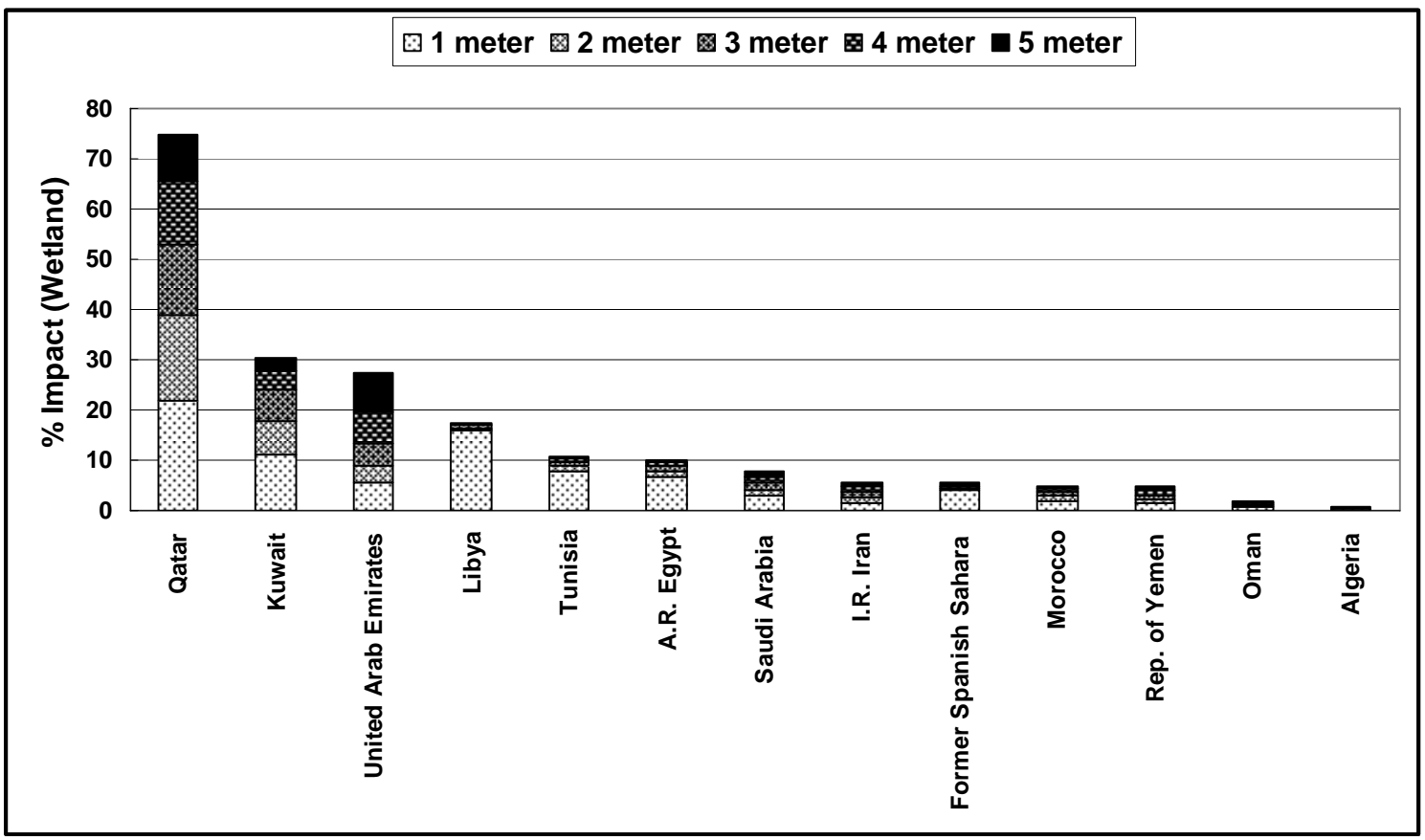

(iii) Sub-Saharan Africa

Of all regions, Sub-Saharan Africa has the least impact. As indicated in Table 6, less than $1 / 4$ of $1 \%$ of the region's GDP would be impacted by a $1 \mathrm{~m} \mathrm{SLR}$, while its agricultural extent would generally remain free of any impact. Only a very small percentage of the region's area and agricultural extent would be impacted, even with a $5 \mathrm{~m}$ SLR, and less than $1 \%$ of the population would be impacted with a $3 \mathrm{~m}$ SLR. 
Table 6

Impacts of sea level rise:

Sub-Saharan Africa

\begin{tabular}{|c|c|c|c|c|c|}
\hline & $1 \mathrm{~m}$ & $2 m$ & $3 m$ & $4 m$ & $5 \mathrm{~m}$ \\
\hline \multicolumn{6}{|c|}{ Area (Total = 16,137,438 sq. km.) } \\
\hline Impacted area & 18,641 & 28,083 & 42,645 & 59,661 & 77,253 \\
\hline$\%$ of total area & 0.12 & 0.17 & 0.26 & 0.37 & 0.48 \\
\hline \multicolumn{6}{|c|}{ Population $($ Total $=463,121,000)$} \\
\hline Impacted population & $2,098,795$ & $3,651,629$ & $4,303,289$ & $8,471,790$ & $11,040,978$ \\
\hline$\%$ of total population & 0.45 & 0.79 & 0.93 & 1.83 & 2.38 \\
\hline \multicolumn{6}{|c|}{ GDP (Total = 963,974 million USD) } \\
\hline Impacted GDP (USD) & 2,228 & 4,368 & 7,143 & 10,897 & 13,722 \\
\hline$\%$ of total GDP & 0.23 & 0.45 & 0.74 & 1.13 & 1.42 \\
\hline \multicolumn{6}{|c|}{ Urban extent (Total = 109,372 sq. km.) } \\
\hline Impacted area & 430 & 742 & 1,268 & 1,853 & 2,449 \\
\hline$\%$ of total area & 0.39 & 0.68 & 1.16 & 1.69 & 2.24 \\
\hline \multicolumn{6}{|c|}{ Agricultural extent (Total $=4,236,159 \mathrm{sq} . \mathrm{km})}$. \\
\hline Impacted area & 1,646 & 3,404 & 6,595 & 11,231 & 16,145 \\
\hline$\%$ of total area & 0.04 & 0.08 & 0.16 & 0.27 & 0.38 \\
\hline \multicolumn{6}{|c|}{ Wetlands area (Total $=805,030$ sq. $\mathrm{km})}$. \\
\hline Impacted area & 8,902 & 13,551 & 20,625 & 29,078 & 37,864 \\
\hline$\%$ of total area & 1.11 & 1.68 & 2.56 & 3.61 & 4.70 \\
\hline
\end{tabular}

Within the region, the countries with greatest land area impact would be The Gambia and, to a lesser extent, Guinea-Bissau (reference Figure 3a). However, even in these two countries, the impact remains well below $4 \%$ with a $2 \mathrm{~m} \mathrm{SLR}$, and it never raises above $10 \%$ except for The Gambia with a SLR of $4 \mathrm{~m}$ or greater.

Figure 3a

Sub-Saharan Africa: Country area impacted

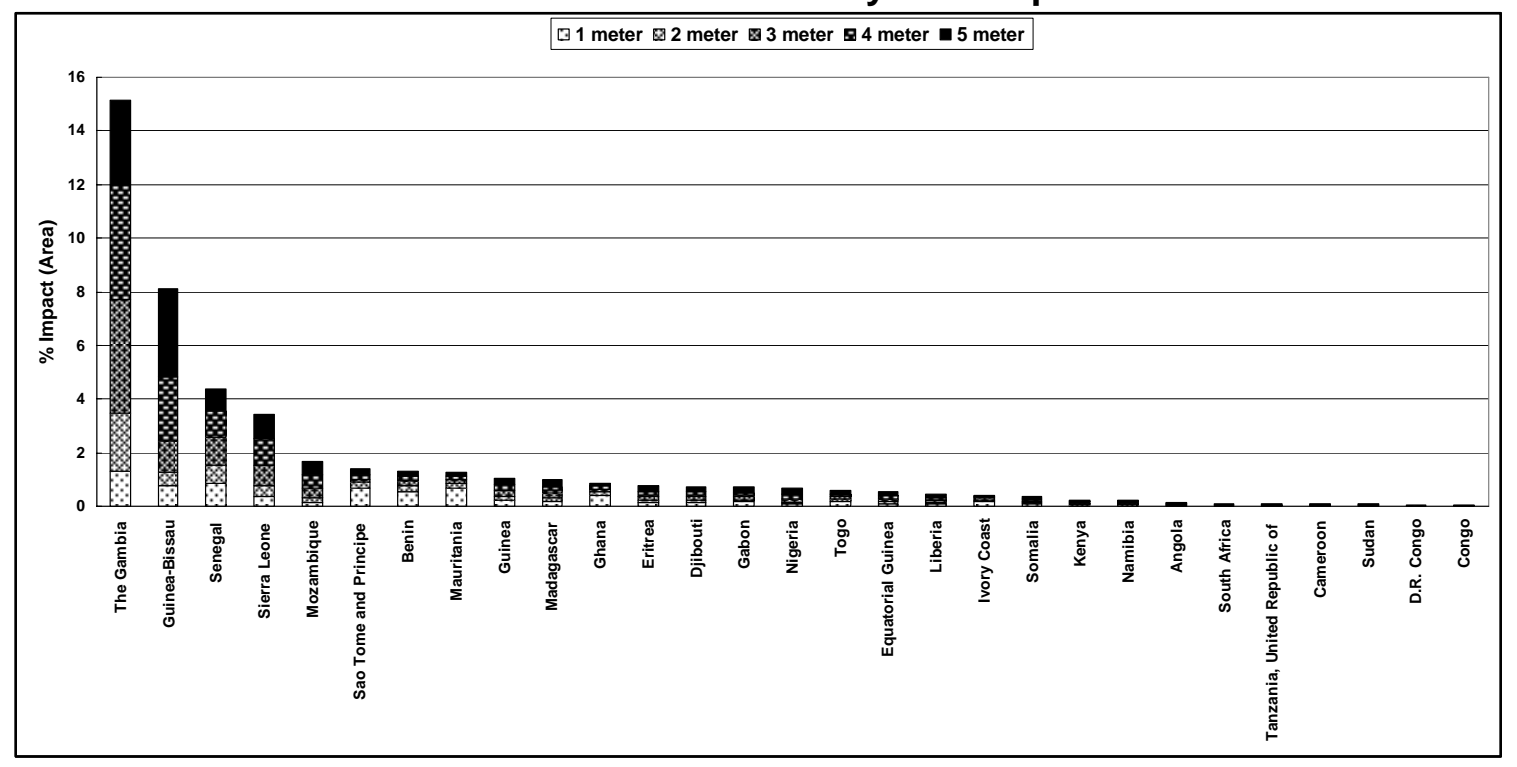


Both The Gambia and Mauritania would experience a significant population impact (Figures $3 \mathrm{~b}$ and $3 \mathrm{c}$ ), reaching approximately $8 \%$ in Mauritania with a $1 \mathrm{~m}$ SLR. For most countries in the region, population impacted remains below $5 \%$ even with a $5 \mathrm{~m}$ SLR. Mauritania's GDP would also experience the largest impact, reaching slightly below 10\% with a $1 \mathrm{~m}$ SLR (Figure 3d). Note that approximately 5\% of Benin's GDP would also be impacted by a $1 \mathrm{~m}$ SLR. Urban extent is most impacted in Mauritania (Figure 3e), while agricultural extent is most impacted in The Gambia, Guinea-Bissau, and Mauritania (Figure 3f). Approximately $15 \%$ of Benin's wetlands would be impacted by a $1 \mathrm{~m}$ SLR (Figure $3 \mathrm{~g}$ ). When SLR reaches $5 \mathrm{~m}$, The Gambia's and Senegal's wetlands are those most affected.

Figure 3b

Sub-Saharan Africa: Exposed population (5m SLR)

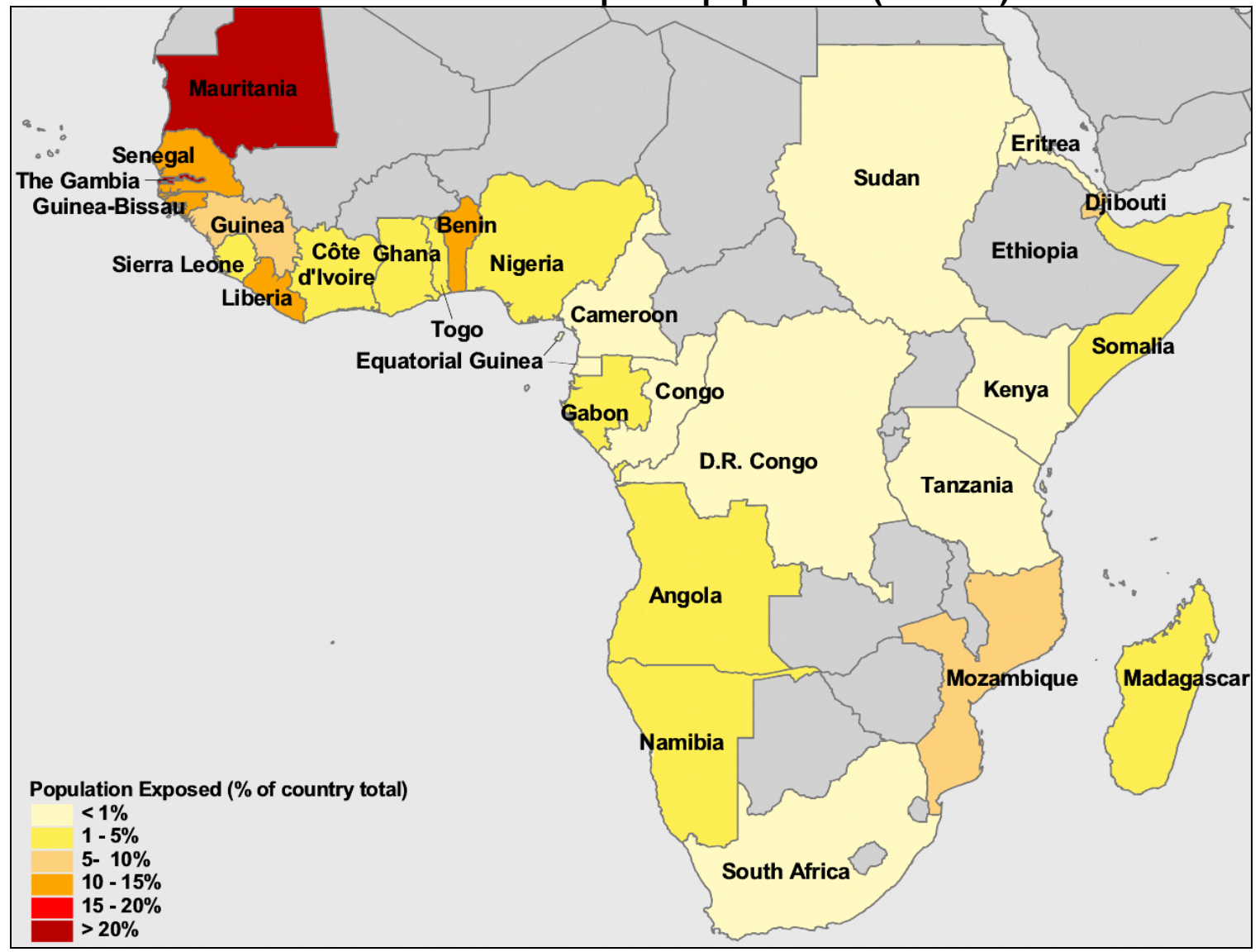


Figure 3c

Sub-Saharan Africa: Population impacted

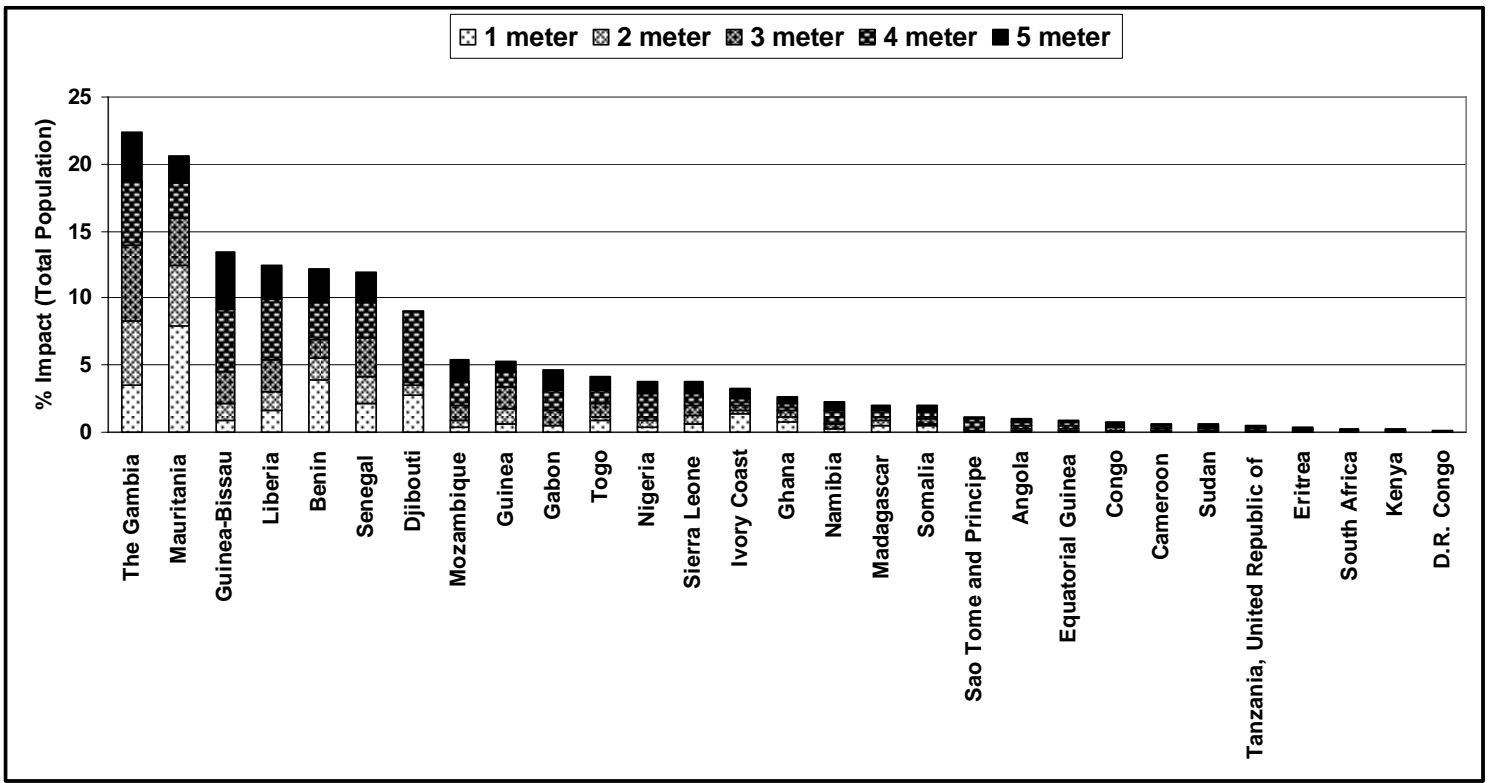

Figure 3d

Sub-Saharan Africa: GDP impacted

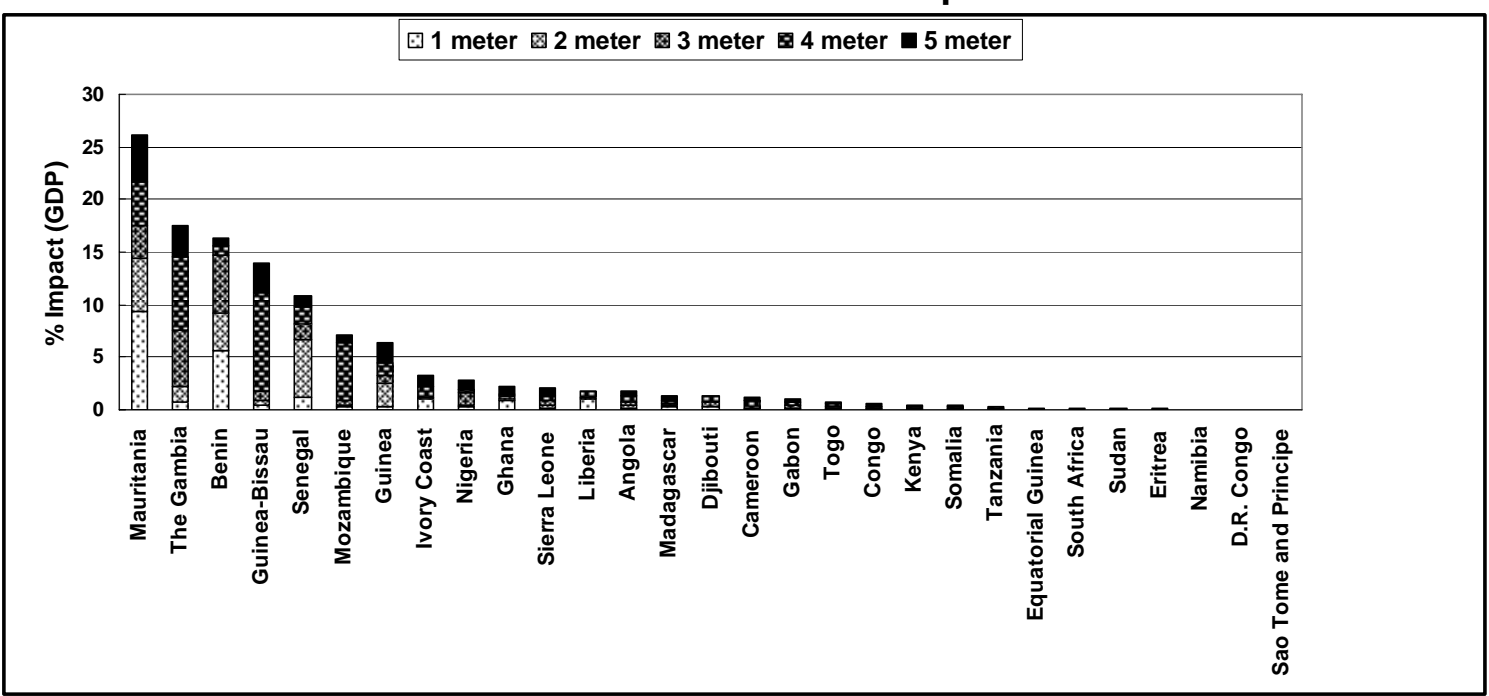


Figure 3e

Sub-Saharan Africa: Urban extent impacted

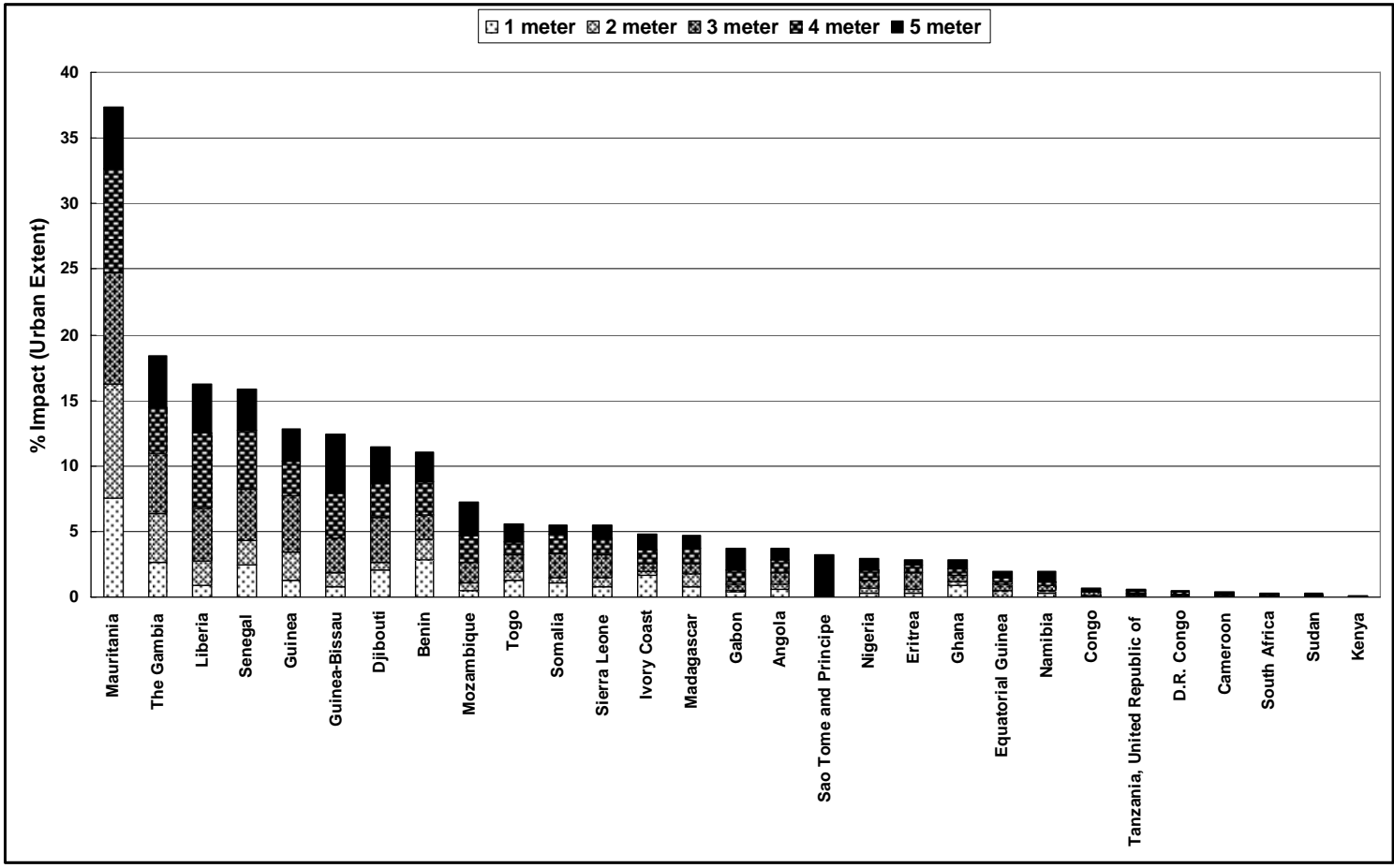

Figure $3 f$

Sub-Saharan Africa: Agricultural extent impacted

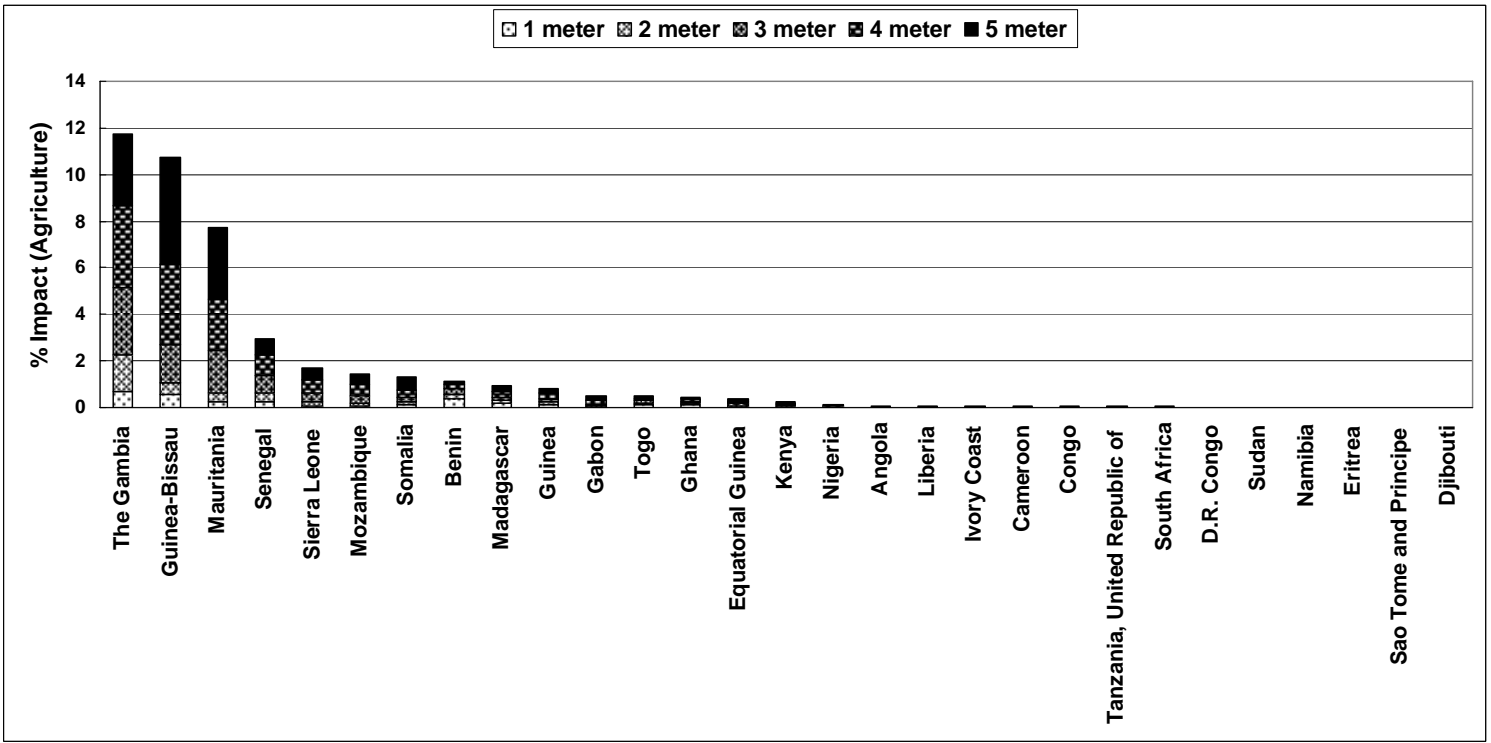


Figure 3g

Sub-Saharan Africa: Wetlands impacted

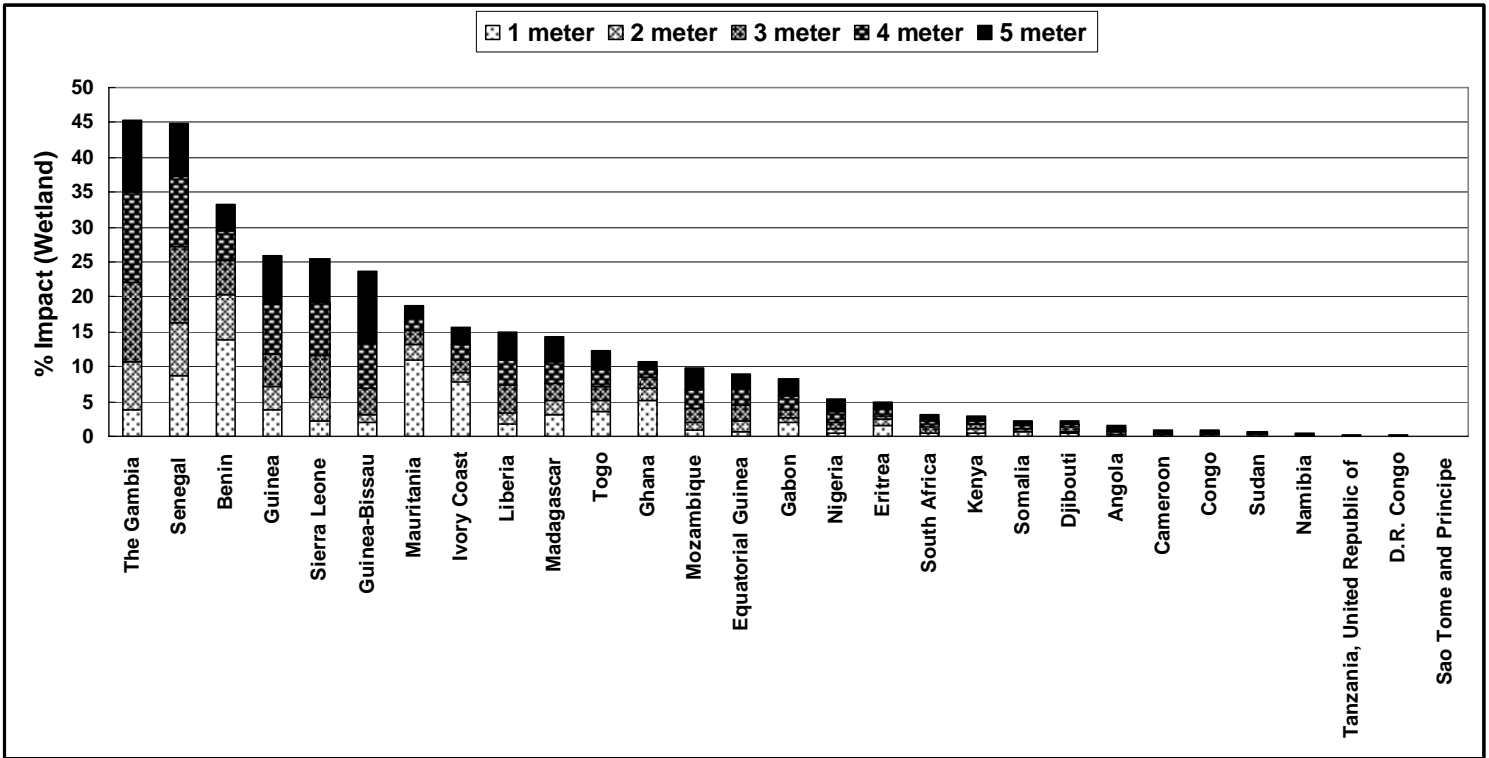

(iv) East Asia

East Asia would be significantly impacted by SLR. At $5 \mathrm{~m}$ SLR, East Asia is the most severely impacted region in the developing world. For $1 \mathrm{~m}$ to $5 \mathrm{~m}$ SLR, the impacted population is $2 \%$ to $8.6 \%$, while impacted GDP is $2.09 \%$ to $10.2 \%$. Urban extent and wetlands are also significantly impacted by SLR (Table 7). 
Table 7

Impacts of sea level rise:

East Asia

\begin{tabular}{|c|c|c|c|c|c|}
\hline & $1 \mathrm{~m}$ & $2 m$ & $3 m$ & $4 m$ & $5 m$ \\
\hline \multicolumn{6}{|c|}{ Area (Total = 14,140,767 sq. km.) } \\
\hline Impacted area & 74,020 & 119,370 & 178,177 & 248,970 & 325,089 \\
\hline$\%$ of total area & 0.52 & 0.84 & 1.26 & 1.76 & 2.30 \\
\hline \multicolumn{6}{|c|}{ Population (Total = 1,883,407,000) } \\
\hline Impacted population & $37,193,866$ & $60,155,640$ & $90,003,580$ & $126,207,275$ & $162,445,397$ \\
\hline$\%$ of total population & 1.97 & 3.19 & 4.78 & 6.70 & 8.63 \\
\hline \multicolumn{6}{|c|}{ GDP (Total = 7,577,206 million USD) } \\
\hline Impacted GDP (USD) & 158,399 & 255,510 & 394,081 & 592,598 & 772,904 \\
\hline$\%$ of total GDP & 2.09 & 3.37 & 5.20 & 7.82 & 10.20 \\
\hline \multicolumn{6}{|c|}{ Urban extent (Total $=388,054$ sq. km.) } \\
\hline Impacted area & 6,648 & 11,127 & 17,596 & 25,725 & 34,896 \\
\hline$\%$ of total area & 1.71 & 2.87 & 4.53 & 6.63 & 8.99 \\
\hline \multicolumn{6}{|c|}{ Agricultural extent (Total $=5,472,581 \mathrm{sq} . \mathrm{km})}$. \\
\hline Impacted area & 45,393 & 78,347 & 121,728 & 174,076 & 229,185 \\
\hline$\%$ of total area & 0.83 & 1.43 & 2.22 & 3.18 & 4.19 \\
\hline \multicolumn{6}{|c|}{ Wetlands area (Total = 1,366,069 sq. km.) } \\
\hline Impacted area & 36,463 & 56,579 & 79,984 & 110,671 & 130,780 \\
\hline$\%$ of total area & 2.67 & 4.14 & 5.86 & 8.10 & 9.57 \\
\hline
\end{tabular}

As shown in Figure 4a, Vietnam is the most seriously impacted by SLR: Up to $16 \%$ of its area would be impacted by a $5 \mathrm{~m}$ SLR, making it second only to The Bahamas among countries analyzed for this paper. Most of this impact is in the Mekong and Red River Deltas. Note in Figure 4b that most of Vietnam's land area southwest of Ho Chi Minh City would be severely impacted by SLR.

Large percentages of Vietnam's population and economic activity are located in these two river deltas. As shown in Figures 4c and 4d, 10.8\% of Vietnam's population would be impacted by a $1 \mathrm{~m}$ SLR. This is the largest percentage of impacted population among all 84 countries (A.R. of Egypt follows with 10.56\%). Vietnam's impacted population would reach $35 \%$ with a $5 \mathrm{~m}$ SLR. The impacts of SLR on Vietnam's GDP (Figure $4 \mathrm{e}$ ) and urban extent (Figure 4f) closely follow the impact on its population. 
Figure 4a

East Asia: Country area impacted

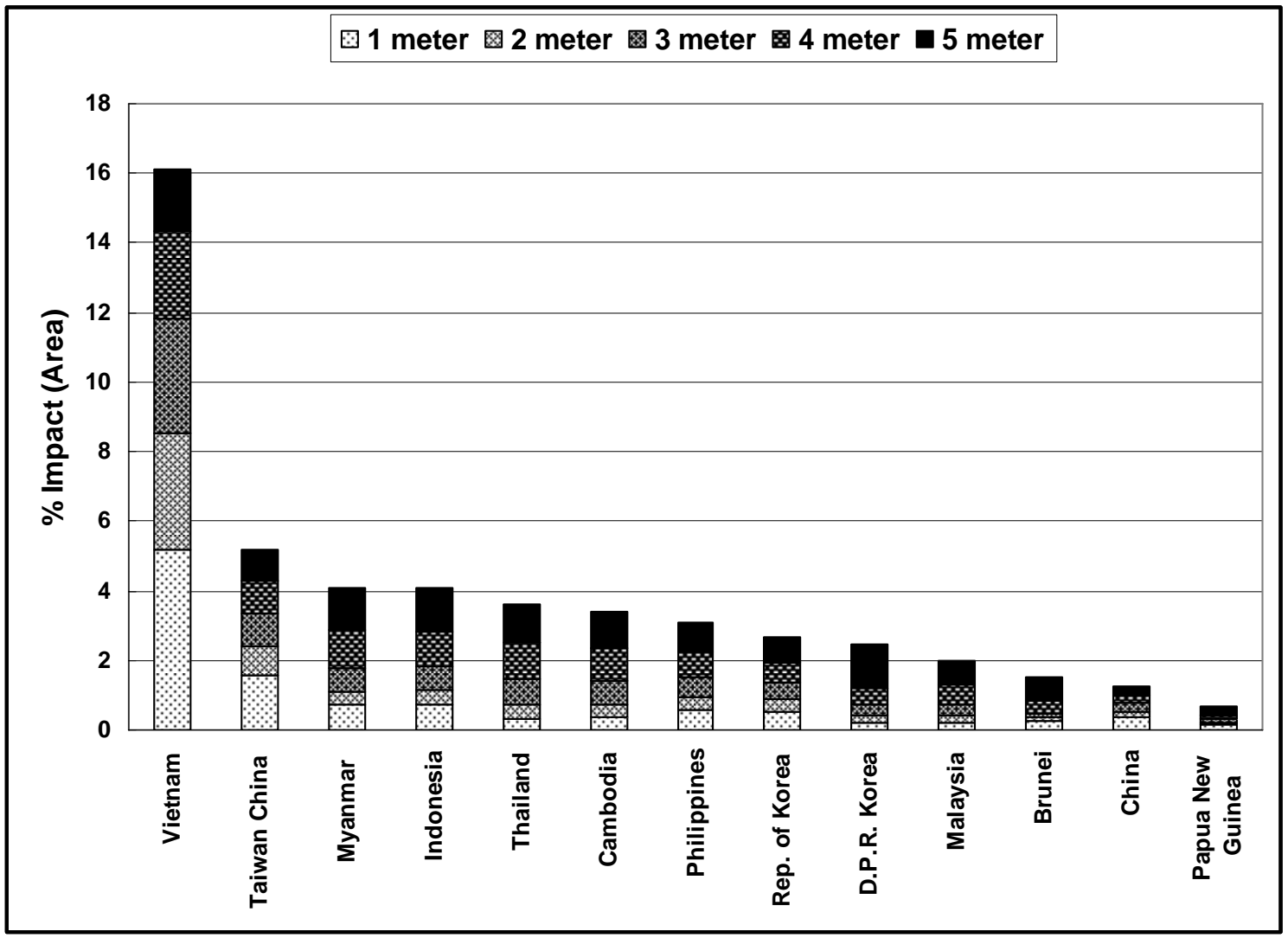


Figure 4b

Inundation zone: Vietnam

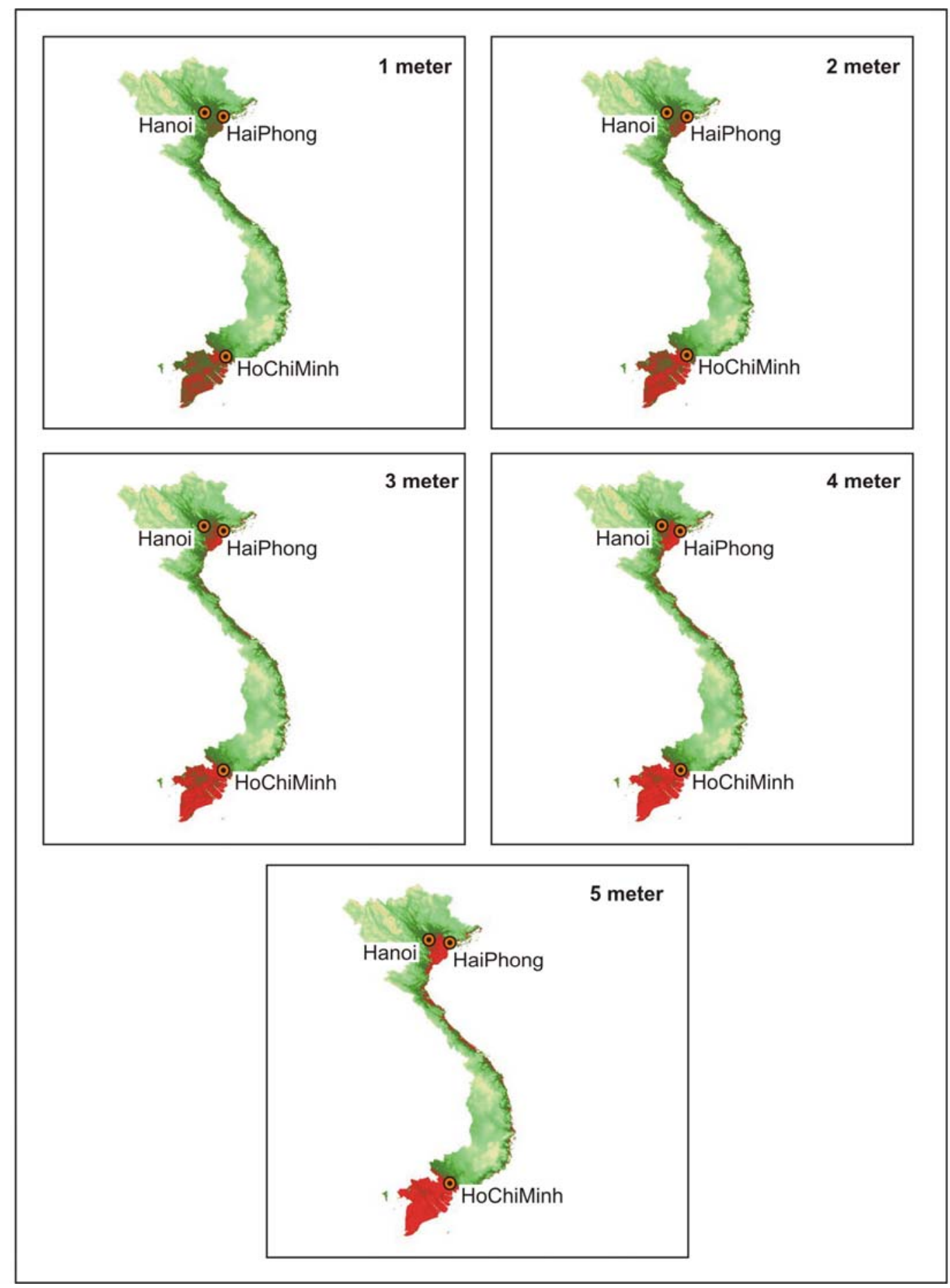


Figure 4c

East Asia: Exposed population (5m SLR)

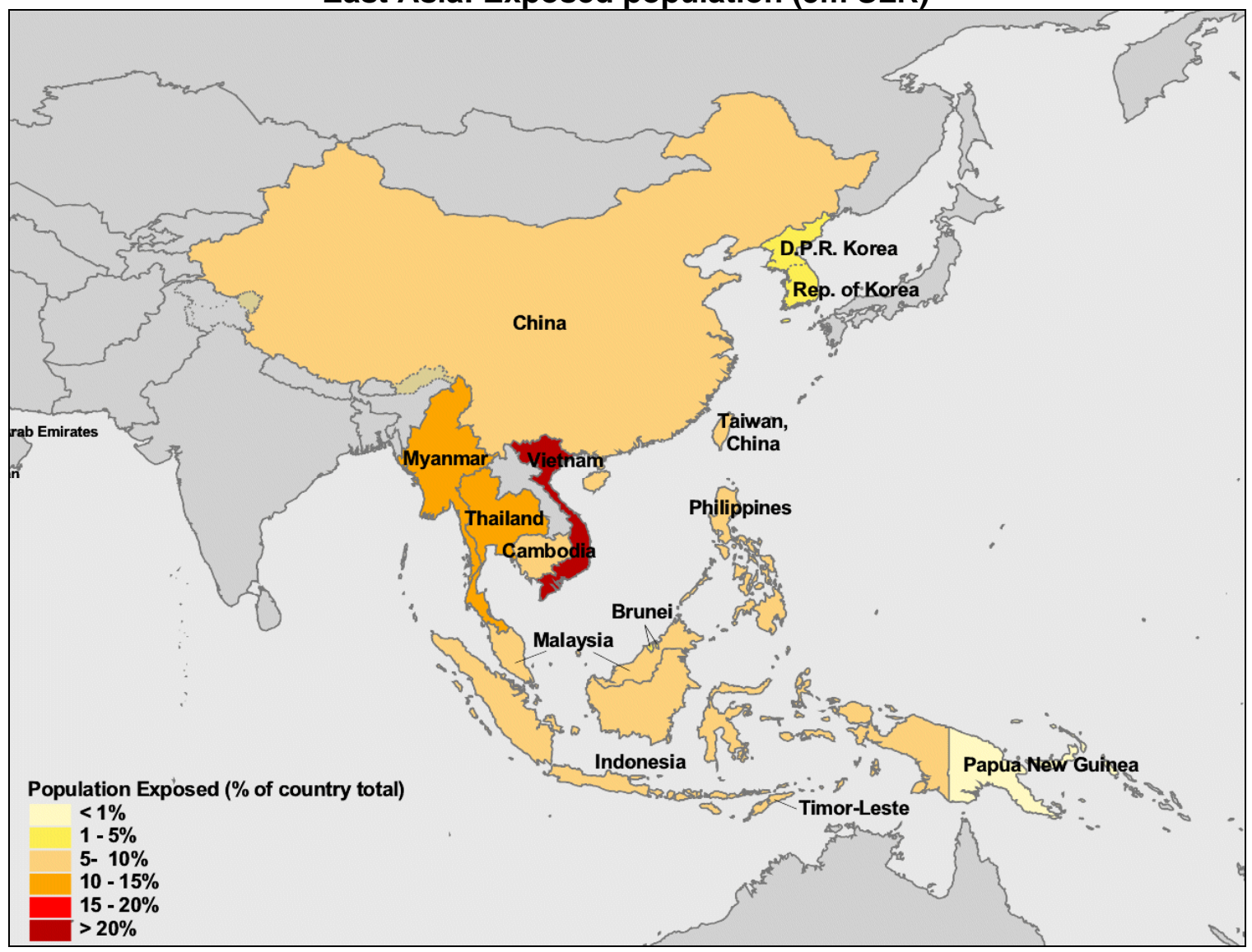

Figure 4d

East Asia: Population impacted

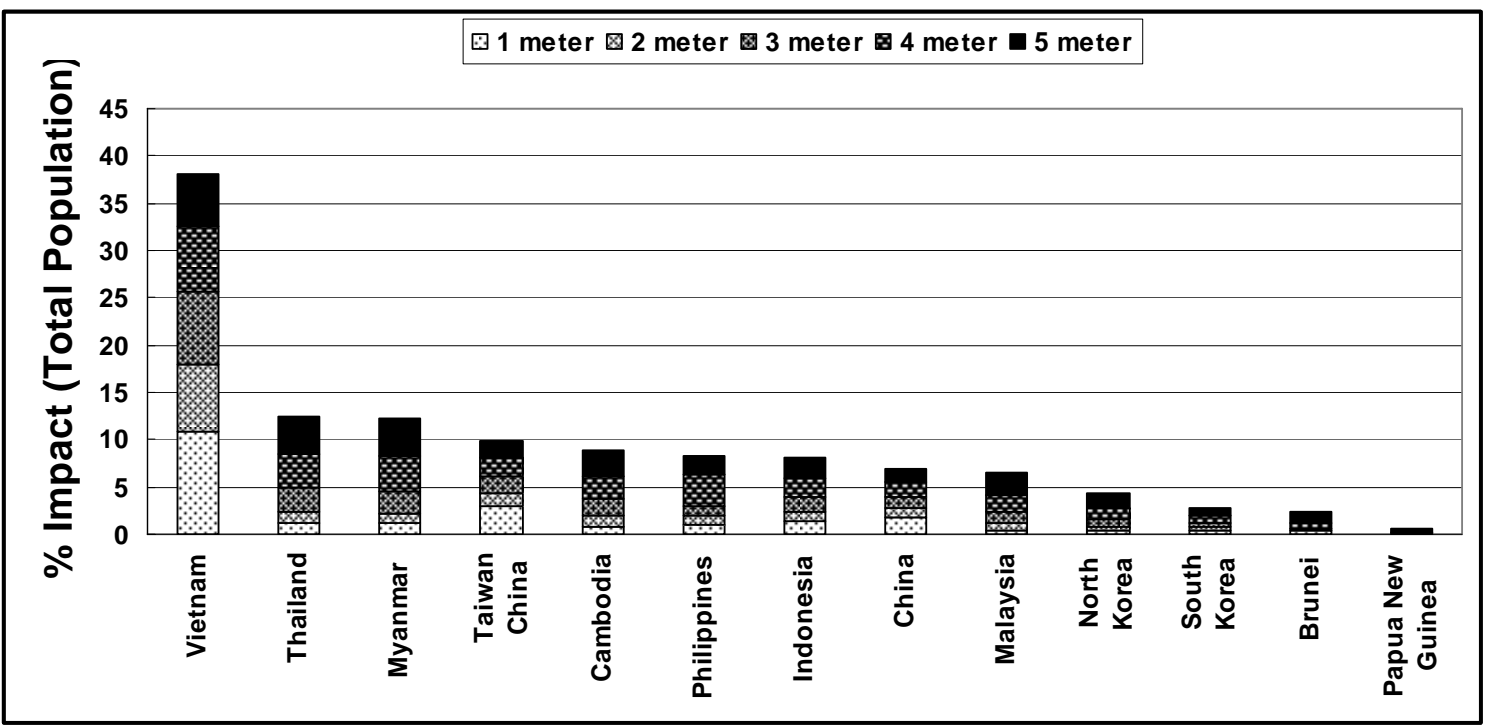


Thailand's GDP would also experience a significant impact. However, as shown in Figure $4 \mathrm{e}$, this impact would be significant only with a $4 \mathrm{~m}$ or $5 \mathrm{~m}$ SLR. Among the other indicators, Vietnam's agricultural extent would be the most severely impacted in East Asia (Figure 4g). Note that Myanmar's agricultural extent, as well as wetlands (Figure 4h) would also be significantly impacted. Most of Vietnam's wetlands would also be impacted by SLR.

Figure 4e

East Asia: GDP impacted

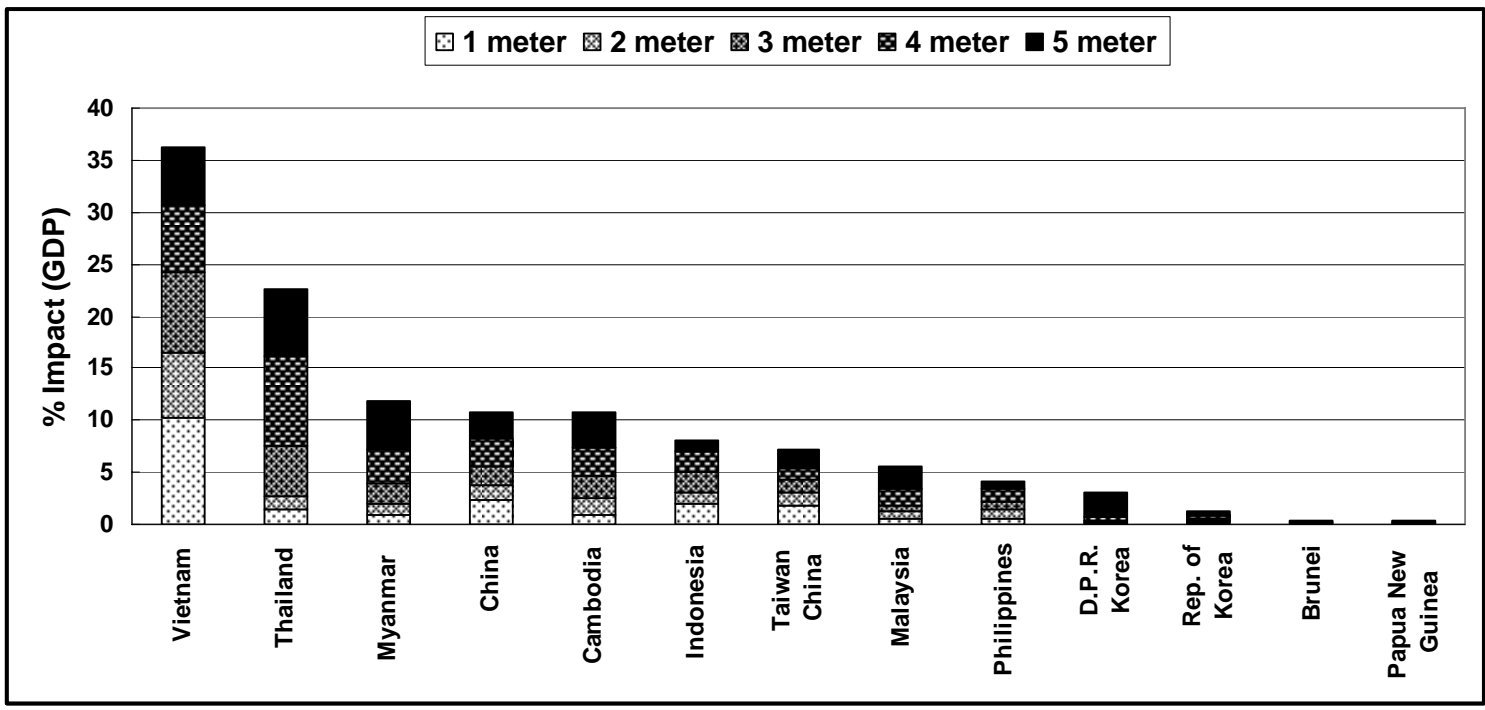

Figure 4f

East Asia: Urban extent impacted

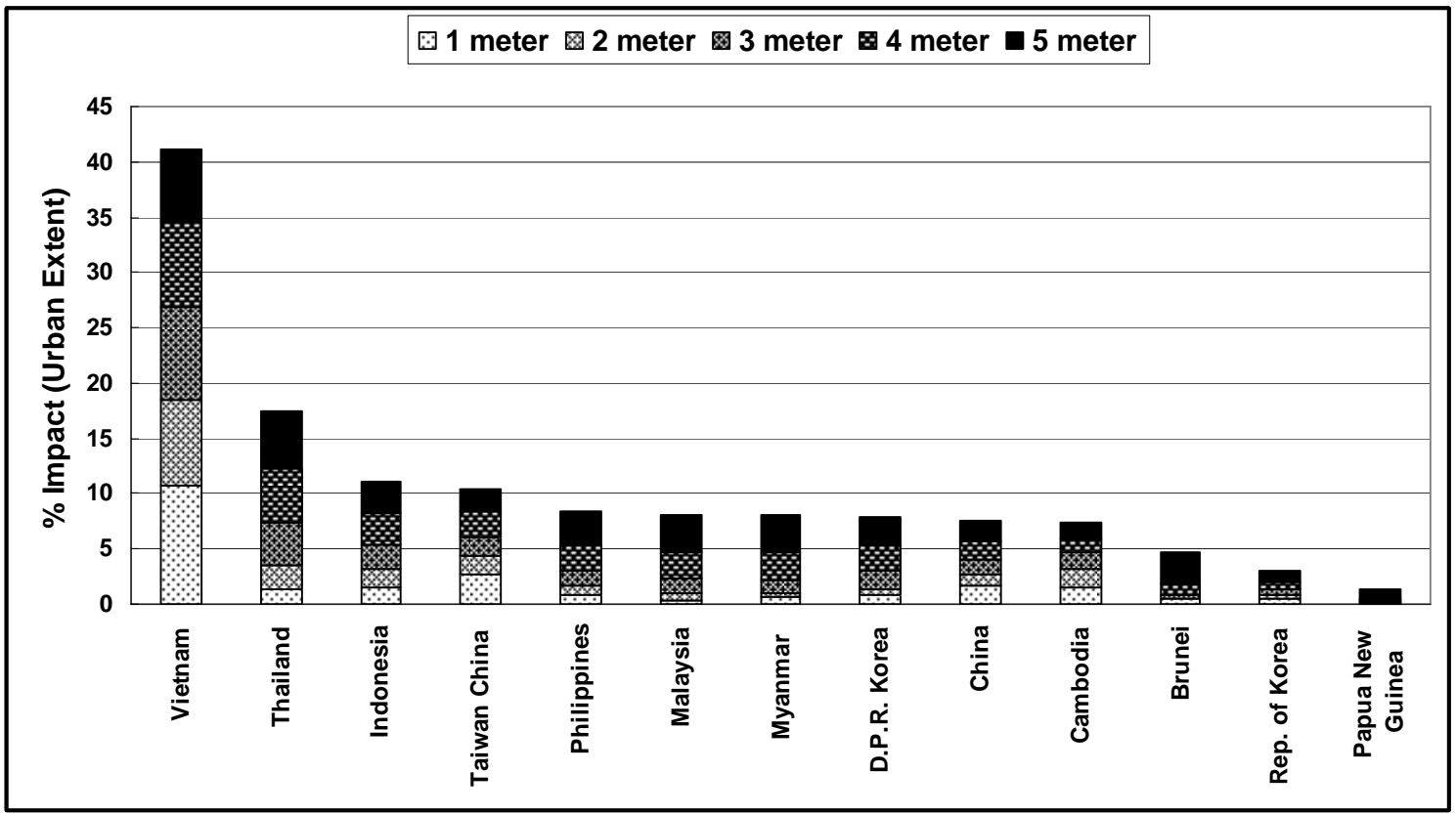


Figure 4g

East Asia: Agricultural extent impacted

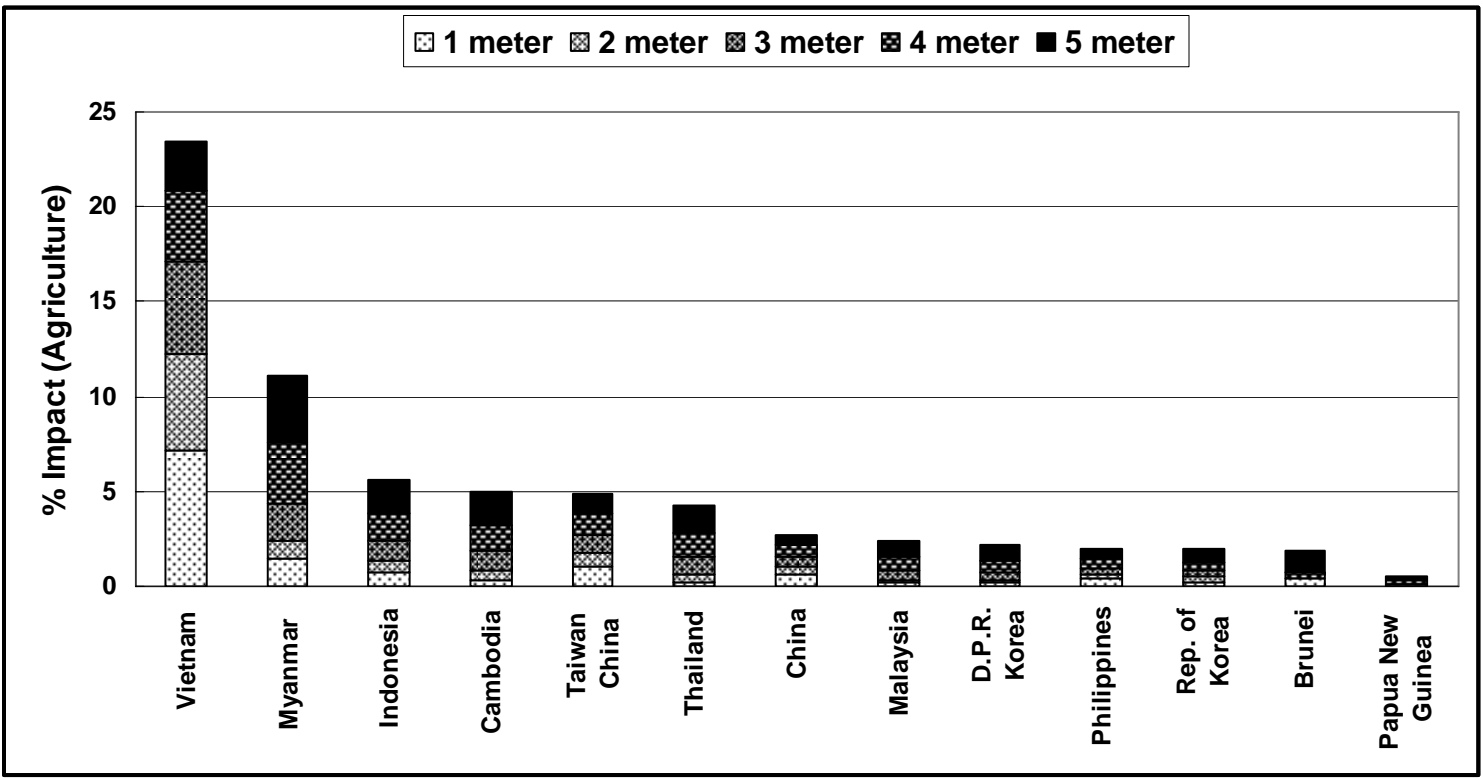

Figure 4h

East Asia: Wetlands impacted

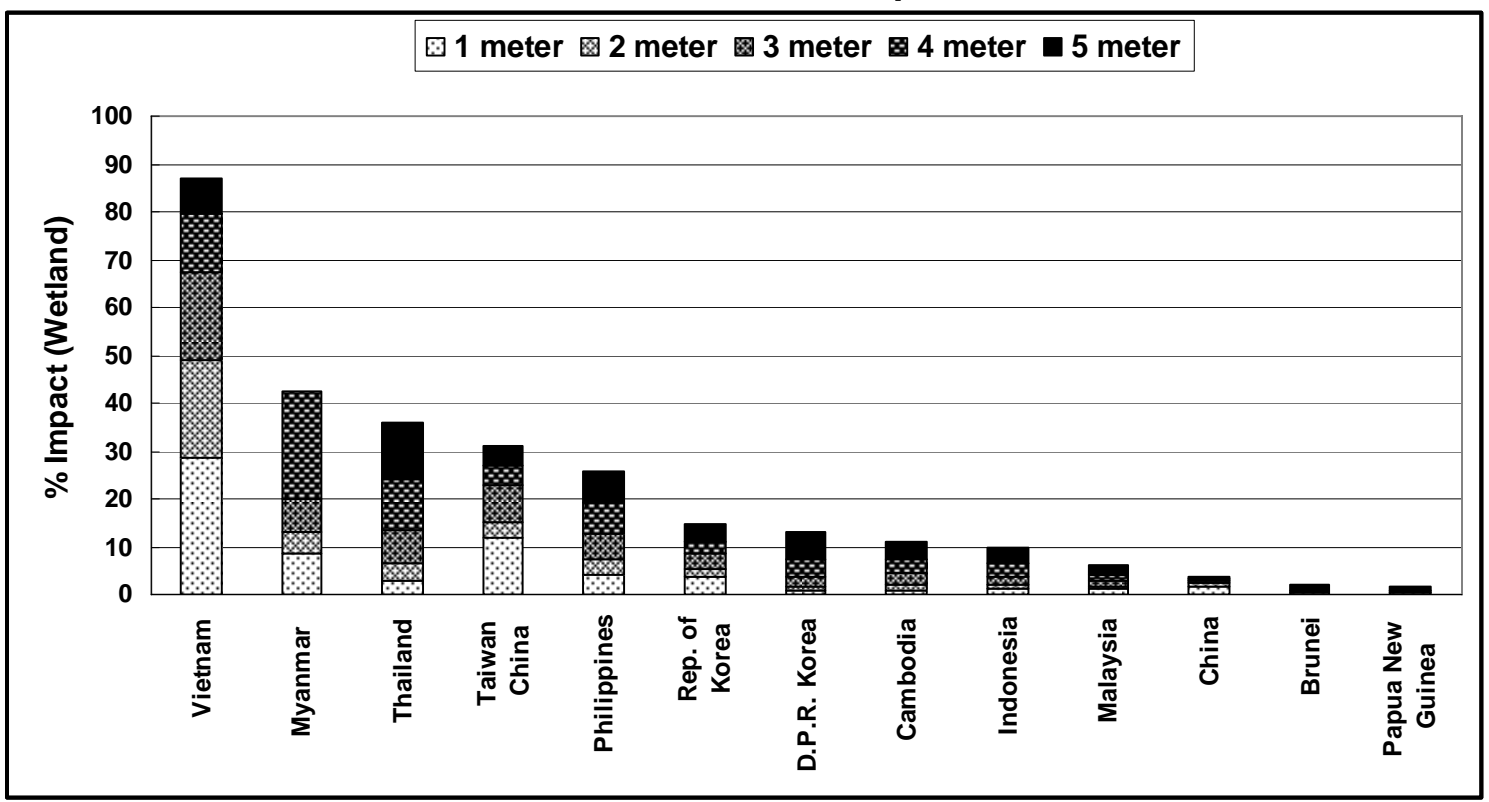


(v) South Asia

For a $1 \mathrm{~m}$ SLR, the impacts of SLR in South Asia resemble those noted in Sub-Saharan Africa, albeit slightly higher. Except for land area, the impacts of SLR in South Asia are smaller than worldwide impacts (Table 8).

Table 8

Impacts of sea level rise:

South Asia

\begin{tabular}{|c|c|c|c|c|c|}
\hline & $1 \mathrm{~m}$ & $2 m$ & $3 m$ & $4 m$ & $5 \mathrm{~m}$ \\
\hline \multicolumn{6}{|c|}{ Area (Total $=4,197,171$ sq. $\mathrm{km}$.) } \\
\hline Impacted area & 12,362 & 21,983 & 35,696 & 52,207 & 69,225 \\
\hline$\%$ of total area & 0.29 & 0.52 & 0.85 & 1.24 & 1.65 \\
\hline \multicolumn{6}{|c|}{ Population $($ Total $=1,306,556,000)$} \\
\hline Impacted population & $5,870,472$ & $10,187,694$ & $17,810,069$ & $22,065,103$ & $39,505,521$ \\
\hline$\%$ of total population & 0.45 & 0.78 & 1.36 & 1.69 & 3.02 \\
\hline \multicolumn{6}{|c|}{ GDP (Total = 3,295,567 million USD) } \\
\hline Impacted GDP (USD) & 18,021 & 30,957 & 52,036 & 72,462 & 94,020 \\
\hline$\%$ of total GDP & 0.55 & 0.94 & 1.58 & 2.20 & 2.85 \\
\hline \multicolumn{6}{|c|}{ Urban extent (Total = 241,779 sq. km.) } \\
\hline Impacted area & 809 & 1,379 & 2,311 & 3,599 & 5,117 \\
\hline$\%$ of total area & 0.33 & 0.57 & 0.96 & 1.49 & 2.12 \\
\hline \multicolumn{6}{|c|}{ Agricultural extent (Total $=3,023,617 \mathrm{sq} . \mathrm{km})}$. \\
\hline Impacted area & 3,442 & 6,951 & 13,501 & 23,716 & 35,190 \\
\hline$\%$ of total area & 0.11 & 0.23 & 0.45 & 0.78 & 1.16 \\
\hline \multicolumn{6}{|c|}{ Wetlands area (Total $=579,130 \mathrm{sq} . \mathrm{km})}$. \\
\hline Impacted area & 9,184 & 16,685 & 25,988 & 36,109 & 46,003 \\
\hline$\%$ of total area & 1.59 & 2.88 & 4.49 & 6.24 & 7.94 \\
\hline
\end{tabular}

Within South Asia, Bangladesh would experience the largest percentage share of land area impacted (Figure 5a). However, this impact exceeds $5 \%$ only when SLR is in excess of $3 \mathrm{~m}$. With a $1 \mathrm{~m}$ SLR, the populations of Bangladesh and Sri Lanka experience similar percentage impacts (Figures $5 b$ and $5 c$ ). However, as the sea level rises, the impact on Bangladesh's population becomes more important. A similar situation prevails for GDP (Figure 5d). 
Figure 5a

South Asia: Country area impacted

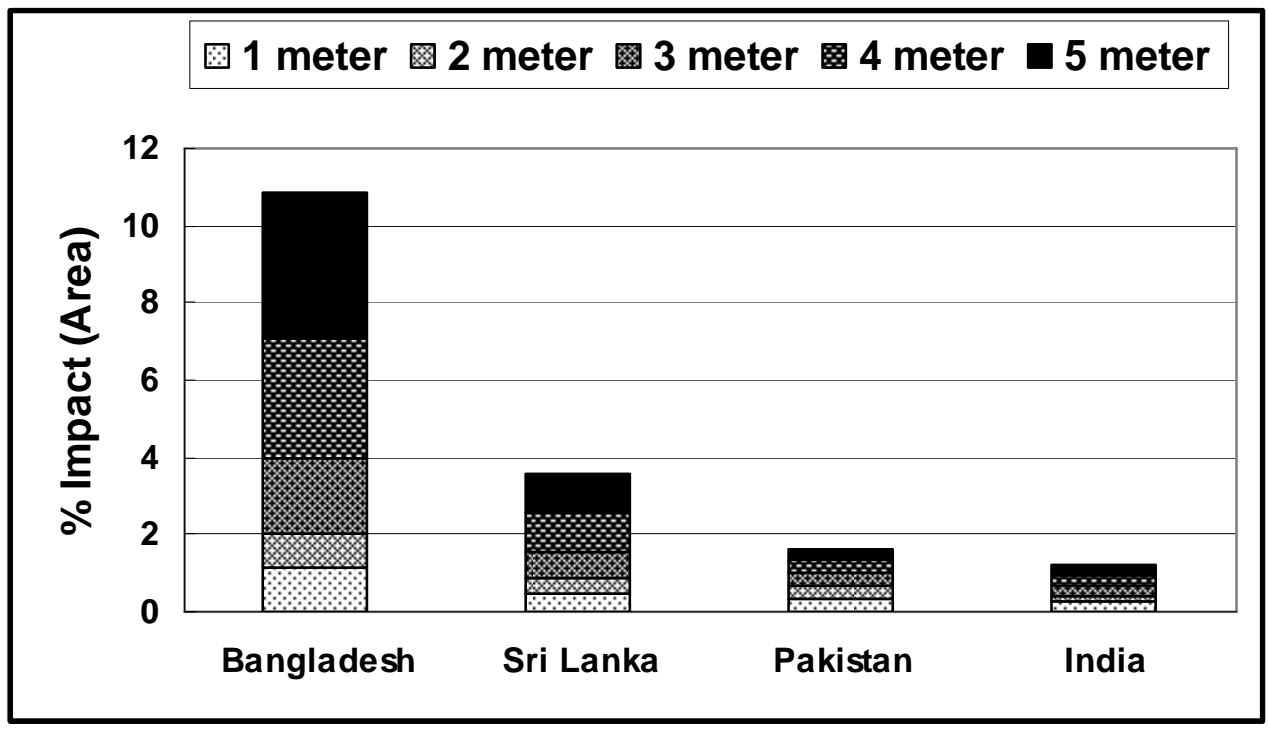

Sri Lanka's urban extent would experience a slightly larger impact than Bangladesh's (Figure 5e), while Bangladesh's agricultural extent would experience a much larger impact than any other South Asian country's (Figure 5f). Insofar as wetlands are concerned, Pakistan would experience the largest impact in South Asia (Figure 5g). 
Figure 5b

South Asia: Exposed population (5m SLR)

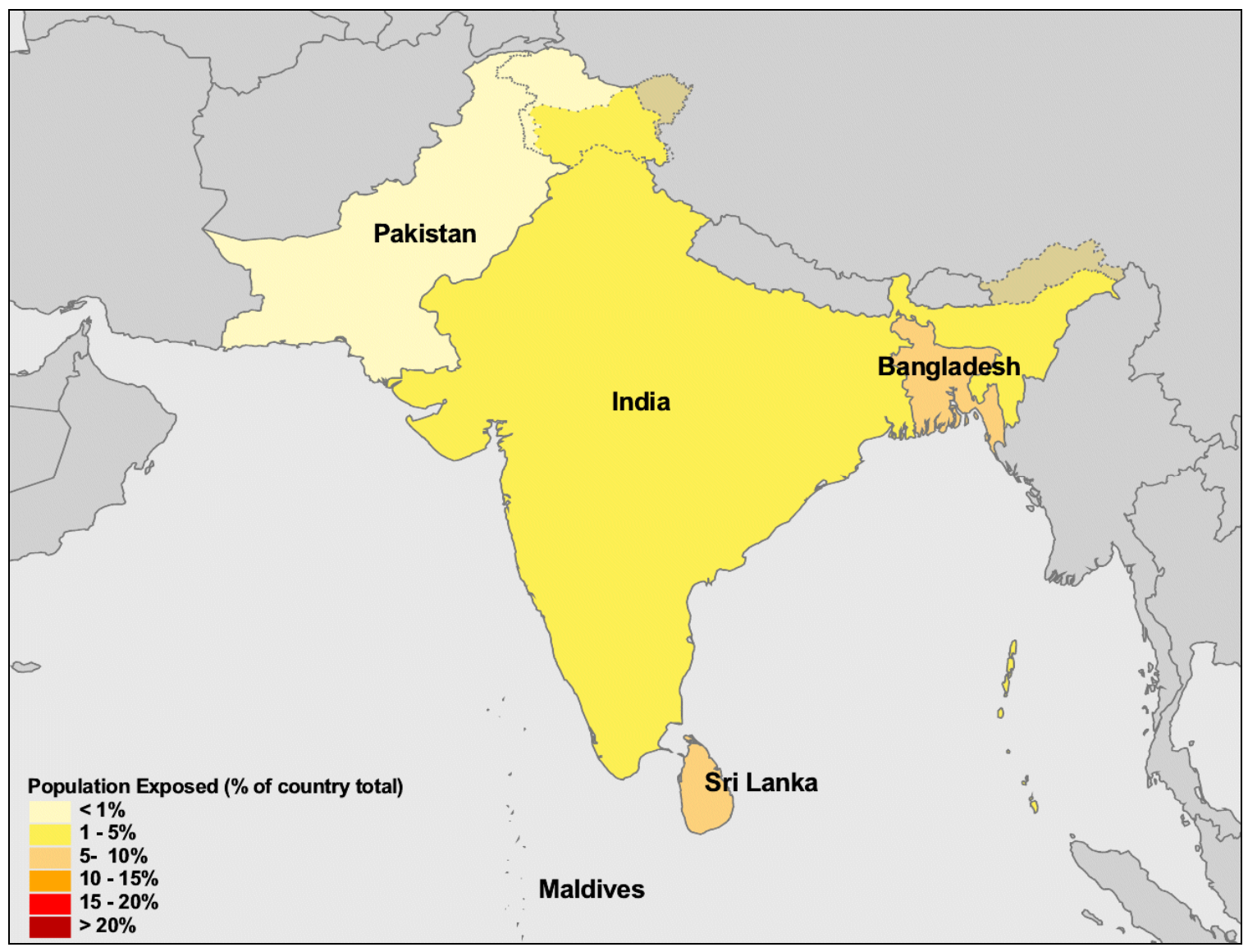


Figure 5c

South Asia: Population impacted

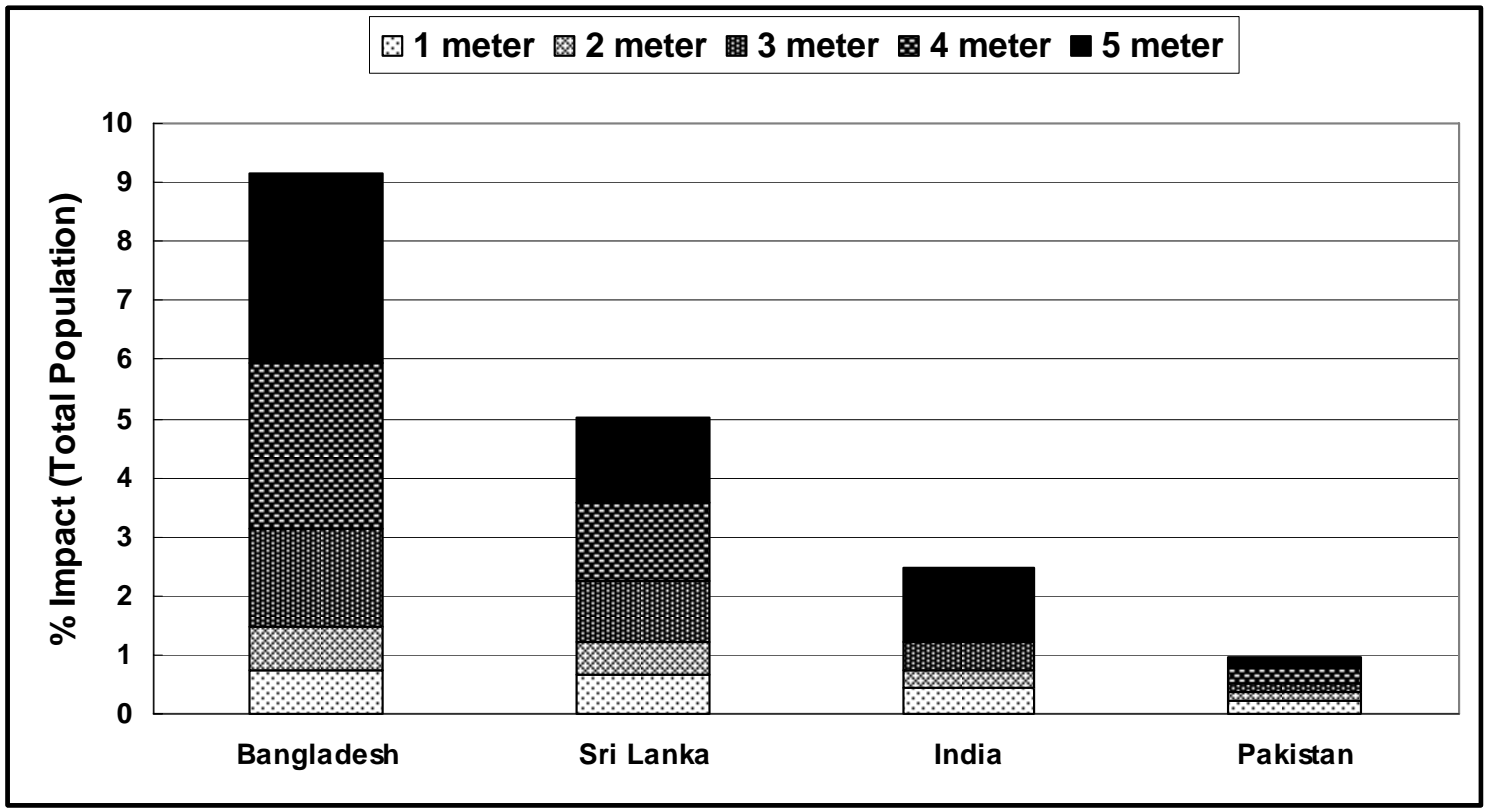

Figure 5d

South Asia: GDP impacted

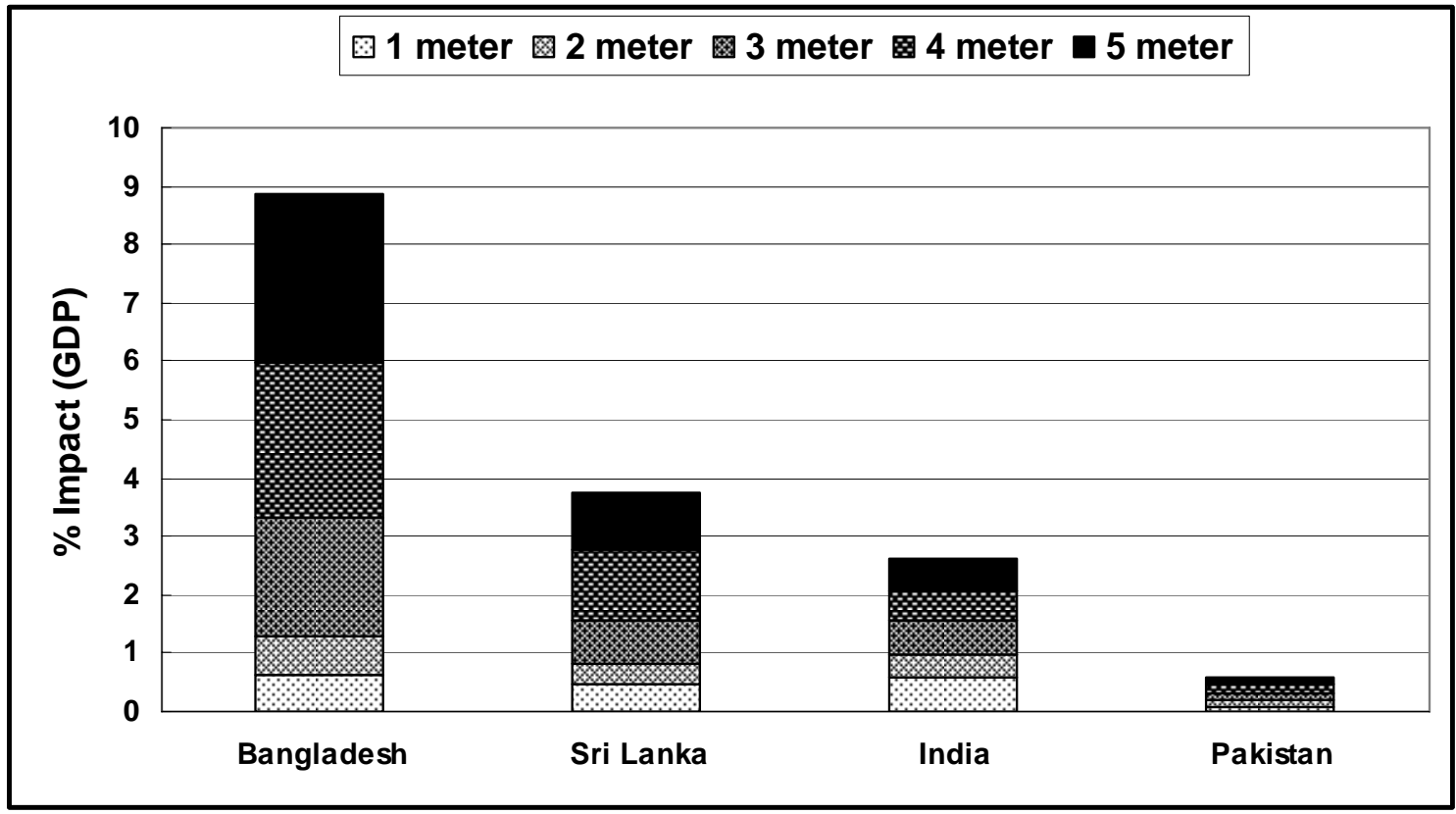


Figure 5e

South Asia: Urban extent impacted

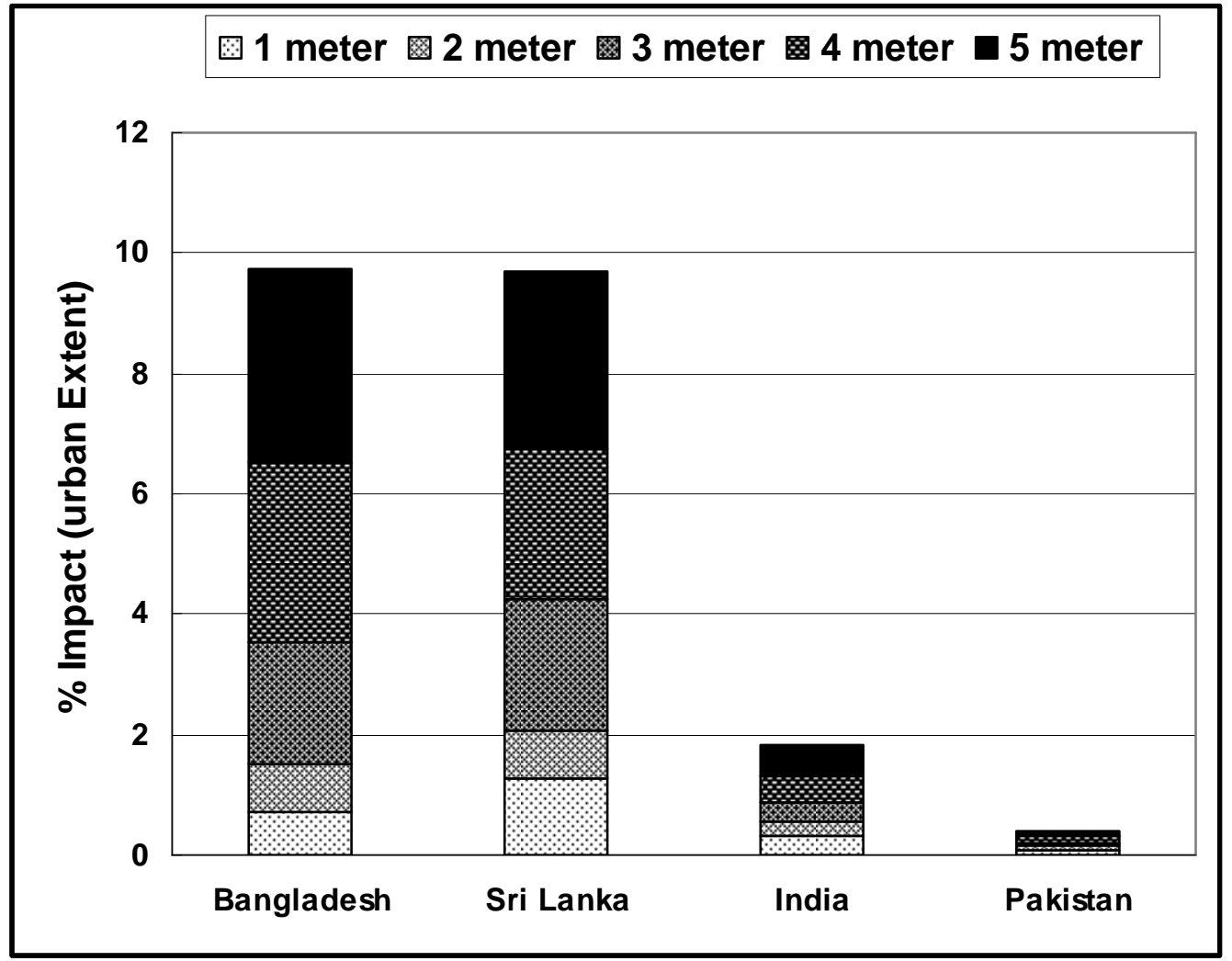

Figure $5 f$

South Asia: Agricultural extent impacted

\section{1 meter 图 2 meter 圈 3 meter 04 meter 5 meter}

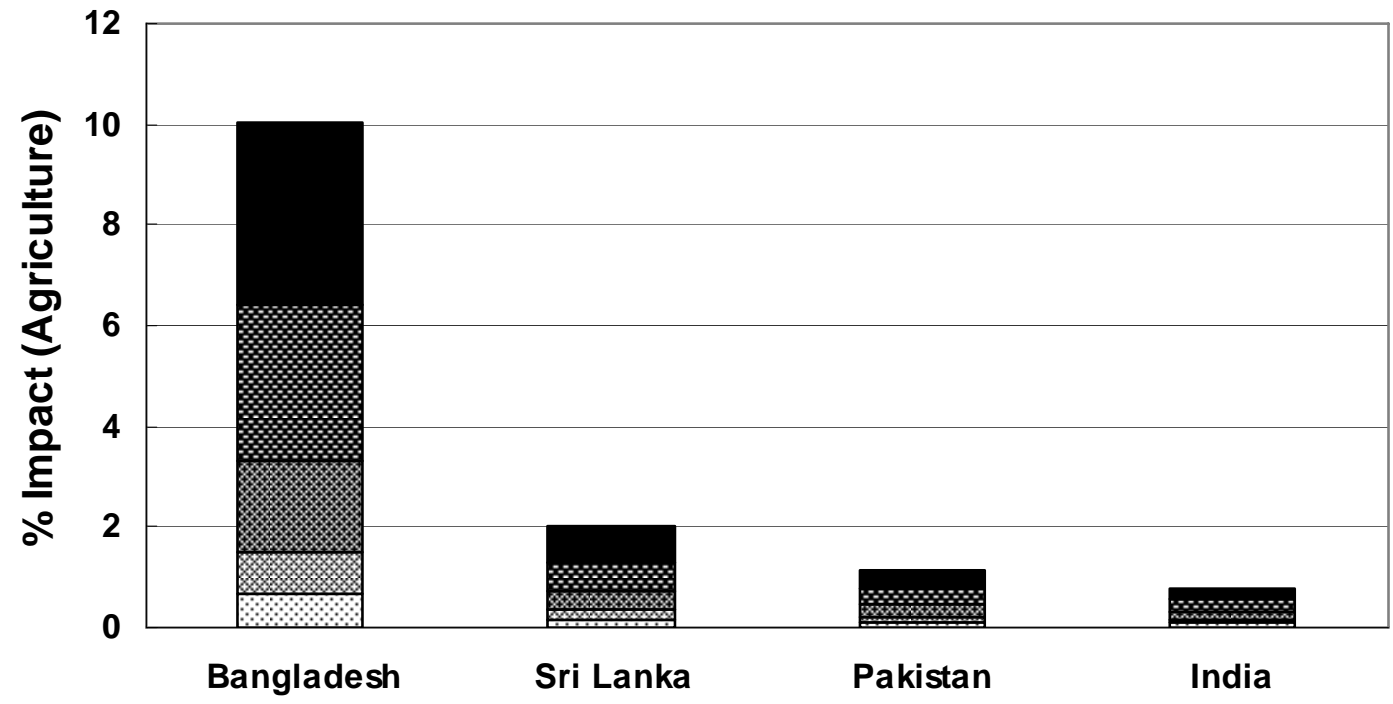


Figure 5g

South Asia: Wetlands impacted

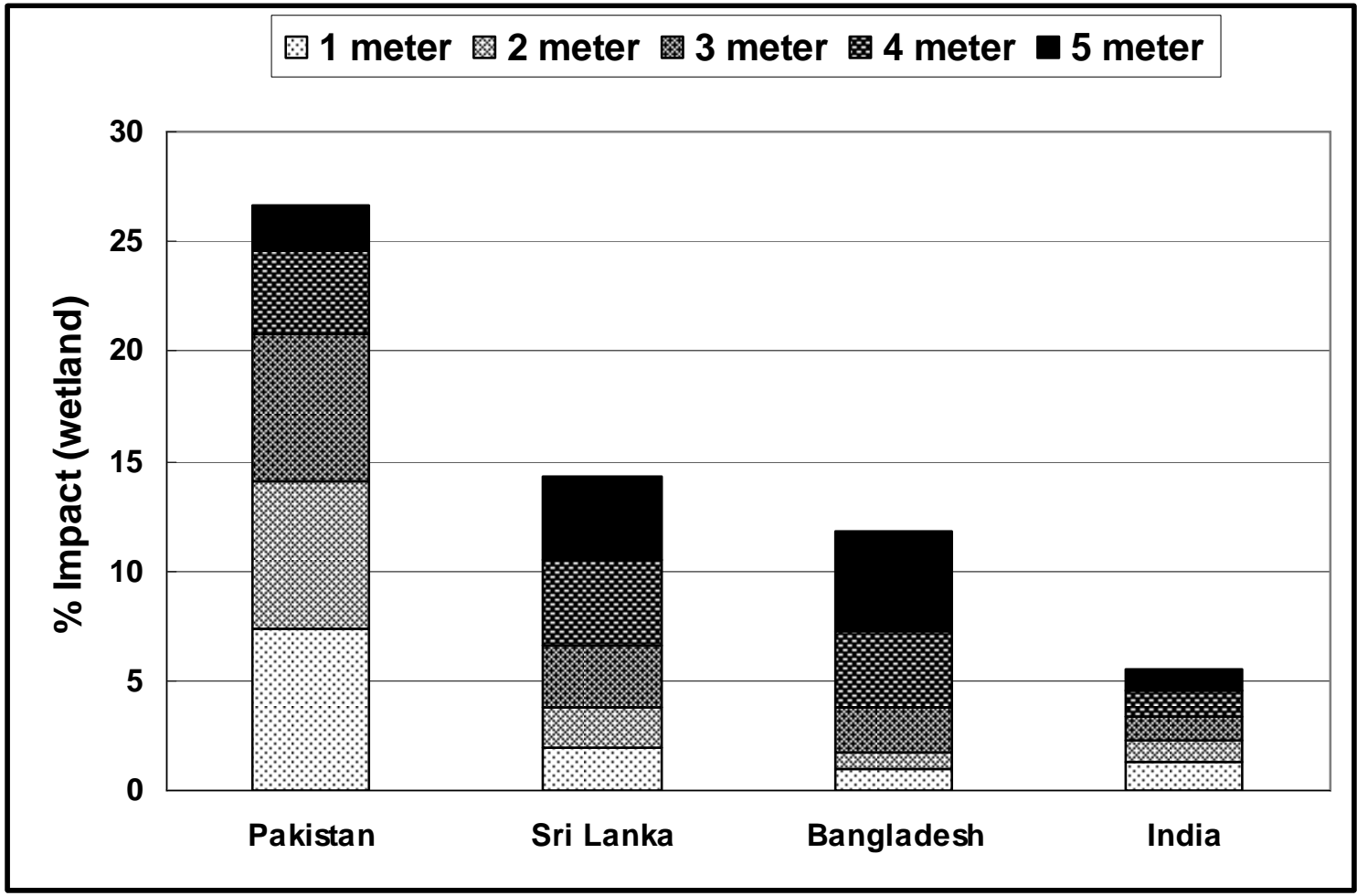

\section{III.3 Summary of results}

(i) World and regional results

As shown in Table 9, East Asia and the Middle East and North Africa would experience the largest percentage impacts from SLR. Population impact is larger in the latter for a $1 \mathrm{~m}$ SLR, but larger in East Asia for a $5 \mathrm{~m}$ SLR. Similar results hold for the impacts on urban extent, agricultural extent, and wetlands. Impact on GDP is much larger in East Asia than in any other region of the world, reaching $10.2 \%$ with a $5 \mathrm{~m}$ SLR. 
Table 9

Summary of world and regional impacts

\begin{tabular}{|l|r|r|r|r|r|r|}
\hline \multirow{3}{*}{ Indicators } & World & LA & MENA & SSA & EA & SA \\
\cline { 2 - 7 } Area & \multicolumn{7}{|c|}{ 1m SLR } \\
\cline { 2 - 7 } Population & 0.31 & 0.34 & 0.25 & 0.12 & 0.52 & 0.29 \\
GDP & 1.28 & 0.57 & 3.20 & 0.45 & 1.97 & 0.45 \\
Urban extent & 1.30 & 0.54 & 1.49 & 0.23 & 2.09 & 0.55 \\
Ag. extent & 1.02 & 0.61 & 1.94 & 0.39 & 1.71 & 0.33 \\
Wetlands & 0.39 & 0.33 & 1.15 & 0.04 & 0.83 & 0.11 \\
& 1.86 & 1.35 & 3.32 & 1.11 & 2.67 & 1.59 \\
\cline { 2 - 8 } Area & \multicolumn{7}{|c|}{ 5m SLR } \\
Population & 1.21 & 1.24 & 0.63 & 0.48 & 2.30 & 1.65 \\
GDP & 5.57 & 2.69 & 7.49 & 2.38 & 8.63 & 3.02 \\
Urban extent & 6.05 & 2.38 & 3.91 & 1.42 & 10.2 & 2.85 \\
Ag. extent & 4.68 & 3.03 & 4.94 & 2.24 & 8.99 & 2.72 \\
Wetlands & 2.10 & 1.76 & 3.23 & 0.38 & 4.19 & 1.16 \\
\hline
\end{tabular}

LA: Latin America and Caribbean; MENA: Middle East and North Africa; SSA: Sub-Saharan Africa; EA: East Asia; SA: South Asia.

\section{(ii) Most impacted countries}

Figures $6 a$ to $6 f$ summarize our results for each indicator by presenting the top 10 impacted countries (as a percentage of their national values). For this purpose, we use the $1 \mathrm{~m}$ SLR scenario. For land area (Figure 6a), The Bahamas is by far the most impacted country, with close to $12 \%$ of its area affected. Around $10 \%$ of Vietnam's and the A.R. of Egypt's populations would be impacted with a $1 \mathrm{~m}$ SLR (Figure 6b). Vietnam would also see 10\% of its GDP (Figure 6c) and urban extent (Figure 6d) impacted. Mauritania's GDP would be significantly impacted. The A.R. of Egypt's agricultural extent would experience the largest percentage impact, reaching approximately $13 \%$. Finally, nearly $28 \%$ of Vietnam, Jamaica and Belize's wetlands would be impacted by a $1 \mathrm{~m}$ SLR. Among all of the indicators used in this paper, Vietnam ranks among the top 5 most impacted countries, with the A.R. of Egypt, Suriname and The Bahamas consistently ranking among the highest. 
Figure 6a

Most impacted countries: Land area

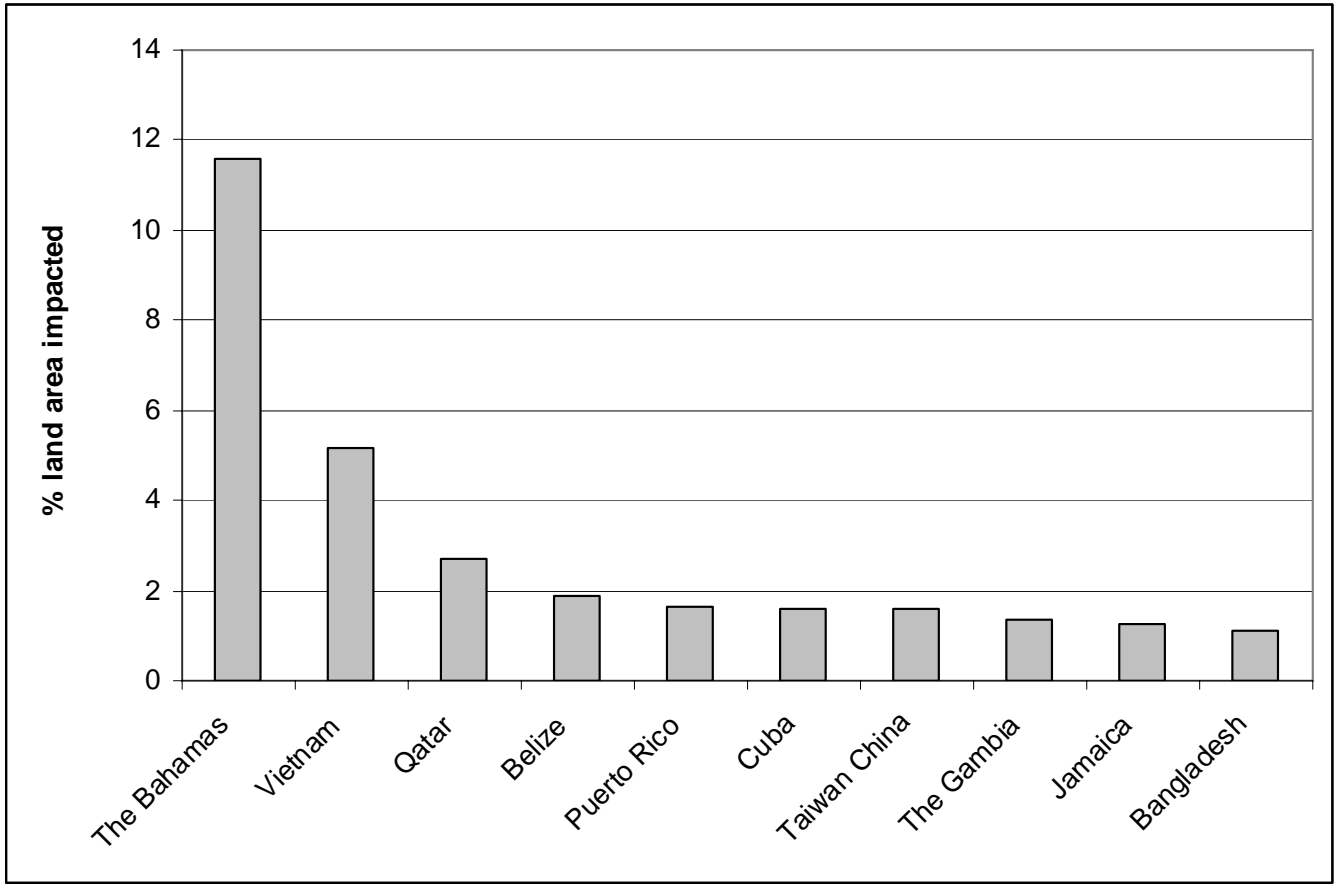

Figure 6b

Most impacted countries: Population

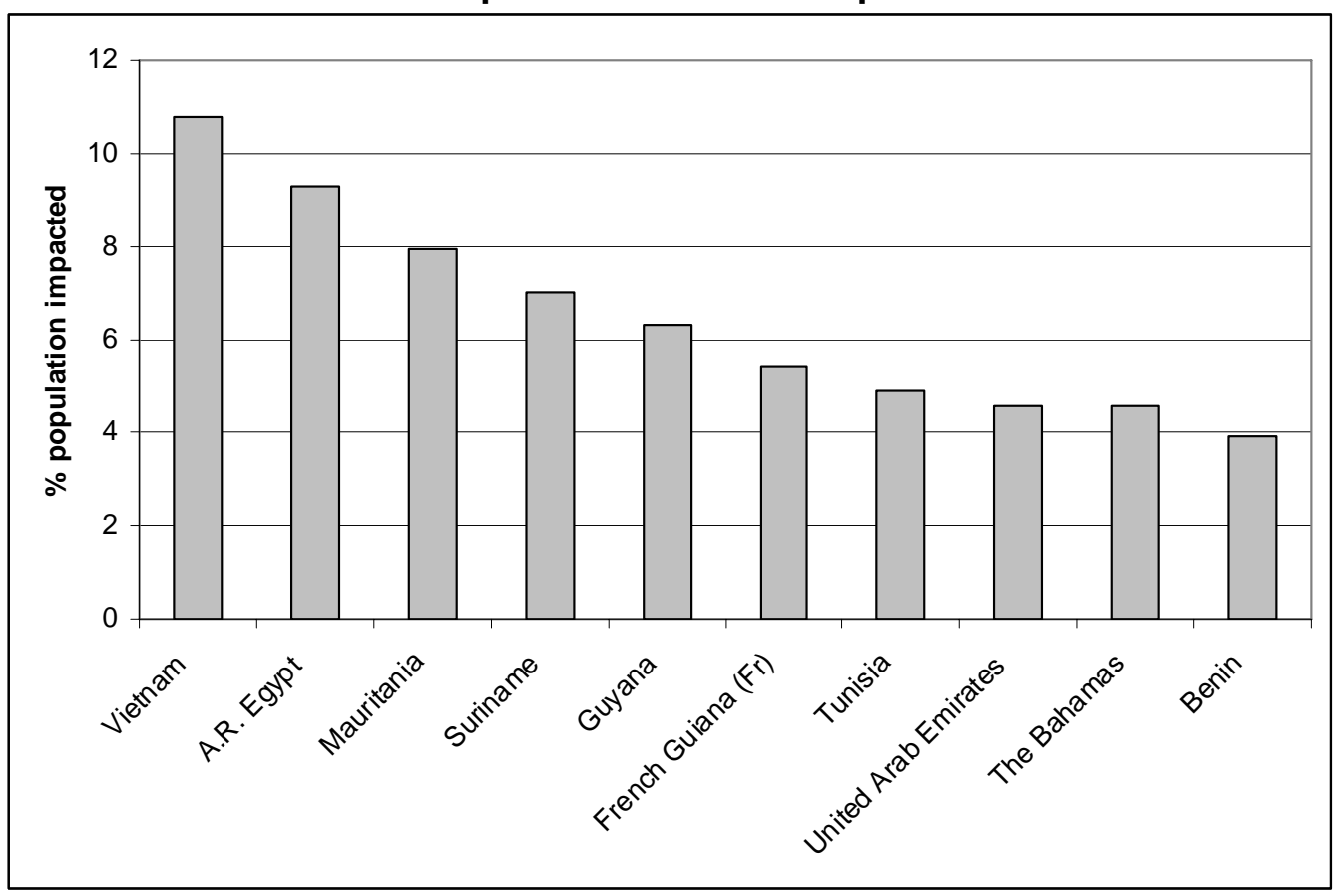


Figure 6c

Most impacted countries: GDP

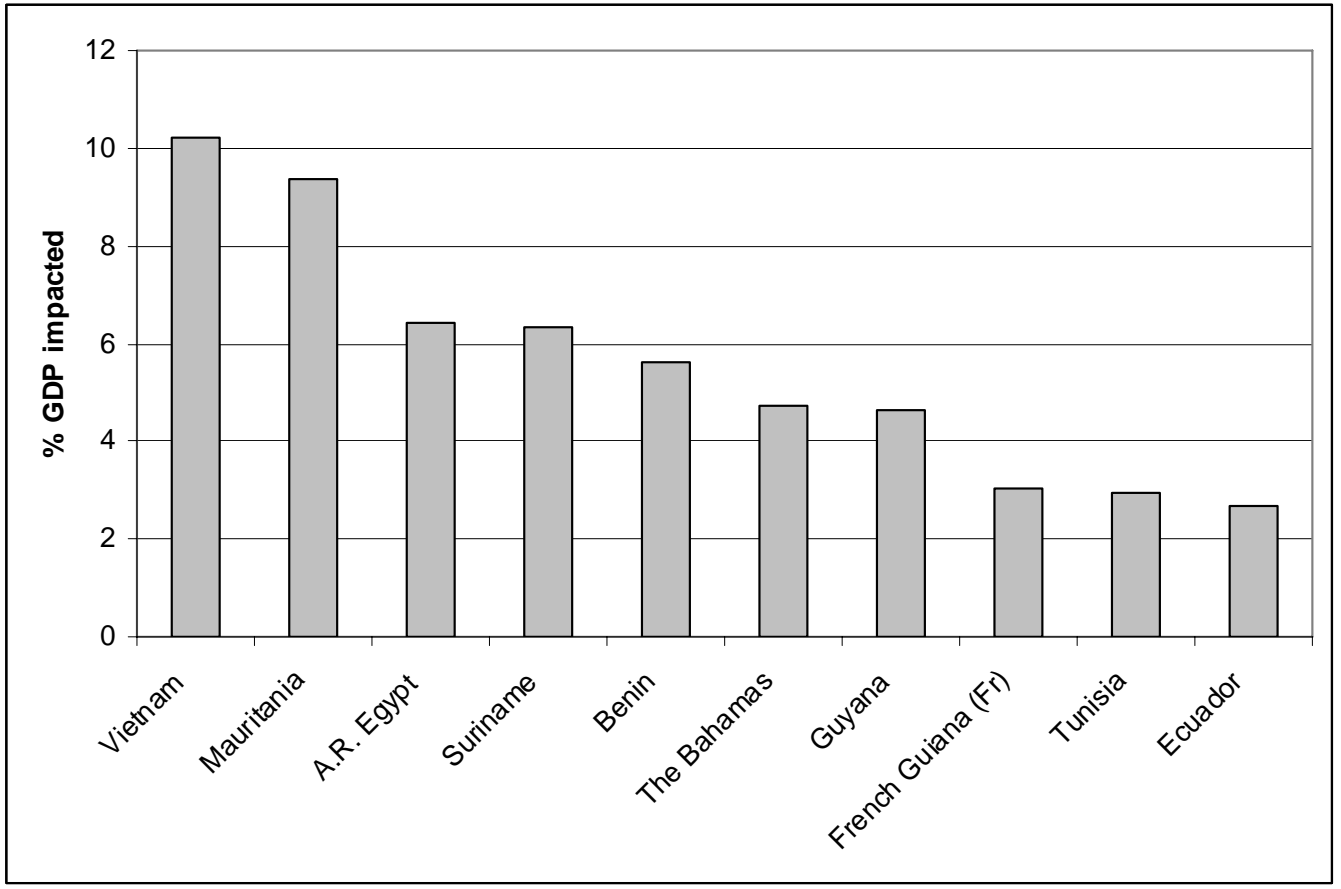

Figure 6d

Most impacted countries: Urban extent

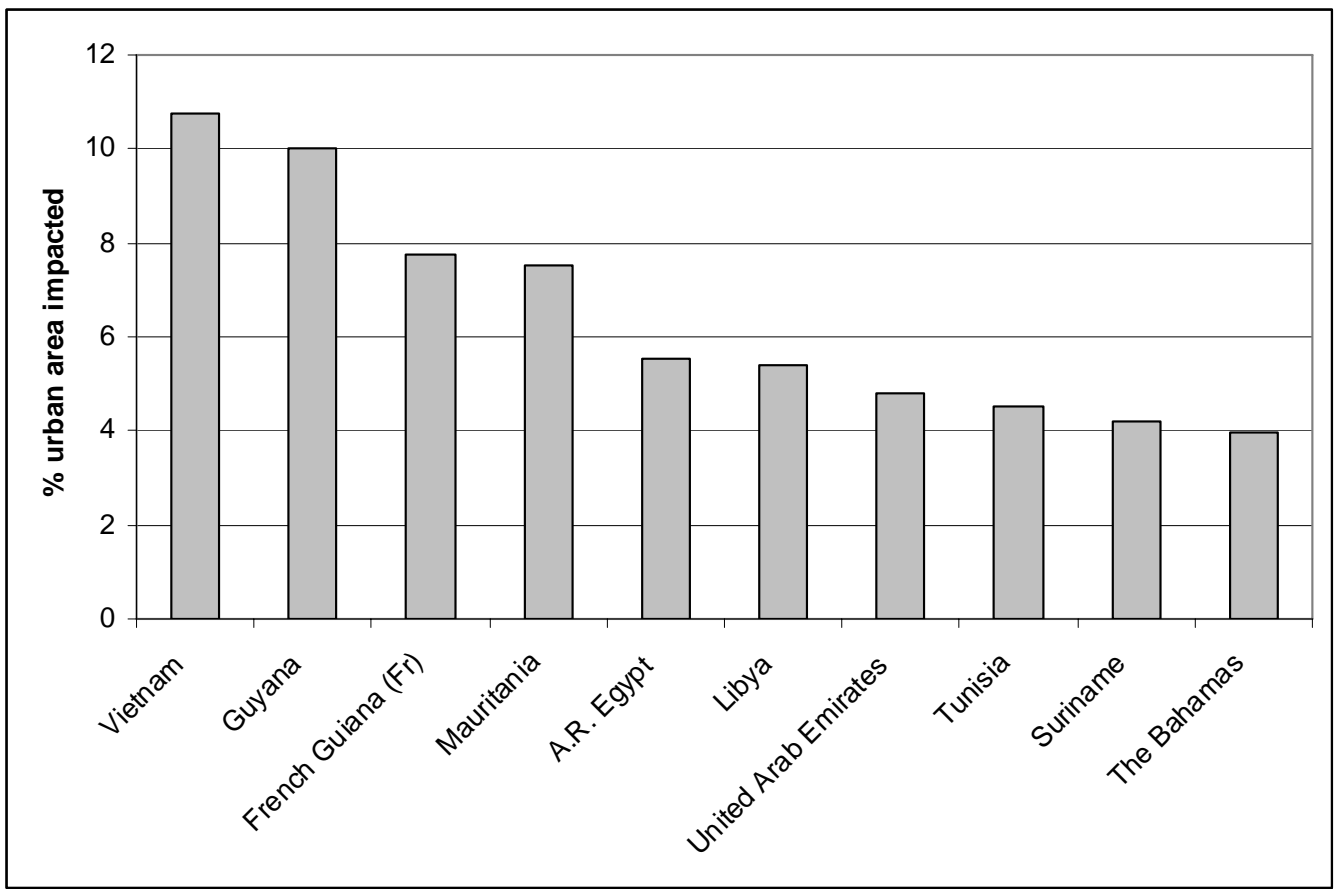


Figure 6e

Most impacted countries: Agriculture extent

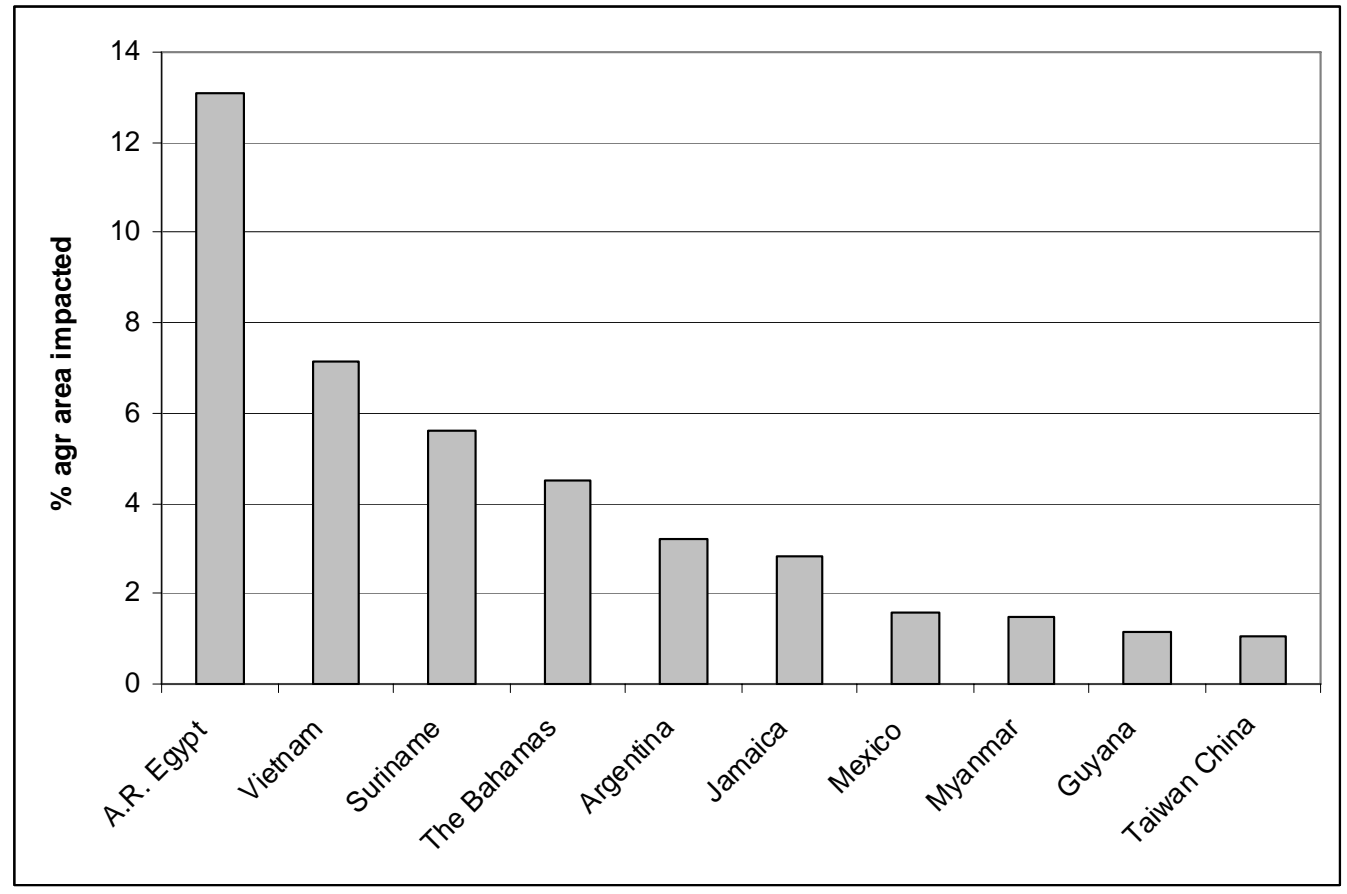

Figure 6f

Most impacted countries: Wetlands

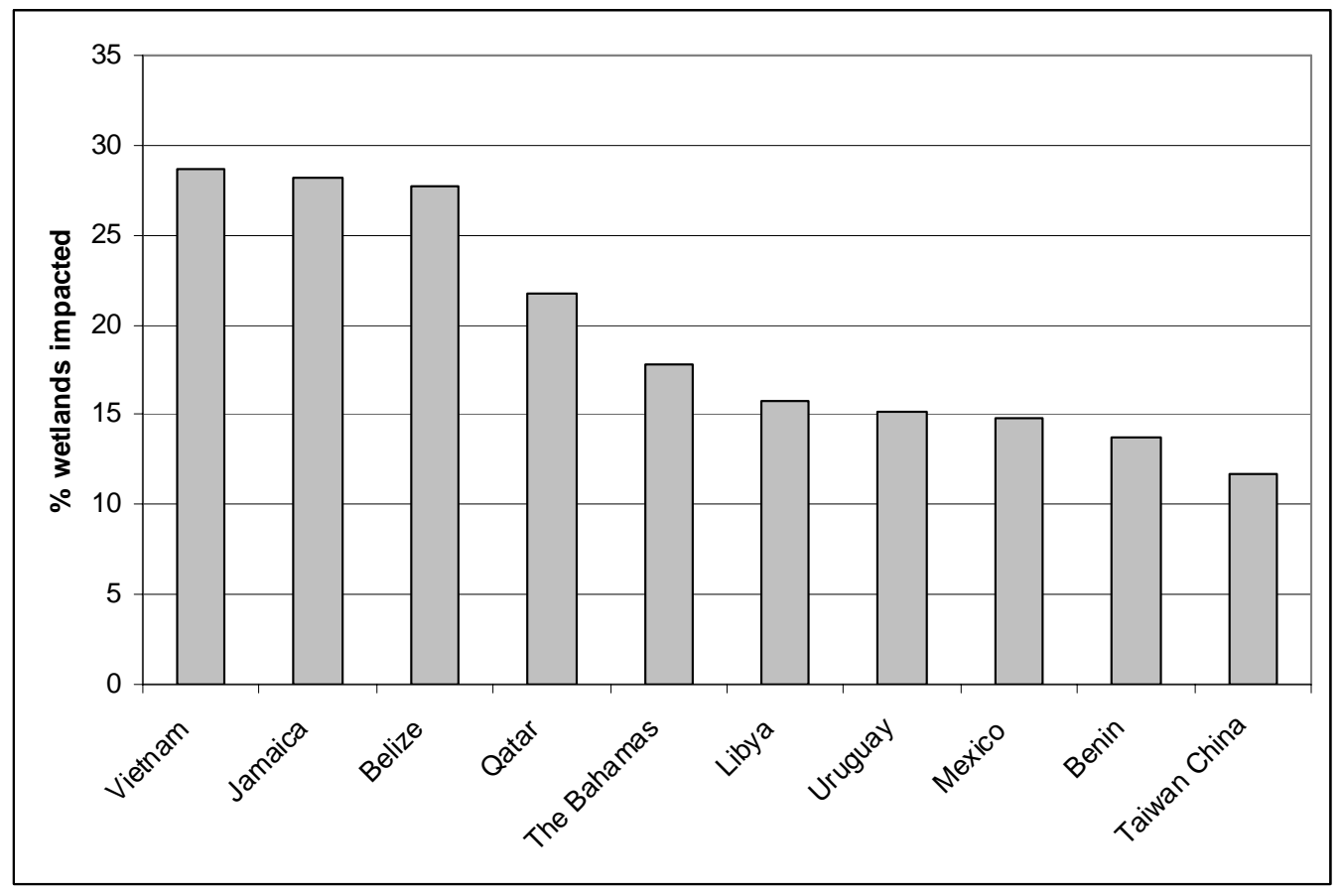




\section{Conclusions}

Even if greenhouse gas (GHG) emissions were stabilized in the near future, thermal expansion and deglaciation would continue to raise the sea level for many decades. Continued growth of GHG emissions and associated global warming could well promote SLR of $1 \mathrm{~m}-3 \mathrm{~m}$ in this century, and unexpectedly rapid breakup of the Greenland and West Antarctic ice sheets might produce a 5m SLR. In this paper, we have assessed the consequences of continued SLR for 84 developing countries. Our results are extremely skewed, with severe impacts limited to a relatively small number of countries. For these countries (e.g., Vietnam, A.R. of Egypt, The Bahamas), however, the consequences of SLR are potentially catastrophic. For many others, including some of the largest (e.g., China), the absolute magnitudes of potential impacts are very large. At the other extreme, many developing countries experience limited impacts. Among regions, East Asia and Middle East/North Africa exhibit the greatest relative impacts.

In this conclusion, we would like to highlight two important implications of our findings. First, the overall magnitudes for the developing world are sobering: Within this century, hundreds of millions of people are likely to be displaced by SLR; accompanying economic and ecological damage will be severe for many. The world has not previously faced a crisis on this scale, and planning for adaptation should begin immediately. Second, international resource allocation strategies should recognize the skewed impact distribution that we have documented in this paper. Some countries will be little-affected by SLR, while others will be so heavily impacted that their national integrity may be threatened. Given the scarcity of available resources, it would seem sensible to allocate aid according to degree of threat.

Under the provisions of the United Nations Framework Convention on Climate Change (UNFCCC), some work has begun on National Adaptation Programmes of Action (NAPAs). These are intended to facilitate the identification of priority activities, including adaptation to SLR, for the least-developed countries. To date however, only 8 countries have developed comprehensive NAPAs: Bangladesh, Bhutan, Comoros, Djibouti, Malawi, Mauritania, Niger and Samoa. Of these, five are coastal states with potential SLR problems. For comparison, our summary above reveals 10 poor countries that will be very severely impacted by SLR. With the exceptions of Bangladesh and Mauritania, 
none are included in the NAPA list above: Benin, Guyana, Suriname, A.R. of Egypt, The Gambia, Guinea-Bissau, Mauritania, Vietnam, Bangladesh and Sri Lanka. Many other developing countries will also experience significant impacts.

We should reiterate that these results are not speculative: The current atmospheric concentration of GHG's is sufficient to drive global warming well into the next century, and much higher concentrations will undoubtedly be reached before any global agreement can be implemented. For precautionary planning purposes, SLR in the range of $1 \mathrm{~m}-3 \mathrm{~m}$ should therefore be regarded as realistic. To date, however, there is little evidence that the international community has seriously considered the implications for population location and infrastructure planning in many developing countries. We hope that the information provided in this paper will encourage more rapid action on this front. 


\section{References}

Adam, K.S., 1995: Vulnerability assessment and coastal management program in the Benin coastal zone. In: Beukenkamp, p. (ed.) Proceedings of WCC93. CZM Management Publication No.4. National Institute for Coastal and Marine Management, The Hague, p. 489-501.

Baarse, G., Peerbolte, E.B., and I. Bijlsma, 1994: Assessment of the vulnerability of the Netherlands to sea-level rise. In: O'Callahan J. (ed), Global Climate Change and the Rising Challenge of the Sea, Proceedings of the $3^{\text {rd }}$ IPCC CZMS Workshop, Margarita Island, March 1992. NOAA, Silver Spring, MD, p. 211-236.

Bijlsma, L, Ehler, C.N. Klein, R.J.T., Julshrestha S.M. McLean, R.F., Mimura, N., Nicholls, R.J., Nurse, L.A., Perez, N.H., Stakhiv, E.Z., Turner, R.K., and R.A. Warrick, 1996: Coastal zones and small islands, In: Watson, R.T., Zinyowera, M.C., Moss, R.H. (eds), Impacts, Adaptations, and Mitigation of Climate Change: Scientifictechnical Analyses, Cambridge University Press, Cambridge, p. 289-324.

Church, J.A., Gregory, J.M., Huybrechts, P., Kuhn, M., Lambeck, K., Nhuan, M.T., Qin, D., Woodworth, P.L., 2001: Changes in sea level. In: Houghton, J.T., Ding, Y., Griggs, D.J., Noguer, M., van der Linden, P.J., Xiaosu, D. (eds.) Climate Change 2001. The Scientific Basis. Cambridge University Press, Cambridge, pp. 639-693.

Darwin, R.F. and R.S.J. Tol, 1999: Estimates of the economic effects of sea level rise, mimeo.

Dennis, K., Niang-Diop, I., and Nicholls, R.J., 1995: Sea-level rise and Senegal: Potential impacts and consequences, Journal of Coastal Research, 14, 242-261.

French, G.T., Awosika, L.F., and C.E. Ibe, 1995: Sea-level rise in Nigeria: Potential impacts and consequences. Journal of Coastal Research, 14, 224-242.

Han, M., Hou, J., and I. Wu, 1995: Potential impacts of sea-level rise on China's coastal environment and cities: A national assessment, Journal of Coastal Research, 14, 7995.

Hanna, E.,, P. Huybrechts, I. Janssens, J. Cappelen, K. Steffen \& A. Stephens, 2005: Runoff and mass balance of the Greenland Ice Sheet: 1958-2003, Journal of Geophysical Research, 110, D13108, doi: 10.1029/2004JD005641.

Hoozemans F.M.J., Marchand, M., and H.A. Pennekamp, 1993: A global vulnerability analysis, vulnerability assessments for population, coastal wetlands, and rice production on a global scale, $2^{\text {nd }}$ ed. Delft Hydraulics and Rijkswaterstaat, Delft.

IPCC, 2001a: Climate Change 2001: The Scientific Basis - Contribution of Working Group I to the IPCC Third Assessment Report 2001.

IPCC, 2001b: Synthesis Report 2001- Contribution of Working Groups I, II, and III to the Third Assessment Report of the Intergovernmental Panel on Climate Change, R.T. Watson (ed.) and the Core Writing Team. Cambridge: Cambridge University Press, $397 \mathrm{pp}$. 
Krabill, W., E. Hanna, P. Huybrechts, W. Abdalati, J. Cappelen, B. Csatho, E. Frederick, S. Manizade, C. Martin, J. Sonntag, R. Swift, R. Thomas, and J. Yunge, 2004: Greenland Ice Sheet: increased coastal thinning. Geophysical Research Letters, 31: L24402, doi:10.1029/2004GL021533.

Lehner, B. and Döll, P., 2004: Development and validation of a global database of lakes, reservoirs and wetlands. Journal of Hydrology, 296/1-4, p.1-22.

Lowe, J.A., Gregory, J.M., Ridley, J., Huybrechts, P., Nicholls, R.J, and M. Collins, 2006: The role of sea-level rise and the Greenland ice sheet in dangerous climate change: Implications for the stabilization of climate, in H.J. Schellnhuber, W. Cramer, N. Nakicenovic, T. Wigley, and G. Yohe (eds), Avoiding Dangerous Climate Change, Cambridge University Press, U.K.

Mendelsohn, R. and J. Neumann (eds), 1999: The Impact of Climate Change on the United States Economy, Cambridge: Cambridge University Press.

Mendelsohn, R., Dinar, A. and L. Williams, 2006: The distributional impact of climate change on rich and poor countries, Environment and Development Economics, 11, 2, 159-178.

Mercer, J.H., 1978: West Antarctic ice sheet and CO2 greenhouse effect: A threat of disaster, Nature, 271, 321-325.

Ng, W.S. and R. Mendelsohn, 2005: The impact of sea level rise on Singapore, Environment and Development Economics, 10, 2, 201-215.

Nicholls, R.J., 1995: Synthesis of vulnerability analysis studies. Proceedings of WORLD COAST 1993, Ministry of Transport, Public Works and Water Management, the Netherlands. pp.181-216. (downloadable at www.survas.mdx.ac.uk)

Nicholls, R.J. and Mimura, N., 1998: Regional issues raised by sea-level rise and their policy implications. Climate Research, 11, 5-18.

Nicholls, R.J., Tol, R.S.J., and N. Vafeidis, 2004: Global estimates of the impact of a collapse of the West Antarctic ice sheet, mimeo.

Nicholls, R.J. and J.A. Lowe, 2006: Climate stabilization and impacts of sea-level rise. In In H.J. Schellnhuber, W. Cramer, N. Nakicenovic, T. Wigley, and G. Yohe (eds), Avoiding Dangerous Climate Change, Cambridge University Press, U.K.

Nicholls, R.J., and Tol, R.S.J., 2006: Impacts and responses to sea-level rise: a global analysis of the SRES scenarios over the twenty-first century. Philosophical Transactions of the Royal Society, A, 364 (1841): 1073-1095.

Olsthoorn, X., van der Werff, P., Bouwer, L, and D. Huitema, 2002: Neo-Atlantis: Ducth Responses to Five Meter Sea Level Rise, mimeo.

Rapley, C, 2006: The Antarctic ice sheet and sea level rise. In H.J. Schellnhuber, W. Cramer, N. Nakicenovic, T. Wigley, and G. Yohe (eds), Avoiding Dangerous Climate Change, Cambridge University Press, U.K. 
Rignot, E. and Kanagaratnam, P., 2006: Changes in the velocity structure of the Greenland Ice Sheet. Science, 311: 986?990.

Sachs, J.D., Mellinger, A.D., and Gallup, J.L., 2001: The geography of poverty and wealth. Scientific American, 284(3), p.70-75.

Tol, R.S.J., Bohn, M., Downing, T.E., Guillerminet, M-L., Hiznyik, E., Kasperson, R., Lonsdale, K., Mays, C., Nicholls, R.J., Olsthoorn, A.A., Pfeifle, G., Poumadere, M., Toth, F.L. Vafeidis, N., wan der Werff, P.E., and I.H. Yetkiner, 2005: Adaptation to Five Meters Sea Level Rise, mimeo.

Vaughan, D.G., and J.R. Spouge, 2002: Risk estimation of collapse of the West Antarctic ice sheet, Climatic Change, 52, 65-91.

Velicogna, I. and Wahr, J., 2006: Measurements of time-variable gravity show mass loss in Antarctica. Science, 311: 1754-1756.

Warrick, R.A., C. Le Provost, M.F. Meier, J. Oerlemans, P.L. Woodworth, 1996: Changes in Sea Level. In: J.T. Houghton, L.G. Meira Filho, B.A. Callander, N. Harris, A. Klattenberg, K. Maskell (eds.) Climate Change 1995, The Science of Climate Change, Cambridge University Press, pp. 359-405.

Yim, W., 1995: Implications of sea-level rise for Victoria Harbour, Hong Kong, Journal of Coastal Research, 14, 167-189.

Zeidler, R.B., 1997: Climate change variability and response strategies for the coastal zones of Poland, Climate Change, 36, 151-173.

Zuo, Z., and J. Oerlemans, 1997: Contribution of glacier melt to sea level rise since AD 1865: a regionally differentiated calculation. Climate Dynamics, 13: 835-845. 


\section{Appendix 1: Data description}

Dataset: Coastline and Country Boundary

Source: The National Geospatial-Intelligence Agency (formerly Defense Mapping Agency)

URL: http://rimmer.ngdc.noaa.gov/mgg/coast/getcoast.html

Description: The World Vector Shoreline dataset is a digital data file at a nominal scale of 1:250,000, containing worldwide coverage of shorelines and international boundaries. The World Vector Shoreline is a standard National Geospatial-Intelligence Agency (formerly Defense Mapping Agency) product. The Pacific Disaster Center performed significant editing on the original dataset to correct numerous topology errors. The international boundaries were also removed, resulting in a dataset of world shorelines and country boundaries.

The main source material for the WVS was the DMA's Digital Landmass Blanking (DLMB) data which was derived primarily from the Joint Operations Graphics and coastal nautical charts produced by DMA. The DLMB data consists of a land/water flag file on a 3 by 3 arc-second interval grid. This raster data set was converted into vector form to create the WVS. For areas of the world not covered by the DLMB data (e.g. the Arctic and Antarctic), the shoreline was taken from the best available hard copy sources at a preferred scale of 1:250000. The WVS data are stored in chain-node format. Pacific Disaster Center processing: Data were downloaded in an ArcINFO Generate format from the NOAA/NGDC Coastline Extractor in 37 sections. The files were converted to ArcINFO line coverages using the GENERATE command and were appended to make a world-wide coverage. The data were re-projected from Geographic to Mercator with a central meridian of 150 degrees and the WGS 1984 Datum. Significant editing was performed on the original dataset to correct numerous topology errors. The line coverage was cleaned with a fuzzy tolerance of 30 meters and a dangle tolerance of 100 meters. Where dangling nodes occurred, line segments were connected in order to build polygons. The lines were connected only to fix topology errors and may not be geographically correct. The international boundaries were also removed, resulting in a dataset of world shorelines and country boundaries

Dataset: SRTM 90m DEM data Version 2

Source: International Centre for Tropical Agriculture (CIAT)

URL: http://gisweb.ciat.cgiar.org/sig/90m_data_tropics.htm

Description: The data are in ARC GRID format, in decimal degrees and datum WGS84. They are derived from the USGS/NASA SRTM data. CIAT have processed this data to provide seamless continuous topography surfaces. Areas with regions of no data in the original SRTM data have been filled in using interpolation methods.

Dataset: GDP

Source: DECRG of the World Bank based on Sachs et al. (2001)

Description: GDP grid dataset was initially produced by DECRG for the World Bank/Columbia University Global Natural Disaster Hotspots Project. The total level of economic activity at the national level is measured by the Gross Domestic Product (GDP), the annual market value of final goods and services produced by a country. For about 50 countries, more than half developing or transitional economies (including Bangladesh, Brazil, China, India, Indonesia, and Mexico), GDP data are available for sub-national units. Following Sachs et al. (2001), DECRG applied these sub-national 
estimates to population density, using the World Bank estimates of GDP based on Purchasing Power Parity (PPP) for 2000.

Dataset: Population

Source: Center for International Earth Science Information Network (CIESIN)

URL: http://sedac.ciesin.columbia.edu/gpw

Description: An estimate of population for the year 2000, developed as part of GPW version 3, is used to characterize the "current" distribution of population. Although population distribution is likely to change in the future due to differential rates of population change, including urban and coastal migration and different fertility and mortality rates, at present we have little basis for projecting these changes into the future (Gaffin et al., 2004).

Dataset: Urban extent (GRUMP Version 1)

Source: Center for International Earth Science Information Network (CIESIN), Columbia University; International Food Policy Research Institute (IPFRI); the World Bank; and Centro Internacional de Agricultura Tropical (CIAT).

URL: http://sedac.ciesin.columbia.edu/gpw/

Description: The data is the alpha release of version 1 of the GRUMP product. The data are stored in geographic coordinates of decimal degrees based on the World Geodetic System spheroid of 1984 (WGS84), 30 arc-second (1-km) resolution. The cell value is integer, where $1=$ rural and $2=$ urban. Large water bodies have been masked and thus appear as "no data".

Dataset: Agriculture extent (PAGE Global Agricultural Extent version 2)

Source: the International Food Policy Research Institute

URL: www.ifpri.org

Description: PAGE Global Agricultural Extent version 2 (1 $\mathrm{km}$ resolution) was created based on version 2 of the Global Land Cover Characteristics Dataset (GLCCD v2.0, USGS/EDC 2000). The methods used to create this dataset were the same as those employed to create the original PAGE Global Agricultural Extent. This dataset identifies approximately 200 seasonal land cover regions (SLCRs) per continent (e.g., 167 for South America and 205 for North America) based on the interpretation of a series of satellite images captured every 10 days over the period April 1992 to March 1993.

Table 3 Cell codes for

\begin{tabular}{|l|l|}
\hline Cell Codes & Label \\
\hline 10 & Cropland \\
\hline 11 & Plantations \\
\hline 12 & Pasture \\
\hline 13 & Cropland / Pasture \\
\hline 14 & Agriculture with forest \\
\hline 15 & Agriculture with other vegetation \\
\hline 20 & Agriculture / Forest mosaic \\
\hline 21 & Agriculture / Other mosaic \\
\hline 30 & Forest with agriculture \\
\hline 31 & Other vegetation with agriculture \\
\hline 40 & Agriculture / 2 other land cover types \\
\hline 41 & Primarily Forest (>60\%) \\
\hline 41 & Primarily Grassland (>60\%) \\
\hline
\end{tabular}




\begin{tabular}{|l|l|}
\hline 50 & Other vegetation: wetlands, mangroves \\
\hline 60 & Non-vegetated / Sparsely vegetated \\
\hline 70 & In-land water \\
\hline 80 & Ocean \\
\hline 100 & Islands \\
\hline
\end{tabular}

Dataset: Wetlands (GLWD-3)

Source: Lehner, B. and Döll, P. (2004): Development and validation of a global database of lakes, reservoirs and wetlands. Journal of Hydrology, 296/1-4, p.122.

URL: http://www.wwfus.org/science/data.cfm

Description: The GLWD-3 dataset comprises lakes, reservoirs, rivers, and different wetland types (Table 4) in the form of a global raster map at 30-sec resolution. It was produced by the Center for Environmental Systems Research (CESR), the University of Kassel, Germany, and the World Wildlife Fund, Washington DC, USA (Lehner and Döll 2004), based on various data sources, mostly 1970s to 1990s. The GLWD-3 dataset may serve as an estimate of wetland extents for global hydrology and climatology models, or to identify large-scale wetland distributions and important wetland complexes. It is supplemented by GLWD-1 and GLWD-2.

Table 4 Cell codes for GLWD-3 dataset.

\begin{tabular}{|l|l|}
\hline Cell Value & Lake or Wetland Type \\
\hline 1 & Lake \\
\hline 2 & Reservoir \\
\hline 3 & River \\
\hline 4 & Freshwater march, floodplain \\
\hline 5 & Swamp forest, flooded forest \\
\hline 6 & Coastal wetland (incl. mangrove, estuary, delta, lagoon) \\
\hline 7 & Pan, brackish/saline wetland \\
\hline 8 & Bog, fen, mire (peatland) \\
\hline 9 & Intermittent wetland/lake \\
\hline 10 & $50-100 \%$ wetland \\
\hline 11 & $25-50 \%$ wetland \\
\hline 12 & Wetland complex (0-25\% wetland) \\
\hline
\end{tabular}

